\title{
Calorimetric and Visual Measurements of R123 Pool Boiling on Four Enhanced Surfaces
}

Mark A. Kedzierski

November 1995

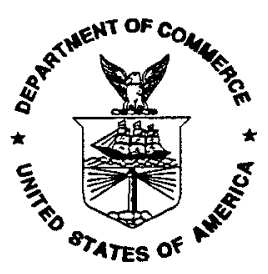

U.S. Department of Commerce Ronald H. Brown, Secretary Mary L. Good, Under Secretary for Technology National Institute of Standards and Technology Arati Prabhakar, Director

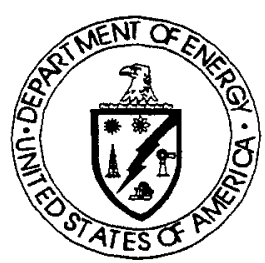

Prepared for:

U.S. Department of Energy Office of Building Technology 1000 Independence Ave., SW Washington, DC 20585 


\section{ABSTRACT}

Pool boiling of R123 on four commercial enhanced surfaces was investigated both calorimetrically and visually. The four surfaces were: (1) Turbo-BII ${ }^{\mathrm{TM}}-\mathrm{LP}$ (2) High-Flux ${ }^{\mathrm{TM}}$, (3) GEWA-K ${ }^{\mathrm{TM}}$, and (4) GEWA-T ${ }^{\mathrm{TM}}$. The surfaces were either machined or soldered onto a flat thick oxygen-free highconductivity copper plate. This permitted 20 sheathed thermocouples to be embedded in the copper for accurate heat transfer measurements. The difference between electric resistance and fluid heating was investigated. The fluid heating condition results in heat fluxes that are as much as $32 \%$ greater than those obtained by electric resistance heating. Hysterisis effects near the onset of nucleate boiling were also investigated. The boiling was visually recorded with $16 \mathrm{~mm}$ high speed film. Mechanistic descriptions of the boiling activity are given for each surface.

Keywords: Building Technology, enhanced heat transfer, porous surface, T-fin, trapezoidal-fin, R123, pool boiling, Turbo-BII ${ }^{\mathrm{TM}}$, High-Flux ${ }^{\mathrm{TM}}$, GEWA-K ${ }^{\mathrm{TM}}, \mathrm{GEWA}^{\mathrm{TM}}$, electric resistance heating, fluid heating 


\section{TABLE OF CONTENTS}

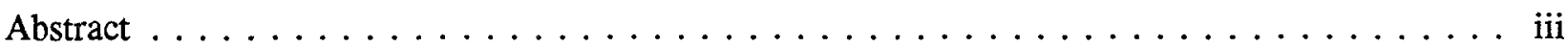

Nomenclature $\ldots \ldots \ldots \ldots \ldots \ldots \ldots \ldots \ldots \ldots \ldots \ldots \ldots \ldots \ldots \ldots \ldots \ldots$

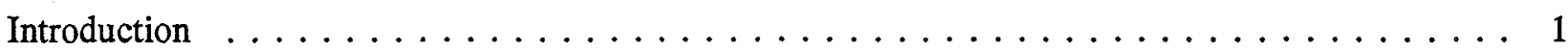

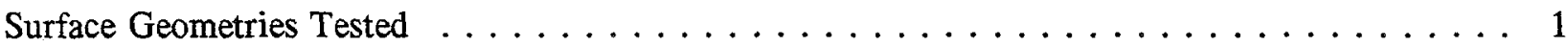

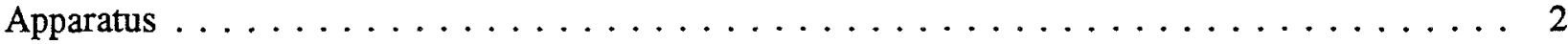

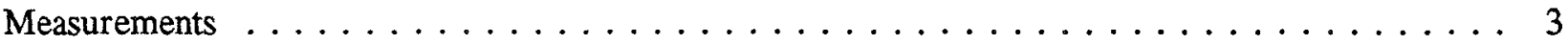

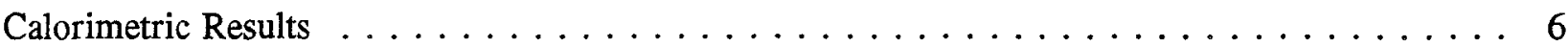

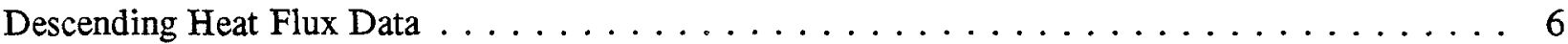

Comparison of Fluid and Electric $\ldots \ldots \ldots \ldots \ldots \ldots \ldots \ldots \ldots \ldots$

Heat Flux Distribution . . . . . . . . . . . . . . . . . . . 8

Speculation on Heat Method Difference $\ldots \ldots \ldots \ldots \ldots \ldots \ldots \ldots$

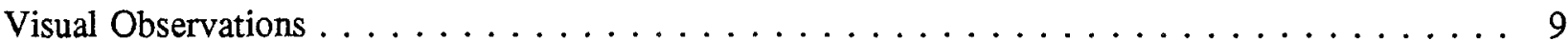

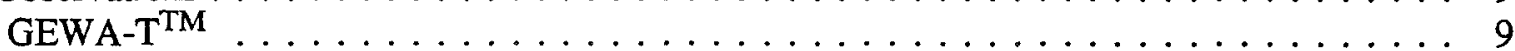

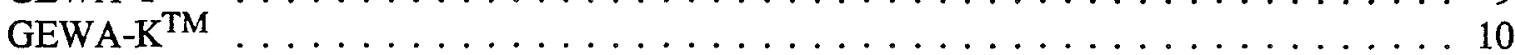

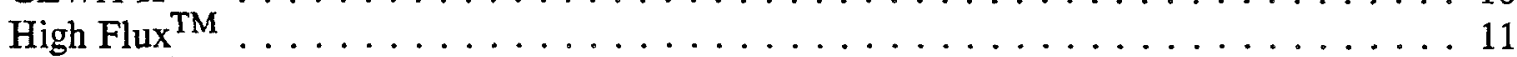

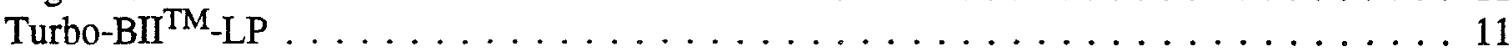

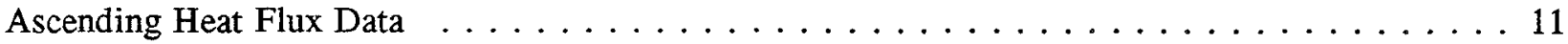

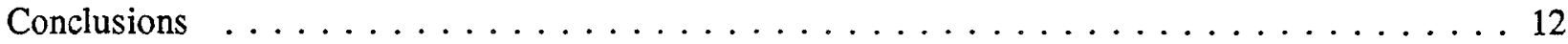

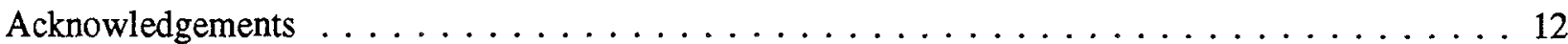

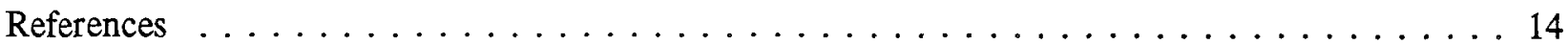

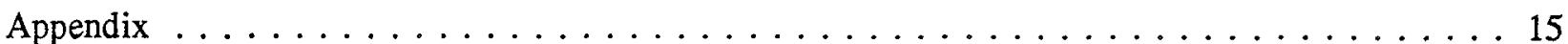




\section{English Symbols}

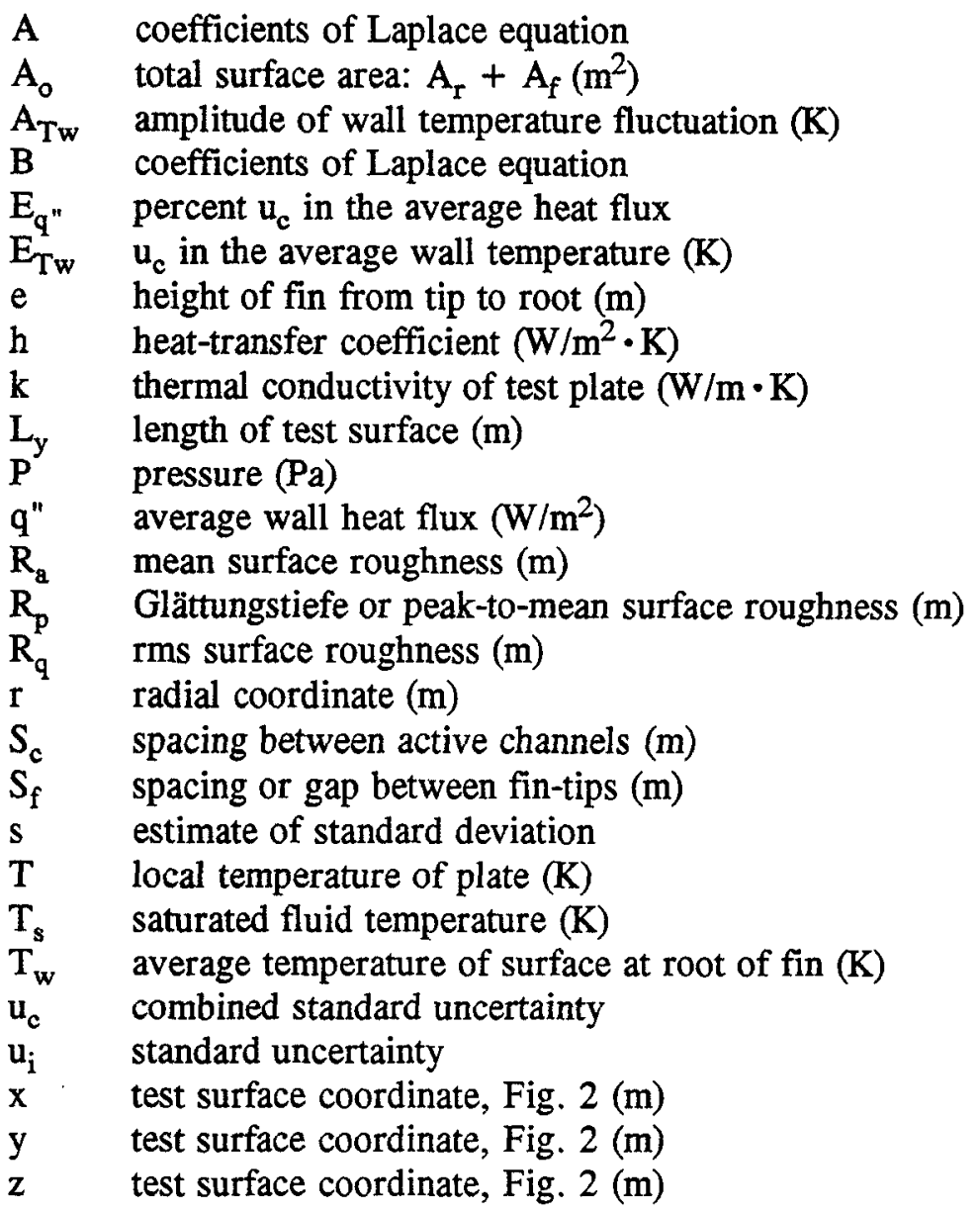

\section{Greek symbols}

$\begin{array}{ll}\Delta \mathrm{T}_{\mathrm{s}} & \overline{\mathrm{T}}_{\mathrm{w}}-\mathrm{T}_{\mathrm{s}}(\mathrm{K}) \\ \delta & \text { transient penetration depth }(\mathrm{m}) \\ \eta & \text { surface efficiency } \\ \eta_{\mathrm{f}} & \text { fin efficiency } \\ \theta & \text { angular coordinate (rad) }\end{array}$


Subscripts

$\begin{array}{ll}\text { a } & \text { ascending heat flux } \\ \text { cu } & \text { copper } \\ \text { d } & \text { descending heat flux } \\ \text { e } & \text { electric heating } \\ \text { f } & \text { fluid heating, fin } \\ \text { GK } & \text { GEWA-K } \\ \text { GT } & \text { GEWA-T } \\ \text { HF } & \text { High-Flux } \\ \text { n } & \text { counting index } \\ \text { r } & \text { root } \\ \text { s } & \text { saturated state, solder } \\ \text { SH } & \text { superheated liquid layer } \\ \text { TB } & \text { Turbo-BII } \\ \end{array}$

\section{Superscripts}

\section{- $\quad$ average}




\section{INTRODUCTION}

Within the next few years, most new centrifugal water chillers will use 1,1-Dichloro-2,2,2Trifluoroethane (R123) as a working fluid. Many new water chiller evaporators will employ enhanced, nucleate boiling tubes to attain high-cycle efficiencies. Unfortunately, little open-literature, experimental heat transfer data on nucleate pool boiling of R123 exists for the design of new chillers.

The comprehensive survey of enhanced single-tube pool boiling literature by Pais and Webb (1991) documents the lack of R123 data. Not one of their cited references used R123 as a test fluid. Many studies have been done with R113 (Marto and Lepere, 1982, Ayub and Bergles, 1990, and Xin and Chao, 1985) and hydrocarbons (Gorenflo et al., 1990, and Yimaz et al., 1981) as test fluids. Since 1991, not much work has been done with R123 and single-tube pool boiling. In 1992, Webb and Pais (1992) presented one of the few enhanced tube studies with R123. The following year, Webb and McQuade (1993) examined R123/lubricant mixtures pool boiling on the Turbo-B, GEWA-K ${ }^{\mathrm{TM}}$, GEWA-T ${ }^{\mathrm{TM}}$ and GEWA-SE tubes. The only other study the author found was by Singh et al. (1993). They presented electrohydrodynamic (EHD) and non/EHD R123 boiling data for a rectangular integral-fin tube.

This paper presents measured pool boiling heat transfer data of $\mathrm{R} 123$ at $277.6 \mathrm{~K}$ on four popular commercial enhanced surfaces. Visual observations were performed to aid in understanding the boiling process. The boiling surfaces were flat and integral to thick oxygen-free high-conductivity (OFHC) copper blocks. The convenience of testing round tubes was sacrificed for increased accuracy in the heat flux and wall superheat measurements. Another benefit of a thick test specimen is that the heat flux and wall superheat could be measured independent of the type of heating. This independence enabled the comparison of electric resistance and fluid heating data from the same surface to be direct and unbiased.

The effect of the heating condition on the pool boiling performance is a focal point of this study. Although industry has speculated that the heating effect exists, no previous experimental work that demonstrated a direct comparison on the same test surface was found in the literature. However, a theoretical study was conducted by Unal and Pasamehmetoglu (1994) that predicted: (1) the nucleate pool boiling curves for the constant temperature and constant heat flux heating conditions are different, (2) the position or magnitude of the nucleate pool boiling curves depends on the thickness of the heater, and (3) the difference between the constant temperature and constant heat flux boundary conditions becomes smaller as the heater thickness is increased. The present study experimentally shows that for a thick copper plate a significant difference between the fluid heating (constant temperature) and the electric resistance heating (constant heat flux) pool boiling curves can exist.

\section{SURFACE GEOMETRIES TESTED}

Figure 1 shows the geometries of the enhanced surfaces tested in this study: (1) the Turbo-BII ${ }^{\mathrm{TM}}$-LP of Wolverine Tube Inc., (2) the High-Flux ${ }^{\mathrm{TM}}$ of UOP, (3) the GEWA-T ${ }^{\mathrm{TM}}$ of Wieland, and (4) the GEWA$\mathrm{K}^{\mathrm{TM}}$ of Wieland. The Turbo-BII ${ }^{\mathrm{TM}}-\mathrm{LP}$, the GEWA-T ${ }^{\mathrm{TM}}$ and the GEWA-K ${ }^{\mathrm{TM}}$ are all extended or "structured" surface enhancements formed by a rolling process that lifts and shapes metal from the outer wall of a smooth tube. The High-Flux ${ }^{\mathrm{TM}}$ surface is a "treated" surface enhancement produced by sintering tiny copper particles onto a smooth tube. Following are descriptions of each enhancement geometry shown in Fig. 1.

The Turbo-BII ${ }^{\text {TM }}$-LP surface has approximately 1660 fins per meter (fpm) oriented along the short axis of the plate. The overall height and root-width of a fin are $0.75 \mathrm{~mm}$ and $0.28 \mathrm{~mm}$, respectively. The surface appears to be formed by first creating hills and valleys on the fin-tips of a trapezoidal-fin tube approximately every $0.5 \mathrm{~mm}$ at $45^{\circ}$ to the fins. Next, the hills of the fins are flattened into $0.83 \mathrm{~mm} \mathrm{x}$ $0.37 \mathrm{~mm}$ oval shapes at a density of approximately 3 fins per square millimeter. The oval shapes create a $0.34 \mathrm{~mm}$ thick canopy over the channels with $0.2 \mathrm{~mm} \times 0.13 \mathrm{~mm}$ openings. The surface density of the openings was approximately $3.5 / \mathrm{mm}^{2}$. Although the openings play a role in determining the boiling, 
the cavities that primarily govern the boiling presumably reside below the fin canopy.

The High-Flux ${ }^{\mathrm{TM}}$ or "porous" surface contains many irregular cavities similar to those of coral. The thickness of the porous coating was $0.645 \mathrm{~mm}$. The porosity of the matrix was $45 \%$. The size of the particle sintered onto the surface is proprietary information held by UOP. However, the particles form randomly shaped cavity openings from approximately 0.04 to $0.13 \mathrm{~mm}$ in diameter.

The cross section of the GEWA-K ${ }^{\mathrm{TM}}$ or "trapezoidal fin" surface is shown in Fig. 1. The fin-tip and the fin-height are $0.24 \mathrm{~mm}$ and $1.53 \mathrm{~mm}$, respectively. The surface has nominally $746 \mathrm{fpm}$ oriented along the short axis of the plate.

Commercially, the GEWA-T ${ }^{\mathrm{TM}}$ or "T-fin" surface is formed by flattening the tips of the GEWA-K $\mathrm{K}^{\mathrm{TM}}$ surface to create a specified gap of $0.35 \mathrm{~mm}$ between the fin-tips. The surface has approximately 667 fpm oriented along the short axis of the plate. The fin-tip width and the fin-height are $1.05 \mathrm{~mm}$ and 1.04 $\mathrm{mm}$, respectively.

As previously mentioned, all four surfaces were adapted to a flat, OFHC copper surface similar to that

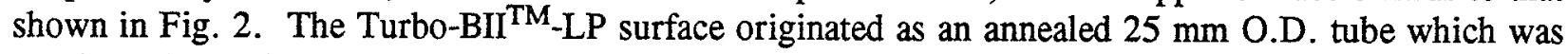
cut through axially, flattened and soldered onto the top of a smooth test plate. Appendix A discusses the procedure used to extrapolate the wall temperature of the Turbo-BII ${ }^{\mathrm{TM}}$-LP surface while accounting for the solder layer. The high flux surface was produced by sintering small diameter copper particles onto the top of a smooth plate. Both the GEWA-T ${ }^{\mathrm{TM}}$ and the GEWA-K ${ }^{\mathrm{TM}}$ surfaces were machined directly onto the top of the test plate by electric discharge machining (EDM).

Flat plates have several advantages over round tubes as heat transfer specimens. More thermocouples can be spaced parallel to the heat flow in a thick plate than in a thin-walled tube. The large number of thermocouples produces two benefits. First, uncertainties in the heat transfer measurement are reduced by increasing the number of thermocouples. Second, the test method relies on thermocouples to measure both the wall temperature and the wall heat flux. Consequently, the test method was independent of the heating method, permitting a fair comparison between electric resistance and fluid heating. Two more advantages of flat plate specimens over tubes involve improved visual observation of the boiling. First, boiling within the channel can be viewed with a plate since a cross section of the surface is visible. Second, the boiling occurs in one plane which provides a somewhat unobstructed view.

\section{APPARATUS}

Following is a description of the apparatus used to measure the pool boiling data for the four test plates of this study. The rig was used to measure the liquid saturation temperature, the average pool-boiling heat flux, and the wall temperature. All measurement uncertainties are reported for a $95 \%$ confidence interval and are evaluated by statistical methods. The standard uncertainty $\left(\mathrm{u}_{\mathrm{i}}\right)$ is the positive square root of the estimated variance $u_{i}{ }^{2}$. The combined standard uncertainty $\left(u_{c}\right)$ is commonly referred to as the law of propagation of uncertainty.

A schematic of the test rig is given in Fig. 3. Three principal components of the apparatus were: test chamber, condenser, and reservoir. The internal dimensions of the test chamber were $25.4 \mathrm{~mm} \mathrm{X} 257$ $\mathrm{mm} \times 1.54 \mathrm{~m}$. The test chamber was charged with approximately $7 \mathrm{~kg}$ of R123 from the reservoir, giving a liquid height of approximately $80 \mathrm{~mm}$ above the test surface. The bottom of the test section, as shown in Fig. 3, was heated with either an electric resistance heater or high velocity $(2.5 \mathrm{~m} / \mathrm{s})$ water flow. The vapor produced by liquid boiling on the test surface was condensed by the brine cooled, shelland-tube condenser and returned to the pool by gravity as liquid.

As shown in Fig. 3, the test section was visible through two, flat $150 \mathrm{~mm} \times 200 \mathrm{~mm}$ quartz windows. A high-speed camera was used to film the boiling at 1000, 3000, and 6000 frames per second (fps). Two 
$500 \mathrm{~W}$ forward lights illuminated the specimens during filming. Films were taken at selected heat fluxes immediately after the measurement of the heat-transfer coefficient to ensure that the heat from the lights did not influence the measurement.

Several precautions were taken to reduce the errors associated with the liquid saturation temperature measurement. The saturation temperature of the liquid was measured with -a $450 \mathrm{~mm}$ long $1.6 \mathrm{~mm}$ diameter stainless steel sheathed thermocouple. The small diameter provided for a relatively fast response time. Nearly the entire length of the thermocouple was in contact with only the test refrigerant vapor and liquid to minimize conduction errors. The tip of the thermocouple was placed approximately $2 \mathrm{~mm}$ above and $200 \mathrm{~mm}$ to the left of the top of the test surface. This placement ensured that approximately $80 \mathrm{~mm}$ of the probe length was in a relatively well-mixed portion of the liquid pool. To provide for a saturated liquid pool state, the mass of liquid in the pool was large compared to mass of liquid condensed. At the highest heat flux, it would require nearly one hour to evaporate and condense the entire test chamber charge. Convection and radiation errors were minimal due to low, uniform temperatures attributed to well-insulated, low emissivity, $38 \mathrm{~mm}$ thick aluminum test chamber walls.

The thermocouples were calibrated against a standard in the NIST Temperature Group to a residual standard deviation of $0.005 \mathrm{~K}$. Considering the fluctuations in the saturation temperature during the test and the standard uncertainties in the calibration, the $u_{c}$ of the average saturation temperature was no greater than $0.04 \mathrm{~K}$. A thermocouple drift of within $0.1 \mathrm{~K}$ was determined by recalibrating the thermocouples one year after the tests were completed. Consequently, the $u_{c}$ of the temperature measurements was less than $0.1 \mathrm{~K}$. The saturation temperature was also obtained from a pressure transducer measurement accurate to within $0.03 \mathrm{kPa}$. The accuracy of the saturation temperature from equilibrium data (Morrison and Ward, 1991) for R123 was $0.17 \mathrm{~K}$. The saturation temperature obtained from the thermocouple and that from the pressure measurement always agreed within $0.17 \mathrm{~K}$.

\section{MEASUREMENTS}

Figure 2 shows the coordinate system for the 20 thermocouple wells in the side of the test plate. The wells were $16 \mathrm{~mm}$ deep to reduce conduction errors. Using a method given by Eckert and Goldstein (1976), errors due to heat conduction along the thermocouple leads were estimated to be well below 0.01 $\mathrm{mK}$. The origin of the coordinate system was centered on the surface at the root of the fin (or just below the porous surface). Centering the origin in the $y$-direction improved the accuracy of the wall heat flux and temperature calculations by reducing the number of fitted constants involved in these calculations. The $y$-coordinate measures the distance perpendicular to the $\mathrm{x}$-coordinate. The $\mathrm{x}$-coordinate measures the distance normal to the heat transfer surface. The thermocouples were arranged in four sets of five aligned in the $\mathrm{x}$-direction. Following a procedure given by Kedzierski and Worthington (1993), the size and arrangement of the thermocouple wells were designed to minimize the errors in the wall temperature and temperature gradient measurement.

The heat flux and the wall temperature were obtained by regressing the measured temperature distribution of the block to the governing conduction equation. In other words, rather than using the boundary conditions to solve for the interior temperatures, the interior temperatures were used to solve for the boundary conditions. One difficulty with this method is determining the appropriate model for a particular data set. The search for the best model started with the general two-dimensional solution to Laplace's equation in cylindrical coordinates (Derrick and Grossman, 1976):

$$
T(r, \theta)=A_{0}+\sum_{n=1}^{\infty} r^{n}\left(A_{n} \cos (n \theta)+B_{n} \sin (n \theta)\right)
$$

It is impossible to fit the infinite number of parameters $\left(A_{n}\right.$ and $\left.B_{n}\right)$ in the above series to 20 measured temperatures. Fortunately, terms above a certain order are unnecessary because the conduction solution is expected to be smooth. As a rule of thumb, a regression model should contain no more than half as 
many parameters as data points; otherwise, the model risks fitting the error. Using this guidance, it was felt that the 20 measured plate temperatures should be fitted to nothing greater than a nine parameter model. Transforming eqn. 1 into rectangular coordinates and completing the sum to $n=4$ gives the following nine parameter two-dimensional conduction model:

$$
\begin{aligned}
T & =A_{0}+A_{1} x+B_{1} y+A_{2}\left(x^{2}-y^{2}\right)+2 B_{2} x y+A_{3} x\left(x^{2}-3 y^{2}\right) \\
& +B_{3} y\left(3 x^{2}-y^{2}\right)+A_{4}\left(x^{4}-6 x^{2} y^{2}+y^{4}\right)+4 B_{4}\left(x^{3} y-x y^{3}\right)
\end{aligned}
$$

Not all of the parameters in eqn. 2 contribute significantly to the solution. Extraneous parameters in the conduction model can increase the uncertainties in the wall temperature and heat flux calculations. A method was devised to reduce - rather than build up - the model to the essential, governing parameters. The traditional statistical method for fitting data (building a model) is to successively include higher order terms in the model until the residual standard deviation becomes sufficiently small and the residual plots are random. A built-up model provides a good fit of the core temperatures. But, it may give slightly erroneous results for extrapolations and gradients because: (1) it does not include all salient governing terms, and (2) it includes some nonessential terms.

In the present method, the contribution of each of the nine terms to the temperature solution was examined, and the term that contributed the least to the magnitude of the temperature solution was removed. The 20 temperatures were then regressed to the reduced form of Laplace's equation. Terms were removed as long as the residual standard deviation was no more than $15 \%$ greater than that of the original nine parameter model, and the wall temperature and heat fluxes remained within the uncertainty of the original nine parameter model. Finally, the residuals of the resulting model were examined for randomness to ensure a valid model. This procedure was repeated for high and low heat flux for each plate.

Two solutions were found: one for fluid heating at a low heat flux

$$
T=A_{0}+A_{1} x+A_{2} Y
$$

and another for electric resistance and high fluid heat flux.

$$
T=A_{0}+A_{1} x+A_{2} y+A_{3}\left(x^{2}-y^{2}\right)+A_{4} y\left(3 x^{2}-y^{2}\right)
$$

Fourier's law and the fitted constants $\left(A_{0}, A_{1}\right.$, and $\left.A_{3}\right)$ were used to calculate the average wall heat flux (q") normal to the heat transfer surface for both the first and third order models as:

$$
q^{\prime \prime}=\left[\frac{1}{\frac{1}{L_{y}}} \int_{\frac{-L_{y}}{2}}^{\frac{L_{y}}{2}} k \frac{\partial T}{\partial x} d y\right]_{x=0}=K A_{1}
$$

where $\bar{k}$ is the average thermal conductivity along the surface of the plate, and $L_{y}$ is the length of the heat transfer surface as shown in Fig. 2. The average heat flux is based on the projected area of the enhancement. 
The average wall temperature for the first order model is:

$$
T_{w}=\left[\begin{array}{c}
\frac{1}{L_{y}} \int_{-\frac{L_{y}}{2}}^{\frac{L_{y}}{2}} T d y \\
{ }_{x=0}
\end{array} A_{0}\right.
$$

and that for the third order model is:

$$
T_{w}=A_{0}-\frac{A_{3} L_{y}^{2}}{12}
$$

Table 1a and $1 \mathrm{~b}$ show the order of solution used for a particular plate and heating condition. In general, electric resistance heating requires a higher order solution.

A two-dimensional solution to Laplace's equation should adequately represent the conduction within the test plate. The sides and ends (see Fig. 2) of the test plate were insulated with a teflon sleeve. The sleeve was $13 \mathrm{~mm}$ thick along the sides of the plate. Approximately $40 \%$ and $60 \%$ of the plate ends were insulated with $13 \mathrm{~mm}$ and $6.4 \mathrm{~mm}$ teflon, respectfully. As determined from the two-dimensional solution, the heat flux leaving the end surfaces was typically $5 \%$ of that leaving the boiling surface. Because the sides were better insulated than the ends, a conservative estimate of the side heat flux would be to assumed it equal to the end heat flux. For this case, the temperature drop in the z-direction is approximately one forth that experienced in the y-direction. In addition, the ratio of the copper and teflon conduction resistances in the $z$-direction is approximately $9 \times 10^{-4}$. Consequently, the temperature in the z-direction is uniform enough to use a two-dimensional conduction solution.

Siu et al. (1976) estimated the uncertainty in the thermal conductivity of OFHC to be about 2 to $3 \%$ by comparing round-robin experiments. Because the purity of OFHC copper is high, the variability of its thermal conductivity from batch to batch should be small and closely estimated from a comparison of round-robin experiments. Accordingly, the percent $u_{c}$ in the average wall heat flux was calculated assuming a $3 \% u_{c}$ in the thermal conductivity of the plate. Figure 4 shows the percent $u_{c}$ in the average

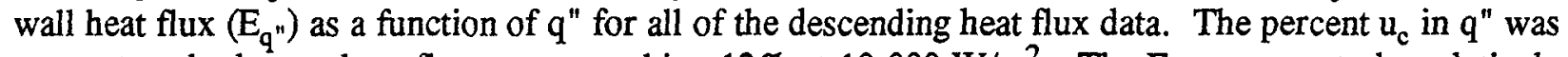
greatest at the lowest heat fluxes, approaching $12 \%$ at $10,000 \mathrm{~W} / \mathrm{m}^{2}$. The $\mathrm{E}_{\mathrm{q} \text { " }}$ appears to be relatively constant between 6 and $4 \%$ for heat fluxes above $30,000 \mathrm{~W} / \mathrm{m}^{2}$. The contribution of the uncertainty in the thermal conductivity to that of the wall heat flux is insignificant for heat fluxes below $30 \mathrm{~kW} / \mathrm{m}^{2}$.

Figure 5 shows the $u_{c}$ in the temperature of the surface at the root of the enhancement $\left(\mathrm{E}_{\mathrm{Tw}}\right)$ as a function of heat flux for all of the data. The $u_{c}$ in the $T_{w}$ measurement was calculated from the regression of Laplace's equation. The $u_{c}$ increases from $0.04 \mathrm{~K}$ at approximately $3 \mathrm{~kW} / \mathrm{m}^{2}$ to approximately $0.12 \mathrm{~K}$ at $180 \mathrm{~kW} / \mathrm{m}^{2}$. The two exceptions are for fluid heating GEWA-T ${ }^{\mathrm{TM}}$ and GEWA-K ${ }^{\mathrm{TM}}$ where the $u_{\mathrm{c}}$ is nearly constant at approximately $0.03 \mathrm{~K}$ and $0.05 \mathrm{~K}$, respectively. The cause of this difference is unknown, but is presumably related to the GEWA-T ${ }^{\mathrm{TM}}$ and GEWA-K ${ }^{\mathrm{TM}}$ surfaces having third order solutions while the other surfaces have first order solutions for fluid heating. The random error in the wall superheat $\left(\Delta T_{s}=\overline{T_{w}}-T_{s}\right)$ on average was within $0.1 \mathrm{~K}$.

The uncertainties shown in Figs. 4 and 5 are "within-run uncertainties" which do not include the uncertainties due to "between-run uncertainties", i.e., differences observed between tests taken on different days. The "within run uncertainties" include only the random effects and uncertainties evident from one particular test. All other uncertainties are reported here as "between-run uncertainties" which include all random effects such as surface past history or seeding. "Within-run uncertainties" are given only in Figs. 4 and 5. 


\section{CALORIMETRIC RESULTS}

When possible, the heat flux was varied from $3 \mathrm{~kW} / \mathrm{m}^{2}$ to $200 \mathrm{~kW} / \mathrm{m}^{2}$ to cover the likely operating conditions of R123 chillers equipped with enhanced tubes. All tests were taken in a saturated pool of liquid at a target temperature of $277.6 \pm 0.15 \mathrm{~K}$. Each test surface was alternately cleaned with acetone and Tarn- $\mathrm{X}^{\circledast}$ before it was installed into the test rig. The test fluid was boiled on the test surface for approximately two hours before taking the first measurements.

Four types of tests were conducted: (1) descending electric resistance heating, (2) ascending electric resistance heating, (3) descending fluid heating, and (4) ascending fluid heating. The descending heat flux tests were initiated at the highest heat flux, and proceeding measurements were taken for consecutively lower heat fluxes. The ascending heat flux tests were started at the lowest heat flux and subsequent measurements were taken for successively higher heat fluxes. The ascending heat flux data were intended to investigate the hysteresis behavior of the surfaces. Table 7 provides the number of test days for each surface and heating condition as well as the starting heat flux for the tests.

\section{DESCENDING HEAT FLUX DATA}

Figures 6 through 9 and Tables 8 through 14 present the pure R123 descending heat flux boiling curves for all of the surfaces for both electric resistance and fluid heating conditions. The fluid heating data for the GEWA-T ${ }^{\mathrm{TM}}$ and GEWA-K ${ }^{\mathrm{TM}}$ surfaces given in Fig. 6 nearly coincide; consequently, these data are also presented in Figs. 7 and 9, respectively. The electrical heating boiling curves for the High-Flux ${ }^{\mathrm{TM}}$, the Turbo-BII ${ }^{\mathrm{TM}}-\mathrm{LP}$, and the GEWA-K ${ }^{\mathrm{TM}}$ surfaces are given in Figure 9.

An overview of the mean and confidence intervals given in Figs. 6 through 9 follows. Closed and opened symbols represent fluid and electric resistance heating data, respectively. Solid lines are cubic regressions or estimated means of the data. The dashed lines to either side of the mean represent the lower and upper $95 \%$ simultaneous (multiple-use) confidence intervals for the mean. The average width of the confidence interval or the $u_{c}$ of the estimated mean wall superheat is given in Table 2. Overall, the $u_{c}$ of the estimated mean wall superheat in the natural convection region and the boiling region is approximately $0.2 \mathrm{~K}$ and $0.06 \mathrm{~K}$, respectively. The residual standard deviation represents the proximity of the data to the mean; it is given in Table 3. On average, the residual standard deviation of the natural convection data and the boiling data about the mean is $0.09 \mathrm{~K}$, and $0.08 \mathrm{~K}$, respectively.

To satisfy the assumption of least squares regression, the data must be regressed against the most accurately known quantity. Consequently, the means shown in Figs. 6 through 9 were obtained from a regression of $\Delta T_{s}$ onto $q "$. The coefficients for the cubic fit of $\Delta T_{s}$ onto $q$ " are given in Table 4. For convenience, the coefficients for the cubic fit of $q^{\prime \prime}$ onto $\Delta T_{s}$ are given in Table 5 . For most of the data, the two regressions agree within $\pm 1 \%$; however, there are a few exceptions. The regressions agree within $\pm 1 \%$ for the GEWA-T ${ }^{\mathrm{TM}}$ and GEWA-K ${ }^{\mathrm{TM}}$ surfaces except for heat fluxes between 20 and 50 $\mathrm{kW} / \mathrm{m} 2$ where the difference expands to a maximum of $7 \%$ at $32 \mathrm{~kW} / \mathrm{m}^{2}$. On average, the differences for the Turbo-BII ${ }^{\mathrm{TM}}$-LP and High-flux surfaces remain within $\pm 1 \%$ except at the ends of the data sets where the difference increases to 2 to $2.5 \%$. The reader should realize the preceding cautions when using the coefficients given in Table 5.

Boiling was always observed to be present on the High-Flux ${ }^{\mathrm{TM}}$ and the Turbo-BII ${ }^{\mathrm{TM}}$-LP surfaces for even the lowest test heat fluxes. The presence of nucleate boiling for all heat flux ranges is implied by the nearly constant slope of the boiling curve. By contrast, the GEWA-T ${ }^{\mathrm{TM}}$ AND GEWA-K ${ }^{\mathrm{TM}}$ data have two characteristic regimes: a natural convection regime and a nucleate boiling regime. The regimes are separated by the cessation of nucleate boiling (CNB) which occurs at approximately $7.6 \mathrm{~K}$ for the fluid heated GEWA-T ${ }^{\mathrm{TM}}$ surface. The CNB for the GEWA-T ${ }^{\mathrm{TM}}$ and the GEWA-K ${ }^{\mathrm{TM}}$ plates is given in Table 6 for electric resistance and fluid heating conditions. The nucleate boiling regime exists for superheats greater than the CNB condition. Here, the heat transfer is governed primarily by the formation of 
isolated bubbles within the fin cavities. For superheats below the CNB, the influence of natural convection becomes dominant. In fact, bubble generation was not visible on the heat transfer surface in the natural convection regime with the exception of the vicinity of CNB.

Figure 10 compares the present R123 electric resistance heating data to that of Webb and Pais (1992) at the same saturation temperature. The figure summarizes the geometry differences between the tubes tested in this study and the Webb and Pais (1992) study. The Webb and Pais (1992) GEWA-K ${ }^{\mathrm{TM}}$ and GEWA-TX ${ }^{\text {TM }}$ data agree with the present data for heat fluxes above $50 \mathrm{~kW} / \mathrm{m} 2$ and below $10 \mathrm{~kW} / \mathrm{m}^{2}$ and is greater than the present data for intermediate heat fluxes. The maximum percent difference occurs at CNB of the present data and is $75 \%$ and $100 \%$ for the GEWA-K ${ }^{\mathrm{TM}}$ and GEWA-T ${ }^{\mathrm{TM}}$ surfaces, respectively. The greater performance of the Webb and Pais (1992) GEWA-K ${ }^{\mathrm{TM}}$ and GEWA-T ${ }^{\mathrm{TM}}$ surfaces was partly due to the greater fpm and the additional notch enhancement of the GEWA-TX ${ }^{\mathrm{TM}}$ surface. The present Turbo-BII ${ }^{\mathrm{TM}}$-LP data is approximately $14 \mathrm{~kW} / \mathrm{m} 2$ greater than the Turbo-B data for heat fluxes above $20 \mathrm{~kW} / \mathrm{m}^{2}$. Credit should probably go to the designers of the Turbo-BII ${ }^{\mathrm{TM}}$-LP surface for its improvement over the original Turbo-B.

Figure 11 compares the heat flux of the High-Flux ${ }^{\mathrm{TM}}$ surface $\left(\mathrm{q}^{\prime \prime}{ }_{\mathrm{HF}}\right)$ to that of the Turbo-BII ${ }^{\mathrm{TM}}-\mathrm{LP}$ surface $\left(q^{\prime \prime} T B\right)$ for both fluid and electric resistance heating. The $95 \%$ simultaneous confidence intervals are shown to either side of the mean relative performance. All comparisons are made for the same wall superheat and at a given Turbo-BII ${ }^{\mathrm{TM}}$-LP heat flux. For a Turbo-BII ${ }^{\mathrm{TM}}$-LP heat flux change from 30 to $75 \mathrm{~kW} / \mathrm{m}^{2}$, the heat flux of the High-Flux ${ }^{\mathrm{TM}}$ surface is approximately 1 to 2.5 times that of the TurboBII $^{\text {TM }}$-LP surface. For a given Turbo-BII ${ }^{\mathrm{TM}}$-LP heat flux, a greater High-Flux ${ }^{\mathrm{TM}}$ enhancement is achieved for the electric resistance than for the fluid heating boundary condition. The Turbo-BII ${ }^{\mathrm{TM}}$-LP performance is greater than that of the High-Flux ${ }^{\mathrm{TM}}$ surface for heat fluxes below 31 and $26 \mathrm{~kW} / \mathrm{m} 2$, for the fluid and electric resistance boundary conditions, respectively.

Figure 12 shows the relative performance of the Turbo-BII ${ }^{\mathrm{TM}}$-LP surface to that of GEWA-T ${ }^{\mathrm{TM}}$ and GEWA-K ${ }^{\mathrm{TM}}$ surfaces. The confidence intervals are too small to be visible at the scale of the figure. Also, the Turbo-BII ${ }^{\mathrm{TM}}-\mathrm{LP} / \mathrm{GEWA}-\mathrm{T}^{\mathrm{TM}}$ and the Turbo-BII ${ }^{\mathrm{TM}}-\mathrm{LP} /$ GEWA-K ${ }^{\mathrm{TM}}$ performance ratios for electric resistance and fluid heating essentially coincide. The Turbo-BII ${ }^{\mathrm{TM}}$-LP performance approaches 20 times that of the GEWA-T ${ }^{\mathrm{TM}}$ and GEWA-K $\mathrm{K}^{\mathrm{TM}}$ surfaces at low GEWA-T ${ }^{\mathrm{TM}}$ and GEWA-K ${ }^{\mathrm{TM}}$ heat fluxes. The large performance difference in this region is a consequence of the Turbo-BII ${ }^{\text {TM }}$-LP actively boiling while heat is transferred by natural convection from the GEWA-T ${ }^{\mathrm{TM}}$ and GEWA-K $\mathrm{K}^{\mathrm{TM}}$ surfaces. As the heat flux nears the CNB, the performance of the GEWA-T ${ }^{\mathrm{TM}}$ and GEWA-K ${ }^{\mathrm{TM}}$ surfaces rapidly

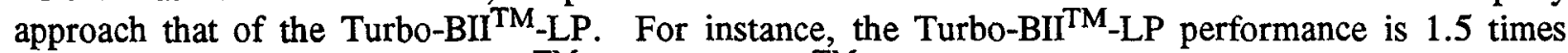
greater than that of the GEWA-T $\mathrm{T}^{\mathrm{TM}}$ and GEWA-K ${ }^{\mathrm{TM}}$ surfaces at a heat flux of approximately 100 $\mathrm{kW} / \mathrm{m} 2$.

Figure 13 shows the ratio of the GEWA-T ${ }^{\mathrm{TM}}$ heat flux to the GEWA-K ${ }^{\mathrm{TM}}$ heat flux at the same wall superheat. Since both confidence intervals are above unity for heat fluxes greater than $40 \mathrm{~kW} / \mathrm{m}^{2}$, the performance of the GEWA-T ${ }^{\mathrm{TM}}$ surface is marginally greater than that of the GEWA-K ${ }^{\mathrm{TM}}$ in this region. Below $20 \mathrm{~kW} / \mathrm{m}^{2}$, i.e., in the natural convection region, a statistical analysis indicated no difference between the data for the two surfaces. The GEWA-T ${ }^{\mathrm{TM}}$ surface has approximately $6 \%$ more surface area per projected area than the GEWA-K ${ }^{\mathrm{TM}}$ surface for natural convection (2.71 versus 2.87 ). Possibly the $\mathrm{T}$-shape obstructs the path of the convection making it less efficient than the GEWA-K ${ }^{\mathrm{TM}}$ for natural convection per unit area.

\section{Comparison of Fluid and Electric}

Figure 14 compares the fluid and electric resistance heat fluxes for the Turbo-BIT ${ }^{T M}-L P$, the GEWA-K ${ }^{\text {TM }}$ and the High-Flux ${ }^{\mathrm{TM}}$ surfaces at the same $\Delta \mathrm{T}_{s}$ and constant pressure. The figure plots the ratio of the fluid heat flux to the electric resistance heat flux $\left(\mathrm{q}_{\mathrm{f}} \mathrm{f}_{\mathrm{q}} \mathrm{q}_{\mathrm{e}}\right)$ against the electric resistance heat flux. For boiling, the fluid heating condition results in heat fluxes as much as $32 \%$ greater than those obtained by 
electric resistance heating. In the natural convection regime, the GEWA-K ${ }^{\mathrm{TM}}$ surface exhibited lower heat fluxes for fluid heating than for electric heating. Similarly, Kays and Crawford (1980) show that the laminar Nusselt number for internal tube flow for constant heat flux is larger than that for constant wall temperature. Within $30 \mathrm{~kW} / \mathrm{m}^{2}<\mathrm{q}_{\mathrm{e}}<78 \mathrm{~kW} / \mathrm{m}^{2}$, there is an insignificant statistical difference between the $\mathrm{q}^{\prime \prime} / \mathrm{q}^{\prime}{ }_{\mathrm{e}}$ for the Turbo-BII ${ }^{\mathrm{TM}}-\mathrm{LP}$ and High-Flux ${ }^{\mathrm{TM}}$ surfaces. The lack of difference suggests the possibility of a universal difference between fluid and electric resistance heating conditions for reentrant cavity surfaces. Moreover, the heating boundary condition may affect reentrant and natural cavity surfaces differently.

Figure 14 demonstrates that fluid heating produces greater heat fluxes than electric resistance heating for pool boiling on the surfaces tested. Individual confidence intervals are given in the figure at the maximum difference between the fluid and electric resistance heat fluxes. The greatest difference between fluid and electric resistance heat fluxes was observed for the GEWA-K ${ }^{\mathrm{TM}}$ surface at q" ${ }_{\mathrm{e}}=34.5 \mathrm{~kW} / \mathrm{m}^{2}$ where the fluid heat flux was $32 \pm 5 \%$ greater than the electric resistance heat flux. A q ${ }_{\mathrm{f}} / \mathrm{q}^{\prime \prime}$ maximum of $1.25 \pm 0.13$ was found at $q_{e}^{\prime \prime}=8.78 \mathrm{~kW} / \mathrm{m}^{2}$ for the Turbo-BI' ${ }^{\mathrm{TM}}$-LP surface. At $\mathrm{q}_{\mathrm{e}}^{\prime \prime}=24 \mathrm{~kW} / \mathrm{m}^{2}$, the fluid heat flux was $15 \pm 7 \%$ greater that the electric resistance heat flux for the High Flux surface. According to the model Unal et al. (1994), thin walled tubes should exhibit a greater difference between fluid and electric heating than that shown here for thick test plates.

Figures 15 through 17 provide a closer examination of the $u_{c}$ of the heat flux ratio profiles of Fig. 14 . The simultaneous confidence intervals shown in Figs. 15 through 17 ensure with $95 \%$ confidence that the actual values lie within the confidence interval. A large boiling curve slope, a small number of measurements, and a large uncertainty in the individual measurement all tend to increase the size of the confidence interval. When considering a particular range of $\mathrm{q}^{\prime \prime}$, the confidence intervals must not contain the value one to assert that $q^{\prime \prime}{ }_{f}$ is different from $q^{\prime \prime}{ }_{e}$.

Figure 15 shows that the $\mathrm{q}_{\mathrm{f}} / \mathrm{q}_{\mathrm{e}}{ }_{\mathrm{e}}$ curve, for the GEWA-K $\mathrm{K}^{\mathrm{TM}}$ surface, has an $\mathrm{u}_{\mathrm{c}}$ of approximately $\pm 5 \%$ for in the boiling region (for heat fluxes above $22 \mathrm{~kW} / \mathrm{m}^{2}$ ). In the natural convection region, i.e., for heat fluxes below $22 \mathrm{~kW} / \mathrm{m}^{2}$, the confidence intervals bracket the value one. Consequently, no statement can be confidently made concerning the relative magnitudes of the fluid and electric resistance heat fluxes in the natural convection region.

Figure 16 shows that the fluid heat flux is greater than the electric resistance heat flux for $\mathrm{q}_{\mathrm{e}}$ above 10 $\mathrm{kW} / \mathrm{m}^{2}$. On average, the confidence interval for this range is approximately $\pm 3 \%$.

Figure 17 shows that fluid heat flux is greater that the electric resistance heat flux for all points between 20 and $50 \mathrm{~kW} / \mathrm{m}^{2}$. On average, the confidence interval in this range is approximately $\pm 9 \%$. The large slope of the High Flux boiling curve contributes to the large confidence interval.

\section{Heat Flux Distribution}

Webb and Pais (1992) measured a maximum circumferential variation in $\Delta \mathrm{T}_{\mathrm{s}}$ of slightly over $1 \mathrm{~K}$ from the top to the bottom of the tube $(30 \mathrm{~mm})$. They also note that McKee and Bell (1968) have reported similar discrepancies with tubes. Fath (1986) measures a top to bottom tube $(24 \mathrm{~mm})$ temperature difference of $0.3 \mathrm{~K}$. He also provides an analysis to suggest that eccentric heater placement can cause a $1 \mathrm{~K}$ temperature difference. For the present data, the wall temperature variation from $\mathrm{y}=-\mathrm{L}_{\mathrm{y}} / 2$ to $\mathrm{L}_{\mathrm{y}} / 2(101.6 \mathrm{~mm})$ increased with heat flux and was typically within $0.3 \mathrm{~K}$ for all plates and for both heating conditions.

\section{Speculation on Heat Method Difference}

The author knows of no other experimental study besides the present one that directly compares fluid to electric resistance heating boiling data from the same test section. However, researchers have been aware of the heating boundary condition effect in boiling. Unal et al. (1994) have used a model to show that 
the heating method can significantly modify the boiling curve, but provide no rationale for the cause. No other theoretical studies predicting the influence of heating method were found in the literature. Nevertheless, Memory (1995) points out that fluid heated smooth tube boiling data taken by McManus et al. (1986) and electric heating smooth tube boiling data taken by Memory et al. (1994) differ by as much as $50 \%$ for the same conditions. Intuitively, the magnitude of the heat flux should rely on a coupling of the heat transfer at three boundaries: boiling on the enhancement, conduction in the copper, and single phase or electric resistance heating at the heated surface.

It is speculated that for the same time-averaged heat flux, a larger fraction of it is used to superheat liquid for electric resistance heating than for fluid heating. Figure 18 shows simplified transient plate temperatures for electric resistance and fluid heating boundary conditions. The transient behavior of the plate is confined to a thin penetration depth $(\delta)$ near the boiling surface. The surface temperature is approximated as a square wave which is high and low for boiling and liquid superheating modes, respectively. The wall temperature drops during boiling since it is a more efficient means of transferring heat than natural convection. The temperature of the plate at the transient-steady state interface $\left(T_{w i}\right)$ is constant for the fluid heating case. The $T_{\text {wi }}$ for the electrically heated surface varies in phase with the same amplitude as $\mathrm{T}_{\text {wo }}$ due to the constant heat flux constraint. For the conditions established in Fig. 19 , setting the fluid and electric resistance time-averaged heat fluxes equal results in the following expression for the superheating portion of the fluid heat flux:

$$
(q " f)_{S H}=\left(q "{ }_{e}\right)_{S H}-\frac{A_{T w} k}{2 \delta}
$$

Equation 8 illustrates that fluid heating superheats the liquid less than electric resistance heating by ${ }^{1 / 2} A_{T w} k / \delta$. Surfaces with a greater degree of superheated liquid tend to have higher surface temperatures and greater wall superheats. Consequently, for the same time-averaged heat flux, the boiling curve for the electrically heated surface will be to the right of that for the fluid heated surface.

In the above heuristic argument, the transient penetration depths were assumed to be the same for electric and fluid heating. The $\delta$ depends on the properties of the copper, the magnitude of the heat flux, and the bubble frequency. The electric and fluid heated penetration depths should be nearly the same because the comparison was made for equal heat fluxes on the same surface. For this case, the properties of the copper and the bubble frequencies for the electric and fluid heated surfaces should be similar in magnitude.

\section{VISUAL OBSERVATIONS}

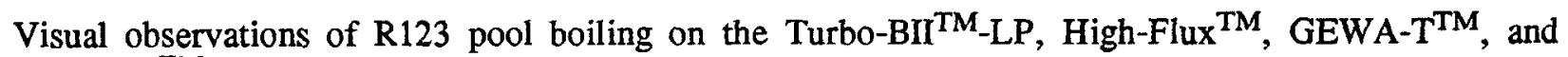
GEWA-K ${ }^{\mathrm{TM}}$ are discussed in the following. The observations were recorded on $16 \mathrm{~mm}$ high-speed film at 1000,3000 , and $6000 \mathrm{fps}$. Two $500 \mathrm{~W}$ forward lights were focused on the boiling surface during filming.

\section{GEWA-T ${ }^{\mathrm{TM}}$}

Figure 19 depicts the three different boiling modes for $\mathrm{R} 123$ at $\mathrm{q}^{\prime \prime}=70 \mathrm{~kW} / \mathrm{m}^{2}$. Each mode depends on the size of the bubble as it exists when it is in the cavity. The bubble modes for small, large (mushroom), and intermediate size bubbles are illustrated from left to right in Figure 19. The small cavity bubble formation mode occurs when small diameter bubbles are individually formed and travel unobstructed through the gap between the fins.

Figure 20 depicts the sequence of events that describe the large cavity bubble mode. First, several small bubbles are almost simultaneously formed. If the bubbles are sufficiently congested within the cavity, they will coalesce into one large bubble. Due to the close proximity of the bubble to the cavity walls, 
the bubble quickly picks up energy from the superheated liquid and ejects vapor through the fin gap while maintaining a vapor root within the cavity. When the buoyancy force on the portion of the bubble above the fins is large enough, it will cause the vapor root to be pulled out of the cavity.

Figure 21 illustrates the bubble formation mode for intermediate size bubbles. This mode occurs when a cavity bubble is larger than the gap between the fins, but not large enough to get close to the superheated liquid layer to grow rapidly. A bubble retained by the fin tips receives energy directly from the corners of the fin and grows until buoyancy forces pull it from the fin. The last two boiling modes are advantageous since they efficiently create additional vapor. That is, vapor is generated when the bubble is large and the surface-tension forces are more easily overcome.

Recall Figure 19 shows that all three boiling modes are present for R123 at $\mathrm{q}^{\prime \prime}=70 \mathrm{~kW} / \mathrm{m}^{2}$. The small bubble formation mode dominates approximately $70 \%$ of the bubble formation occurrences. The bubbles are approximately $0.2 \mathrm{~mm}$ in diameter. The intermediate and large cavity bubble modes occur at about equal frequencies and together contribute $30 \%$ of the bubble activity.

Figure 22 is a schematic of the bubble activity for the GEWA-T ${ }^{\mathrm{TM}}$ surface with R123 at q" $=30$ $\mathrm{kW} / \mathrm{m}^{2}$. Natural convection density gradients or Schliere are visible over the entire surface. Most of the heat transfer surface is inactive with the exception of few sparse sites. Mushroom bubbles are not present.

\section{$\underline{\text { GEWA-K }}$}

Figure 23 shows four different boiling modes for the GEWA-K ${ }^{\mathrm{TM}}$ surface with R123. These modes occur in two regions: (1) the fin-tip, and (2) the fin-root. Rarely was boiling observed on the flat tops of the fins or on the smooth portion of the sides of the fins as shown in Fig. 23. Either large, lowfrequency bubbles or small, high-frequency bubbles were generated in the fin-tip or fin-root areas yielding the four modes of boiling for the GEWA- $\mathrm{K}^{\mathrm{TM}}$. In the fin-tip region, small $0.1 \mathrm{~mm}$ to $0.5 \mathrm{~mm}$ diameter bubbles originated within $0.2 \mathrm{~mm}$ of the corners of the fin-tips. High frequency bubble formation in the fin-tip region was the most prevalent boiling mode. Infrequently, and only for $30 \mathrm{~kW} / \mathrm{m}^{2}$, single, large (approximately $1 \mathrm{~mm}$ diameter) bubbles were produced in the fin-tip region. In the fin-root region, discrete $0.3 \mathrm{~mm}$ diameter bubbles were produced. Less frequently, these would coalesce into a single large bubble which would fill the space between the fins and receive heat from the root and sides of the fin. More often, the large root bubble would originate from a single bubble. The large root bubble would then grow until it was approximately twice the fin height before it was released.

The heat flux influenced the intensity of the boiling mode. Overall, the fin-tip and fin-root regions were observed to be active for the range of heat flux investigated (30 to $\left.100 \mathrm{~kW} / \mathrm{m}^{2}\right)$. In general and for all heat flux ranges, boiling from the side of the fin tip was most prevalent. At a heat flux of $30 \mathrm{~kW} / \mathrm{m}^{2}$ bubble production alternated from the fin-tip to the root of the fin. Large bubbles were seldom generated at the fin root for $30 \mathrm{~kW} / \mathrm{m}^{2}$. At a higher heat flux between 70 and $100 \mathrm{~kW} / \mathrm{m}^{2}$, the large bubbles from the fin root and small bubbles from the fin-tips are predominantly formed. But, most of the activity appeared to be on the side of the fin-tip.

At first consideration, it is surprising that the fin-tip boiling mode exists because the greatest wall superheat is expected at the root of the fin. However, Fath (1986) presents photographs of what appears to be boiling from the tips of the fins of a GEWA-K ${ }^{\mathrm{TM}}$ tube. Also, microscopic examination of the finned surface revealed a nonuniform roughness along the fin profile. Apparently, boiling in the fin-tip region is a consequence of that region having the greatest roughness of the profile. For example, the average measurred $\mathrm{R}_{\mathrm{a}}$ roughness was $1.3 \mu \mathrm{m}$, and $0.4 \mu \mathrm{m}$ for the fin-tip, and fin-root, respectively. The roughness of the smooth fin-side areas could not be measured directly; however, it appeared to be nearly the same roughness as the fin-root. The representative cavity openings were $0.03 \mathrm{~mm}$ and $0.02 \mathrm{~mm}$ for the fin-tip and the fin-root areas, respectively. Most of the fin heat flux was directed to the fin-tip side and hence was diverted from the very top of the fin. The fin side was relatively smooth; consequently no boiling was observed there. 
Figure 24 shows schematics of the boiling activity for the High-Flux ${ }^{\mathrm{TM}}$ surface at 28 , 69 , and 143 $\mathrm{kW} / \mathrm{m}^{2}$. In general, the High-Flux ${ }^{\mathrm{TM}}$ surface produced discrete, approximately $0.3 \mathrm{~mm}$ diameter, bubbles for all heat fluxes. For $28 \mathrm{~kW} / \mathrm{m}^{2}$, a few small, inactive areas were observed on the surface. No inactive areas were observed for the two higher heat fluxes. The bubble frequency increased from approximately 500 bubbles per second for heat fluxes of 28 and $69 \mathrm{~kW} / \mathrm{m}^{2}$ to approximately 1000 bubbles per second for $143 \mathrm{~kW} / \mathrm{m}^{2}$. The frequency of bubble coalescence increased as site density and bubble frequency increased with heat flux. For example, at low heat flux, bubbles formed completely, detached and then joined with other bubbles several millimeters above the surface. At $143 \mathrm{~kW} / \mathrm{m}^{2}$, the $0.3 \mathrm{~mm}$ diameter bubbles never completely formed before they were immediately sucked into large 1.5 to $5 \mathrm{~mm}$ bubbles nearly creating a sheet of vapor which momentarily thrashed fractions of millimeters above the surface.

\section{Turbo-BII ${ }^{\text {TM }}$-LP}

Figure 25 shows a sketch of R123 boiling activity on the Turbo-BII ${ }^{\text {TM }_{-}}$-LP surface. Table 15 provides the departure diameter, the bubble frequency as a function of heat flux, and comments on the boiling activity. The representative bubble diameter and bubble frequency were essentially invariant with heat flux. The site density - or more appropriately the number of active channels - increased with increasing heat flux. At $1.2 \mathrm{~kW} / \mathrm{m} 2$ one site per approximately $200 \mu \mathrm{mm}^{2}$ actively produced discrete bubbles. For all observed heat fluxes greater than $1.2 \mathrm{~kW} / \mathrm{m}^{2}$, bubbles simultaneously popped up between the fin-tips for apparently the entire length of a channel. Possibly, the canopy of fins retains a long tubular vapor seed within the channel. Similarly, Stephan and Mitrovic (1982) speculated that a thin film exists in the channel around the root of the GEWA-T ${ }^{\mathrm{TM}}$ tube.

Figure 25 depicts the synchronous production of bubbles from adjacent channels spaced $S_{c}$ apart. For low heat fluxes, the $S_{\mathrm{c}}$ spacing was large, and the bubbles were formed from particular channels at regular intervals. For greater heat fluxes, the $S_{c}$ spacing diminished and an interaction between channels was evident from the irregular activity of the channels. For example, active channels were spaced approximately $3 \mathrm{~mm}$ and $1.4 \mathrm{~mm}$ apart for $9 \mathrm{~kW} / \mathrm{m}^{2}$ and $12.8 \mathrm{~kW} / \mathrm{m}^{2}$, respectively.

One mode of interaction between adjoining channels is illustrated in Fig. 25. The figure shows large bubbles from one channel drawing incipient bubbles from within the adjoining channel. The larger bubbles spread and coalesce with the smaller bubbles, enveloping them. It is not known if the coalescing mechanism enhances vapor production in the incipient channel.

\section{ASCENDING HEAT FLUX DATA}

Ascending heat flux tests were conducted to examine the hysteresis of the test surface performance near the onset of nucleate boiling (ONB) condition. The ascending heat flux tests were initiated at the lowest heat flux and proceeding measurements were taken for consecutively higher heat fluxes. No ascending heat flux data were taken for the GEWA-T $\mathrm{T}^{\mathrm{TM}}$ surface. Also, no electric resistance heating ascending data were taken for the Turbo-BII ${ }^{\text {TM }}$-LP surface. Table 7 provides the number of test days for each surface and heating condition with the starting heat flux for the tests.

The ascending heat flux test procedure examines the influence of prior vapor seeding on the boiling curve. As implied by Corty and Foust (1955), a greater superheat is required to grow a bubble from a flooded cavity than from a cavity containing a vapor nucleus. In an attempt to extinguish the active cavities before testing, the Turbo-BII ${ }^{\mathrm{TM}}$-LP and GEWA-K ${ }^{\mathrm{TM}}$ surfaces were free of boiling prior to testing the lowest heat flux. Boiling was always present on the High-Flux ${ }^{\mathrm{TM}}$ surface. Consequently, Fig. 26 shows that no difference between ascending and descending heat flux data can be claimed since the $95 \%$ confidence intervals on $\mathrm{q}_{\mathrm{d}} / \mathrm{q}_{\mathrm{a}}{ }_{\mathrm{a}}$ bound unity. 
Figure 26 shows the fluid heating ascending heat flux data for the Turbo-BII ${ }^{\text {TM}}-\mathrm{LP}$ surface. The solid line represents the mean for the fluid heating descending heat flux data for the Turbo-BII ${ }^{\text {TM }}$-LP. For heat fluxes below $60 \mathrm{~kW} / \mathrm{m} 2$, the ascending data differ noticeably from the descending data. The maximum temperature difference between the ascending and descending data - loosely defined as the temperature overshoot - is approximately $2.4 \mathrm{~K}$ at $12 \mathrm{~kW} / \mathrm{m}^{2}$. By contrast, Jung and Bergles (1989) show a negligible temperature overshoot for the Turbo-B S tube in R113.

Figure 26 also shows the fluid heating ascending heat flux data for the GEWA-K ${ }^{\mathrm{TM}}$ surface. The solid line represents the mean for the fluid heating descending heat flux data for the GEWA-K ${ }^{\mathrm{TM}}$ surface. The ascending data agree with the descending data in the natural convection region. The temperature overshoot is approximately $0.1 \mathrm{~K}$. Memory and Marto (1992) report a $2.7 \mathrm{~K}$ temperature overshoot for their GEWA-K ${ }^{\mathrm{TM}}$ surface in R114.

Figure 27 demonstrates that a temperature overshoot of $0.6 \mathrm{~K}$ was measured for the electrically heated High-Flux ${ }^{\mathrm{TM}}$ surface. Three test days suggest an overshoot and one test day (shaded boxed) closely follows the descending heat flux data for the High-Flux ${ }^{\mathrm{TM}}$ surface. Although boiling was observed on the surface prior to testing on each day, apparently the ascending heat flux data is sensitive to an unknown effect.

Figure 27 also shows a negligible temperature overshoot for the electrically heated GEWA-K ${ }^{\mathrm{TM}}$ surface as was the case for the fluid heated GEWA-K ${ }^{\mathrm{TM}}$ data. The GEWA-K ${ }^{\mathrm{TM}}$ ascending boiling data fall with in the confidence intervals of the descending boiling data below $40 \mathrm{~kW} / \mathrm{m}^{2}$. For heat fluxes above 40 $\mathrm{kW} / \mathrm{m}^{2}$, the ascending data lie to the left of the confidence interval for the descending data. Either the ascending data above $40 \mathrm{~kW} / \mathrm{m}^{2}$ is erroneous or some unknown phenomenon is the cause.

\section{CONCLUSIONS}

Pool boiling of R123 on four commercial enhanced surfaces was investigated both calorimetrically and visually. The four surfaces were: (1) Turbo-BII ${ }^{\mathrm{TM}}-\mathrm{LP}$, (2) High-Flux ${ }^{\mathrm{TM}}$, (3) GEWA-K ${ }^{\mathrm{TM}}$, and (4) GEWA-T ${ }^{\mathrm{TM}}$. For a Turbo-B⿰丿⿴囗⿱一一) ${ }^{\mathrm{TM}}-\mathrm{LP}$ heat flux change from 30 to $75 \mathrm{~kW} / \mathrm{m} 2$, the heat flux of the HighFlux $^{\mathrm{TM}}$ surface is approximately 1 to 2.5 times that of the Turbo-BII ${ }^{\mathrm{TM}}$-LP surface. The Turbo-BII ${ }^{\mathrm{TM}}$ LP performance is 1.5 times greater than that of the GEWA-T ${ }^{\mathrm{TM}}$ and GEWA-K ${ }^{\mathrm{TM}}$ surfaces at a heat flux of approximately $100 \mathrm{~kW} / \mathrm{m} 2$.

Fluid heating produced a greater heat flux than electric resistance heating for pool boiling on the surfaces tested. The fluid heating condition results in heat fluxes that are as much as $32 \%$ greater than those obtained by electric resistance heating. It is speculated that an interaction between the fluctuating wall temperature and the fixed electrical heat flux induced a higher degree of superheated liquid on the electrically heated surface than on the fluid heated surface. The heating boundary condition may affect reentrant and natural cavity surfaces differently.

Bubble formation varied with surface and heat flux. Bubbles were formed on the root and tips of the fins of the GEWA-K ${ }^{\mathrm{TM}}$ surface. The GEWA-T ${ }^{\mathrm{TM}}$ surface produced mushroom bubbles at high heat flux. The High-Flux ${ }^{\mathrm{TM}}$ surface produce discrete, tiny $0.3 \mathrm{~mm}$ diameter bubbles. Bubbles were simultaneously produced along the channels of the Turbo-BII ${ }^{\text {TM }}$-LP surface.

\section{ACKNOWLEDGEMENTS}

This work was jointly funded by NIST and the U.S. Department of Energy (project no. DE-0195CE23808.000 modification \#A004) under Project Managers Esher Kweller and Bill Noel. Thanks goes to the following NIST personnel for their constructive criticism of the first draft of the manuscript: Dr. P. Domanski, Mr. P. Rothfleisch, Dr. D. Ripple, and Mrs. J. Land. The author would also like to 
express his appreciation to E. Bellinger and A. Dashottar for their contributions towards data collection. Furthermore, the author extends his appreciation to Dr. E. Lagergren and Dr. J. Blue for their consultations on the uncertainty analysis, and conduction solution, respectively. 


\section{REFERENCES}

Ayub, Z.H., and Bergles, A.E., 1990, "Nucleate Pool Boiling CurveHysteresis for GEWA-T ${ }^{\mathrm{TM}}$ Surfaces in Saturated R-113," Experimental Thermal and Fluid Science, Vol. 3, pp. 249-255.

Corty, C., and Foust, A. S., 1955, "Surface Variables in Nucleate Boiling," Chem. Eng. Prog. Symp. Ser., No. 17, Vol. 51, pp. 1-12.

Derrick, W. R., and Grossman, S. I., 1976, Elementary Differential Equations with Applications, 1st ed., Addison-Wesely, Reading, p. 451.

Eckert, E. R. G., and Goldstein, R. J., 1976, Measurements in Heat Transfer, Hemisphere, Washington, 2nd ed., pp. 9-11.

Fath, W., 1986, "Waermeuebergangsmessungen an Glatt- und Rippenrohren in Einer Standardapparatur Fuer Siedeversuche," Dissertation, Paderborn.

Gorneflo, D., Blein, P., Caplanis, S., and Sokol, P., 1990, "Pool Boiling Heat Transfer from A GEWA$\mathrm{T}^{\mathrm{TM}} \mathrm{X}$ Finned Tube to Low Boiling Hydrocarbons," Progress in the Science and Technology of Refrigeration in Food Engineering, pp. 249-256.

Jung, C. and Bergles, A. E., 1989, "Evaluation of Commercial Enhanced Tubes in Pool Boiling," Topical Report, Rensselaer Polytechnic Institute, Troy, NY, DOE/ID/12772--1.

Kays, W. M. and Crawford, M. E., 1980, Convective Heat and Mass Transfer, McGraw Hill Book Co., 2nd ed., New York, pg. 109.

Kedzierski, M. A. and Worthington III, J. L., 1993, "Design and Machining of Copper Specimens with Micro Holes for Accurate Heat Transfer Measurements, " Experimental Heat Transfer, vol. 6, pp. 329344.

Marto, P.J., and Lepere, V.J., 1982,"Pool Boiling Heat Transfer From Enhanced Surfaces to Dielectric Fluids," Journal of Heat Transfer, Vol. 104, pp. 292-301.

McKee, H.R., and Bell, K.J., 1968, "Forced Convection Boiling from a Cylinder Normal to the Flow," Chem. Eng. Prog. Symp., Vol. 65, pp. 222-230.

McManus, S.M., Marto, P.J., and Wanniarachchi, 1986, "An Evaluation f Enhanced Heat Transfer Tubing for Use in R-114 Chillers," Heat Transfer in Air Conditioning and Refrigeration Equipment, ASME, HTD-Vol. 65, pp. 11-19.

Memory, S. B., 1995, Private communications, University of Miami, Coral Gables, Florida.

Memory, S.B., and Marto, P.J.,1992, "The Influence of Oil on Boiling Hysteresis of R-114 from Enhanced Surfaces," Pool and External Flow Boiling, ASME pp 63-71.

Memory, S.B., Sugiyama, D.C., and Marto, P.J., 1944, "Nucleate Pool Boiling of R-114 and R-114/Oil Mixtures from Smooth and Enhanced Surfaces: Part I - Single Tubes," Int J. Heat Mass Trans. Vol. 38 no. 8, pp. 1347-1361.

Morrison, G, and Ward, D. K., 1991, "Thermodynamic Properties of Two Alternative Refrigerants: 1,1Dichloro-2,2,2-Trifluoroethane (R123) and 1,1,1,2-Tetrafluoroethane (R134a)," Fluid Phase Equilibria, Vol 62, pp. 65-86.

Pais, C., and Webb, R, L., 1991, "Literature Survey of Pool Boiling on Enhanced Surfaces, " ASHRAE Transactions, Vol. 97, Pt. 1, pp. 79-89. 
Pasamehmetoglu, K. O., and Nelson, R. A., 1991, "Cavity-to-Cavity Interaction in Nucleate Boiling: The Effect of Heat Conduction Within the Heater," AIChE Sym. Ser, No. 283, Vol. 87, pp. 342-351.

Singh, A., Kumar, A., Dessiatoun, S., Faani, M. A., Ohadi, M. M., and Ansari, A. I., 1993, "Compound EHD-Enhanced Pool Boiling of R-123 in a Liquid-to-Refrigerant Heat Exchanger," ASME paper \#93-WA-HT-40.

Siu, M. C. I., Carroll, W. L., and Watson, T. W., 1976, "Thermal Conductivity and Electrical Resistivity of Six Copper-Base Alloys," NBSIR 76-1003, U.S. Department of Commerce, Washington.

Smith, C. S., and Palmer, E. W., 1935, "Thermal and Electric Conductivities of Copper Alloys," Trans. Amer. Inst. Min. Metall. Engrs., Vol. 117, pp. 225-243.

Stephan, and Mitrovic, 1982, "Heat Transfer in Natural Convective Boiling of Refrigerant-oil Mixtures," Proc. 7th Int. Heat Transfer Conf. in Munchen, Vol. 4, pp. 73-87.

Unal, C., and Pasamehmetoglu, K.O., 1994, "A Numerical Investigation of the Effect of Heating Methods on Saturated Nucleate Pool Boiling," International Communications in Heat and Mass Transfer, Vol. 21, No. 2, pp. 167-177.

Webb, R. L., and McQuade, W. F., 1993, "Pool Boiling of R-11 and R-123 Refrigerant-Oil Mixtures on Plain and Enhanced Tube Geometries," ASHRAE Trans., Vol, 99, pp. 1225-1236.

Webb, R.L., and Pais, C., 1992, "Nucleate Pool Boiling Data for Five Refrigerants on Plain, Integral-fin and Enhanced Tube Geometries," Int. J. Heat Mass Transfer, Vol. 35, No. 8, pp. 1893-1904.

Yilmaz, S., Hwalek, J.J., and Westwater, J.W., 1980, "Pool Boiling Heat Transfer Performance for Commercial Enhanced Tube Surfaces," ASME 19th Nat. Heat transfer Conference, Paper 80-HT-41. 


\section{APPENDIX A}

This appendix outlines the procedure used to extrapolate the wall temperature of the Turbo-BII ${ }^{\mathrm{TM}}$-LP surface. The boiling surface on the Turbo-BII ${ }^{\mathrm{TM}}-\mathrm{LP}$ plate originated as a round tube. The tube was annealed, flattened and soldered onto the top of the plate. The average temperature of the plate-solder interface $\left(\mathrm{T}_{\mathfrak{1}}\right)$ was calculated from the regression of the two-dimensional conduction equation as described in the body of this paper. Because the solder layer was thin, a one-dimensional conduction model was used to extrapolate the temperature drop across it.

The solder was $6 \%$ silver and $94 \%$ tin by mass. The thermal conductivity of the solder was fitted to a modified form of the Smith-Palmer equation (Smith and Palmer, 1935) as:

$$
k_{s}=\left[\frac{57.858 \frac{W}{m K}}{T-38.65 K}\right] T+7.5 \frac{W}{m K}
$$

where $T$ is the temperature of the solder layer in kelvins. The Smith-Palmer equation was modified by replacing the electrical conductivity with a linear relationship with temperature.

The flattened Turbo-BII ${ }^{\mathrm{TM}}$-LP tube was phosphorus-deoxidized copper (C12200). The thermal conductivity of the copper $\left(\mathrm{k}_{\mathrm{cu}}\right)$ was fitted to:

$$
k_{c u}=\left[\frac{422.46 \frac{W}{m K}}{T-63.33 K}\right] T+37.79 \frac{W}{m K}
$$

where $T$ is the temperature of the copper in kelvins. The average thickness of the solder layer $\left(t_{s}\right)$ and the average distance between the copper-solder layer interface and the root of the fin $\left(t_{T}\right)$ were measured with an optical-video coordinate-measurement instrument (OVCM). The OVCM instrument had a resolution of $0.005 \mathrm{~mm}$.

The average wall temperature at the root of the fin for the Turbo-BII ${ }^{\mathrm{TM}}-\mathrm{LP}$ plate was calculated from:

$$
T_{w}=T_{i}-q^{\prime \prime}\left[\frac{t_{r}}{k_{122}}+\frac{t_{s}}{k_{s}}\right]
$$

The combined standard uncertainty of $T_{w}$ was calculated considering the $u_{c}$ of each parameter of eqn. 11. The uncertainty of the thickness measurements were estimated to be four times the resolution of the OVCM instrument. Capillary forces during the soldering process should provide for a uniform solder thickness. The uncertainty of $\mathrm{t}_{\mathrm{r}}$ was taken as $0.13 \mathrm{~mm}$ to allow for machining tolerances. The thermal conductivities of the copper and the solder were assumed to be known to within $5 \%$. For these conditions, the temperature correction for the solder layer contributes $0.027 \mathrm{~K}, 0.01 \mathrm{~K}$ and $0.0002 \mathrm{~K}$ to the $u_{c}$ of the average wall temperature for $160 \mathrm{~kW} / \mathrm{m}^{2}, 80 \mathrm{~kW} / \mathrm{m}^{2}$, and $5 \mathrm{~kW} / \mathrm{m}^{2}$, respectively. This additional uncertainty must be added to that shown in Fig. 5 for the Turbo-BII ${ }^{\text {TM }}$-LP surface. 
Table 1a Conduction model choice: descending heating

\begin{tabular}{|c|c|c|c|c|}
\hline surface & $\begin{array}{l}\text { low } \\
\text { fluid q" }\end{array}$ & $\begin{array}{l}\text { high } \\
\text { fluid q" }\end{array}$ & $\begin{array}{l}\text { low } \\
\text { electric q" }\end{array}$ & $\begin{array}{l}\text { high } \\
\text { electric q" }\end{array}$ \\
\hline GEWA-T ${ }^{T M}$ & 3 rd order & 3rd order & N/A & N/A \\
\hline Turbo-BII ${ }^{\mathrm{TM}}$-LP & 1st order & 1 st order & $\begin{array}{c}\text { 1st order } \\
(<3 \mathrm{~kW} / \mathrm{m} 2)\end{array}$ & $\begin{array}{c}\text { 3rd order } \\
\left(>3 \mathrm{~kW} / \mathrm{m}^{2}\right)\end{array}$ \\
\hline GEWA-K ${ }^{\mathrm{TM}}$ & $\begin{array}{c}1 \text { st order } \\
\left(<10 \mathrm{~kW} / \mathrm{m}^{2}\right)\end{array}$ & $\begin{array}{c}\text { 3rd order } \\
\left(>10 \mathrm{~kW} / \mathrm{m}^{2}\right)\end{array}$ & $\begin{array}{c}\text { 1st order } \\
\left(<5 \mathrm{~kW} / \mathrm{m}^{2}\right)\end{array}$ & $\begin{array}{c}3 \mathrm{rd} \text { order } \\
\left(>5 \mathrm{~kW} / \mathrm{m}^{2}\right)\end{array}$ \\
\hline High-Flux $^{\mathrm{TM}}$ & 1 st order & 1st order & 3rd order & 3 rd order \\
\hline
\end{tabular}

Table $1 \mathrm{~b}$ Conduction model choice: ascending heating

\begin{tabular}{|c|c|c|c|c||}
\hline surface & $\begin{array}{c}\text { low } \\
\text { fluid q" }\end{array}$ & $\begin{array}{c}\text { high } \\
\text { fluid q" }\end{array}$ & $\begin{array}{c}\text { low } \\
\text { electric q" }\end{array}$ & $\begin{array}{c}\text { high } \\
\text { electric q" }\end{array}$ \\
\hline GEWA-T $^{\mathrm{TM}}$ & N/A & N/A & N/A & N/A \\
\hline Turbo-BII TM-LP & 1st order & 1st order & N/A & N/A \\
\hline GEWA-K & 3rd order & 3rd order & 3rd order & 3rd order \\
\hline High-Flux & 1st order & 1st order & $\begin{array}{c}1 \mathrm{st} \mathrm{order} \\
\left(<8 \mathrm{~kW} / \mathrm{m}^{2}\right)\end{array}$ & $\begin{array}{c}3 \mathrm{rd} \text { order } \\
\left(>8 \mathrm{~kW} / \mathrm{m}^{2}\right)\end{array}$ \\
\hline
\end{tabular}


Table 2 Average magnitude of $95 \%$ confidence interval for mean $T_{w}-T_{s}(K)$ descending heat flux

\begin{tabular}{|c|c|c|}
\hline surface & fluid q" & electric q" \\
\hline GEWA-T $^{\mathrm{TM}}$ & $\begin{array}{l}0.10(\mathrm{C}) \\
0.07(\mathrm{~B})\end{array}$ & $\mathrm{n} / \mathrm{a}$ \\
\hline Turbo-BII $^{\mathrm{TM}}$-LP & 0.07 & 0.07 \\
\hline GEWA-K $^{\mathrm{TM}}$ & $\begin{array}{l}0.37(\mathrm{C}) \\
0.06(\mathrm{~B})\end{array}$ & $\begin{array}{l}0.13(\mathrm{C}) \\
0.08(\mathrm{~B})\end{array}$ \\
\hline High-Flux $^{\mathrm{TM}}$ & 0.04 & 0.06 \\
\hline
\end{tabular}

Table 3 Residual standard deviation of descending q" data from the mean $(\mathrm{K})$

\begin{tabular}{|c|c|c|}
\hline surface & $\begin{array}{c}\text { descending } \\
\text { fluid q" }\end{array}$ & $\begin{array}{c}\text { descending } \\
\text { electric q" }\end{array}$ \\
\hline GEWA-T $^{\mathrm{TM}}$ & $\begin{array}{l}0.03(\mathrm{C}) \\
0.07(\mathrm{~B})\end{array}$ & N/A \\
\hline TURBO-BII $^{\mathrm{TM}}$-LP & 0.11 & 0.08 \\
\hline GEWA-K $^{\mathrm{TM}}$ & $0.13(\mathrm{C})$ & $0.11(\mathrm{C})$ \\
& $0.07(\mathrm{~B})$ & $0.08(\mathrm{~B})$ \\
\hline High-Flux $^{\mathrm{TM}}$ & 0.06 & 0.06 \\
\hline
\end{tabular}

Table 4 Constants for Boiling Curve Fits: $\Delta \mathrm{T}_{\mathrm{s}}$ vs. $\mathrm{q}^{\prime \prime}$ $\Delta T_{s}=A_{0}+A_{1} q^{\prime \prime}+A_{2} q^{1 / 2}+A_{3} q^{/ 3}$

\begin{tabular}{|c|c|c|c|c|}
\hline $\begin{array}{l}\text { surface } \\
\text { (HEATINE) }\end{array}$ & $A_{0}$ & $A_{1}$ & $\mathrm{~A}_{2}$ & $A_{3}$ \\
\hline $\begin{array}{c}\text { GEWA-TTM } \quad \Delta T_{s} \geq 7.5 \mathrm{~K} \\
\text { (FLUID) } \Delta T_{s} \leq 7.5 \mathrm{~K}\end{array}$ & $\begin{array}{c}6.89731 \\
-1.52146\end{array}$ & $\begin{array}{l}0.530960 \times 10^{-4} \\
0.920022 \times 10^{-3}\end{array}$ & $\begin{array}{l}-0.937179 \times 10^{-9} \\
-0.327272 \times 10^{-7}\end{array}$ & $\begin{array}{l}0.703352 \times 10^{-14} \\
0.471743 \times 10^{-12}\end{array}$ \\
\hline $\begin{array}{l}\text { Turbo-BII IM-LP } \\
\text { (FLUID) }\end{array}$ & 0.733265 & $0.311122 \times 10-4$ & $0.241225 \times 10^{-9}$ & $-0.385672 \times 10^{-15}$ \\
\hline $\begin{array}{l}\text { Turbo-BII IM-LP } \\
\text { (ELECTRIC) }\end{array}$ & 0.709359 & $0.443598 \times 10-4$ & $0.511582 \times 10^{-10}$ & $0.395632 \times 10^{-15}$ \\
\hline $\begin{array}{c}\text { GEWA-KTM } \Delta \mathrm{T}_{\mathrm{s}} \geq 7.59 \mathrm{~K} \\
\text { (FLUID) } \Delta \mathrm{T}_{\mathrm{s}} \leq 7.59 \mathrm{~K}\end{array}$ & $\begin{array}{l}7.05375 \\
1.62458\end{array}$ & $\begin{array}{l}0.372209 \times 10^{-4} \\
0.243625 \times 10^{-3}\end{array}$ & $\begin{array}{l}-0.446787 \times 10^{-9} \\
0.131528 \times 10^{-9}\end{array}$ & $\begin{array}{c}0.330430 \times 10^{-14} \\
-0.528259 \times 10^{-12}\end{array}$ \\
\hline $\begin{array}{l}\text { GEWA-KTM } \Delta T_{s} \geq 7.78 \mathrm{~K} \\
\text { ELECTRIC) } \Delta T_{s} \leq 7.78 \mathrm{~K}\end{array}$ & $\begin{array}{l}6.30498 \\
0.947130\end{array}$ & $\begin{array}{l}0.995919 \times 10^{-4} \\
0.527379 \times 10^{-3}\end{array}$ & $\begin{array}{l}-0.182387 \times 10^{-8} \\
-0.156592 \times 10^{-7}\end{array}$ & $\begin{array}{l}0.136843 \times 10^{-13} \\
0.288654 \times 10^{-12}\end{array}$ \\
\hline $\begin{array}{l}\text { High-FluxiM } \\
-\quad \text { (FLUID) }\end{array}$ & 1.42189 & $0.167478 \times 10^{-4}$ & $-0.444194 \times 10^{-11}$ & $-0.240319 \times 10^{-16}$ \\
\hline $\begin{array}{l}\text { High-Flux TM } \\
\text { (ELECTRIC) }\end{array}$ & 1.33200 & $0.274190 \times 10^{-4}$ & $-0.222084 \times 10^{-9}$ & $0.129175 \times 10^{-14}$ \\
\hline
\end{tabular}


Table 5 Constants for Boiling Curve Fits: q" vs. $\Delta \mathrm{T}_{\mathbf{s}}$ $q^{\prime \prime}=A_{0}+A_{1} \Delta T_{s}+A_{2} \Delta T_{s}^{2}+A_{3} \Delta T_{s}{ }^{3}$

\begin{tabular}{|c|c|c|c|c|}
\hline $\begin{array}{l}\text { surface } \\
\text { (HEATING) }\end{array}$ & $A_{0}$ & $A_{I}$ & $A_{2}$ & $A_{3}$ \\
\hline $\begin{array}{c}\text { GEWA-TTM } \quad \Delta T_{8} \geq 7.5 \mathrm{~K} \\
\text { (FLUID) } \Delta \mathrm{T}_{8} \leq 7.5 \mathrm{~K}\end{array}$ & $\begin{array}{c}0.122228 \times 10^{8} \\
-7628.71\end{array}$ & $\begin{array}{c}-0.482244 \times 10^{7} \\
7013.96\end{array}$ & $\begin{array}{l}625757 \\
-1154.96\end{array}$ & $\begin{array}{l}-26655.8 \\
93.9596\end{array}$ \\
\hline $\begin{array}{l}\text { Turbo-bII } \\
\text { (FLUID) }\end{array}$ & -17330.1 & 27872.2 & -1705.49 & 65.0673 \\
\hline $\begin{array}{l}\text { Turbo-bII } \\
\text { (ELECTRIC) }\end{array}$ & -16285.0 & 23520.8 & -621.034 & -23.8223 \\
\hline $\begin{array}{l}\text { GEWA-KTM } \Delta \mathrm{T}_{\mathrm{s}} \geq 7.59 \mathrm{~K} \\
\text { (FLUID) } \Delta \mathrm{T}_{\mathrm{s}} \leq 7.59 \mathrm{~K}\end{array}$ & $\begin{array}{l}-5904.62 \\
-13204.4 \\
\end{array}$ & $\begin{array}{l}-158327.0 \\
9317.05\end{array}$ & $\begin{array}{r}34799.2 \\
-1445.05\end{array}$ & $\begin{array}{l}-1787.72 \\
105.047\end{array}$ \\
\hline $\begin{array}{l}\text { GEWA-KTM } \Delta \mathrm{T}_{\mathrm{s}} \geq 7.78 \mathrm{~K} \\
\text { ELECTRIC) } \Delta \mathrm{T}_{\mathrm{s}} \leq 7.78 \mathrm{~K}\end{array}$ & $\begin{array}{c}0.189468 \times 10^{8} \\
222.250\end{array}$ & $\begin{array}{c}-0.687951 \times 10^{7} \\
10.4304\end{array}$ & $\begin{array}{c}828591 \\
514.308 \\
\end{array}$ & $\begin{array}{l}-33029.4 \\
-22.4823 \\
\end{array}$ \\
\hline $\begin{array}{l}\text { High-Flux TM } \\
\text { (FLUID) }\end{array}$ & -49287.5 & 18015.0 & 14747.2 & -1446.91 \\
\hline $\begin{array}{l}\text { High-Flux TM } \\
\text { (ELECTRIC) }\end{array}$ & 188701 & -308939 & 160825 & -22950.7 \\
\hline
\end{tabular}

Table 6 CNB for GEWA-T TM and GEWA-K ${ }^{T M}$ Plates

\begin{tabular}{|c|c|c|}
\hline Surface & $\begin{array}{c}\text { CNB Fluid } \\
\text { Heating (K) }\end{array}$ & $\begin{array}{c}\text { CNB Electric } \\
\text { Heating (K) }\end{array}$ \\
\hline GEWA-T & 7.5 & $\mathrm{~N} / \mathrm{A}$ \\
\hline GEWA-K & 7.59 & 7.78 \\
\hline
\end{tabular}

Table 7 Number of Test Days and Nominal initial heat flux

\begin{tabular}{|c|c|c|c|c|}
\hline surface & $\begin{array}{l}\text { ascending } \\
\text { fluid q" }\end{array}$ & $\begin{array}{l}\text { descending } \\
\text { fluid q" }\end{array}$ & $\begin{array}{l}\text { ascending } \\
\text { electric q" }\end{array}$ & $\begin{array}{c}\text { descending } \\
\text { electric } \\
\text { q" }\end{array}$ \\
\hline GEWA-T TM & $\mathrm{n} / \mathrm{a}$ & $\begin{array}{c}\text { six days } \\
(54 \mathrm{points}) \\
80 \mathrm{~kW} / \mathrm{m}^{2} \\
\end{array}$ & $\mathrm{n} / \mathrm{a}$ & $\mathrm{n} / \mathrm{a}$ \\
\hline $\begin{array}{c}\text { TURBO- } \\
\text { BII TM-LP }^{\text {TM }}\end{array}$ & $\begin{array}{c}\text { four days } \\
(39 \mathrm{points}) \\
1.5 \mathrm{~kW} / \mathrm{m}^{2}\end{array}$ & $\begin{array}{l}\text { six days } \\
(107 \mathrm{pts} .) \\
160 \mathrm{~kW} / \mathrm{m}^{2} \\
\end{array}$ & $\mathrm{n} / \mathrm{a}$ & $\begin{array}{l}\text { four days } \\
(59 \mathrm{pts} .) \\
80 \mathrm{~kW} / \mathrm{m}^{2} \\
\end{array}$ \\
\hline GEWA-K $\mathrm{K}^{\mathrm{TM}}$ & $\begin{array}{c}\text { four days } \\
(14 \text { points }) \\
9.7 \mathrm{~kW} / \mathrm{m}^{2}\end{array}$ & $\begin{array}{c}\text { six days } \\
(75 \text { points }) \\
110 \mathrm{~kW} / \mathrm{m}^{2}\end{array}$ & $\begin{array}{c}\text { One day } \\
\text { (26 points) } \\
13 \mathrm{~kW} / \mathrm{m}^{2}\end{array}$ & $\begin{array}{c}\text { six days } \\
(82 \mathrm{pts} .) \\
80 \mathrm{~kW} / \mathrm{m}^{2}\end{array}$ \\
\hline High-FIux & $\begin{array}{l}\text { three days } \\
(30 \text { points } \\
12-38 \mathrm{~kW} / \mathrm{m}^{2}\end{array}$ & $\begin{array}{l}\text { five days } \\
(73 \text { points }) \\
180 \mathrm{~kW} / \mathrm{m}^{2}\end{array}$ & $\begin{array}{l}\text { four days } \\
\text { (29 points) } \\
2 \mathrm{~kW} / \mathrm{m}^{2} \\
\end{array}$ & $\begin{array}{c}\text { three days } \\
(42 \mathrm{pts}-)^{2} \\
90 \mathrm{~kW} / \mathrm{m}^{2} \\
\end{array}$ \\
\hline
\end{tabular}


Table 8 GEWA-TTM fluid descending heating

$\Delta T_{.} \quad q^{\prime \prime}$

$\begin{array}{ll}8.86484 & 80039.1 \\ 8.77969 & 80658.0 \\ 8.78644 & 79629.4 \\ 8.64417 & 75278.9 \\ 8.49976 & 70874.8 \\ 8.40533 & 66531.6 \\ 8.22449 & 57422.9 \\ 8.10867 & 49311.0 \\ 8.00348 & 41011.5 \\ 7.92111 & 35171.8 \\ 7.84769 & 28609.5 \\ 7.66995 & 22779.6 \\ 7.17474 & 17941.8 \\ 6.46906 & 14837.9 \\ 6.45282 & 14800.6 \\ 5.40524 & 11240.0 \\ 5.33685 & 11245.8 \\ 5.39380 & 11426.2 \\ 4.57019 & 9219.97 \\ 4.54178 & 9226.65 \\ 4.59836 & 9367.33 \\ 8.75296 & 82008.3 \\ 8.75897 & 82040.7 \\ 8.59363 & 74940.3 \\ 8.51382 & 70214.5 \\ 8.51385 & 71537.8 \\ 8.48810 & 70629.5 \\ 8.45071 & 70629.7 \\ 8.42072 & 68374.3 \\ 8.38223 & 66486.4 \\ 8.18240 & 55820.2 \\ 7.97855 & 38974.5 \\ 8.78680 & 75984.5 \\ 8.69168 & 76412.1 \\ 8.56131 & 69423.5 \\ 8.14877 & 50283.6 \\ 8.17905 & 50494.2 \\ 7.99146 & 38052.2 \\ 8.01279 & 38121.2 \\ 7.87909 & 32388.8 \\ 7.77036 & 25910.7 \\ 7.74783 & 25543.9 \\ 8.47626 & 76140.5 \\ 8.47760 & 76018.7 \\ 8.32248 & 67925.4 \\ 8.31311 & 68296.2 \\ 8.25708 & 64048.4 \\ 8.23755 & 64123.3 \\ 8.22150 & 62318.7 \\ 8.17999 & 62607.9 \\ 8.09698 & 58639.6 \\ 8.09378 & 58053.5 \\ 8.00772 & 50448.1 \\ 7.82315 & 36960.0\end{array}$


Table 9 High-Flux TM fluid descending heating

$\Delta T_{s}$

4.10724
3.93167

3.73483

3.37521

3.11890

2.90338

2.55820

2.34982

2.15161

1.90619

1.83942

1.78696

3.45743

3.43271

3.17212

2.92905

2.63559

2.48383

2.28699

2.06992

1.95483

1.77124

1.64829

1.58719

1.53638

1.60046

1.45630

1.48016

3.71759

3.58872

3.30597

3.10199

2.83923

2.63187

2.44553

2.26831

2.24054

1.85345

1.97543

1.82922

1.81137

1.75754

1.68698

1.66248

1.70425

1.62082

1.65430

1.55115

1.61700

1.60629

1.54785

3.74194

3.65414

3.43414

3.20734

2.90289

2.70239

2.49887

2.28183

2.05655

1.81430

1.80878

1.78073

1.75842

1.66238

1.62967

1.64825

1.62558

1.63174

1.64468

1.66025

1.62875

1.59976 q"

174903.

168494 .

155409.

128187.

112015.

93762.1

71490.3

58232.6

43259.2

29563.4

22519.5

17939.7

130594.

125173.

112326.

95877.7

80081.8

69082.1

55058.5

44343.6

30935.1

22330.5

16100.9

12863.3

11239.5

8115.09

7655.67

5279.21

140951.

131010 .

117797.

99332.9

86937.5

73504.7

60172.0

50326.4

38511.4

32697.5

26028.4

22761.4

18840.1

17313.1

15429.6

14890.3

14960.4

12376.5

11871.5

10784.3

12045.9

12215.9

13470.8

143865.

138675 .

126724 .

109271.

93546.5

79672.0

64082.9

53564.0

35435.0

28402.1

21968.4

18755.6

16524.8

14456.3

12996.9

13603.9

13595.8

12441.4

12256.5

11574.5

11445.6

12434.7 
Table 10 GEWA-KTM fluid descending heating
$\Delta T$
$q^{\prime \prime}$
$\Delta \mathrm{T}_{\mathbf{s}}$
$q^{\prime \prime}$

9.76880
9.62399

107272.

8.44568

63701.4

9.13107

103124.

88867.7

8.25146

49899.0

8.92618

84683.7

8.96063

85637.0

8.89975

84026.2

8.56689

72253.0

8.28806

58887.1

8.20654

43067.4

8.02429

33381.3

$7.76196 \quad 22276.3$

$9.70151 \quad 102497$.

$9.53790 \quad 98533.9$

$9.51041 \quad 99006.6$

$9.15222 \quad 89201.0$

$9.22272 \quad 90686.2$

$9.05338 \quad 86110.6$

$9.05728 \quad 86281.0$

$8.96835 \quad 84461.5$

$9.00443 \quad 84796.5$

$8.93295 \quad 83134.5$

$8.92883 \quad 83728.2$

$8.78125 \quad 78826.8$

$8.82037 \quad 79560.4$

$8.55704 \quad 70699.2$

$8.57571 \quad 70185.8$

$8.27316 \quad 56841.9$

$8.11557 \quad 42396.2$

$7.91672 \quad 33099.1$

$7.64941 \quad 23481.8$

$9.79239 \quad 102106$.

$9.47992 \quad 95382.1$

$9.19006 \quad 88409.0$

$9.01160 \quad 82926.6$

$8.93066 \quad 80966.0$

$8.78601 \quad 76443.8$

8.49545

65803.4

$8.50546 \quad 65888.5$

$8.23941 \quad 52775.1$

$8.10840 \quad 41721.2$

$7.79150 \quad 28251.6$

$7.77292 \quad 28569.2$

$7.45752 \quad 19405.6$

$6.15616 \quad 13876.4$

$4.72024 \quad 9763.38$

$4.01511 \quad 7792.51$

$3.34064 \quad 5448.35$

$8.51917 \quad 64087.7$

$9.80469 \quad 104624$.

$9.78958 \quad 104433$.

$9.58813 \quad 100208$.

$9.25266 \quad 92499.8$

$9.05847 \quad 87649.1$

$8.99826 \quad 86663.7$

$8.89401 \quad 82413.3$

$8.56067 \quad 71762.5$

$8.23630 \quad 56523.6$

$8.12555 \quad 43775.2$

$7.94443 \quad 33411.1$

$7.64688 \quad 22291.2$

$6.33481 \quad 14855.1$

$5.11163 \quad 10014.4$

$4.32736 \quad 8924.48$

$3.56375 \quad 6439.85$

$3.22455-5429.35$

$9.62927 \quad 95133.6$

$9.57651 \quad 94701.5$

$9.28903 \quad 88856.5$

$9.04645 \quad 81052.2$

$8.87479 \quad 77146.6$

$8.80695 \quad 74846.4$

$8.80942 \quad 74957.0$

$8.65872 \quad 71780.8$ 
Table 11 Turbo-BII ${ }^{\mathrm{TM}}$-LP fluid descending heat ing

$\Delta \mathrm{T}_{\mathrm{s}} \quad \mathrm{q}^{\prime \prime}$

10.2746

10.0995

9.26923

8.66162

8.42810

7.89710

6.24231

4.55344

4.59604

3.49493

2.75299

2.75299

9.92673

9.68677

9.36884

8.90378

9.13736

8.69861

7.72803

7.91574

6.29614

4.96716

4.95596

4.01852

4.00046

2.99017

2.87561

2.80658

2.26746

2.21594

1.63086

1.61780

1.26050

1.21344

1.22492

3.38504

3.57449

3.04593

3.05743

2.73630

2.68631

2.34445

2.41556

2.09537

2.12790

1.78796

1.74356

1.55563

1.59759

1.41489

1.45975

1.28177

1.31564

1.12863

1.12863

1.11816

10.5053

10.4612

10.5548

9.98398

9.48340

9.30984

9.12103

8.11252

6.58481

5.55810

4.40448

3.25366

2.59363

2.03662

1.65863

8.95450

8.75412

9.01407
158366.

157814.

146795.

138406.

134002.

126918.

103866.

79384.0

79677.8

62471.9

49427.7

49427.7

158684.

156063.

149725.

143614.

145939.

140015.

128213.

129840.

109087.

89264.1

89514.8

74038.5

73738.0

53642.4

52144.0

50411.7

37689.8

36776.5

22048.6

22273.9

13195.7

12731.1

13013.7

60260.4

63568.8

53774.3

54050.1

47885.6

47120.2

40218.3

41233.8

35353.2

35286.7

27415.9

27288.3

21977.4

22720.3

17595.4

17778.1

14393.1

14576.0

11292.6

11292.6

9227.81

161308.

160880.

161665.

150440.

147211.

145355.

142826.

129199.

108310.

94998.8

77430.6

55433.8

43895.2

28933.8

20089.9

144208.

142107.

144686.
$\Delta \mathrm{T}_{\mathrm{s}}$

$q^{\prime \prime}$

$\begin{array}{ll}8.91528 & 143738 . \\ 8.96359 & 141354 . \\ 7.93472 & 128049 . \\ 7.23712 & 117537 . \\ 6.67773 & 109543 . \\ 6.06094 & 101191 . \\ 5.52020 & 94139.6 \\ 4.87750 & 83610.7 \\ 4.41898 & 76356.7 \\ 3.86267 & 68181.3 \\ 3.23697 & 56428.1 \\ 2.46002 & 41634.8 \\ 3.85587 & 67871.5 \\ 3.90930 & 69398.4 \\ 3.98682 & 71266.6 \\ 3.90997 & 71243.7 \\ 3.29465 & 59163.9 \\ 2.78107 & 49387.3 \\ 2.44275 & 42441.9 \\ 2.15344 & 36741.3 \\ 1.90283 & 31256.0 \\ 1.47934 & 21508.8 \\ 1.35925 & 18978.5 \\ 1.19986 & 14733.4 \\ 1.05542 & 11263.7 \\ 0.974884 & 9522.98 \\ 0.962799 & 8622.63 \\ 0.906830 & 7760.74 \\ 0.906189 & 7485.84 \\ 0.882538 & 7271.23 \\ 0.879639 & 6856.52 \\ 0.825012 & 6568.47 \\ 0.837677 & 6472.51\end{array}$

43738.

128049.

109543.

83610.7

76356.7

41634.8

67871.5

9387.3

978.5

760.74

85.84

6472.51 
Table 12 High-Flux ${ }^{T M}$ electric resistance descending heating

$\begin{array}{cc}\Delta T_{s} & \text { q" } \\ 2.83548 & 90764.7 \\ 2.73718 & 80612.7 \\ 2.61566 & 74199.0 \\ 2.46991 & 66543.5 \\ 2.38260 & 59612.2 \\ 2.28809 & 53973.9 \\ 2.23810 & 48276.6 \\ 2.10300 & 41352.8 \\ 2.06183 & 36325.0 \\ 1.94104 & 32368.0 \\ 1.94476 & 28509.2 \\ 1.83984 & 24587.0 \\ 1.78839 & 21354.7 \\ 1.71948 & 18265.2 \\ 1.68366 & 15670.6 \\ 1.62787 & 13446.0 \\ 1.56479 & 11198.0 \\ 3.01175 & 90842.7 \\ 2.85446 & 81068.8 \\ 2.74246 & 74904.5 \\ 2.59363 & 66730.4 \\ 2.51019 & 60219.1 \\ 2.41022 & 54128.3 \\ 2.34106 & 48362.0 \\ 2.25455 & 43011.3 \\ 2.18839 & 37509.7 \\ 2.05661 & 31939.6 \\ 2.02295 & 28221.8 \\ 1.94339 & 24908.7 \\ 1.89011 & 21241.2 \\ 1.84259 & 18562.6 \\ 1.76251 & 15920.4 \\ 1.70267 & 13468.8 \\ 2.94098 & 88426.3 \\ 2.81595 & 80893.6 \\ 2.66659 & 73272.5 \\ 2.61206 & 66741.7 \\ 2.45868 & 61261.6 \\ 2.36612 & 53884.6 \\ 2.27811 & 49285.0 \\ 2.18552 & 42181.1 \\ 2.14407 & 37774.1\end{array}$


Table 13 GEWA-KTM electric resistance descending heating

$\Delta \mathrm{T}$,

8.90222

8.70941

8.55338

8.51205

8.33438

8.23682

8.08530

7.95740

7.50668

6.83713

6.12411

5.54211

4.99805

4.53427

4.03299

3.68332

3.22726

3.09222

2.61899

2.41214

2.11456

1.88455

1.65659

1.65659

8.88931

8.69327

8.54248

8.38168

8.31024

8.14807

7.95795

7.81281

7.58850

7.09338

6.19232

5.47000

5.06006

4.46939

5.31455

6.67029

7.81677

7.81677

9.13443

9.04575

9.04355

8.82764

8.63184

8.54166

8.38623

8.23428

8.07361

7.90533

7.65375

7.00140

7.75635

8.84378

8.66272

8.54706

8.35342

8.29065

8.18356

7.94589

7.79358

7.60644

6.85281

7.55630

7.82480

7.92157

7.96585

8.91290

8.53931

8.50412

8.23734

8.31348 q"

68874.5

62685.3

56355.3

47831.6

41101.4

34978.4

30286.4

25265.9

20482.3

17472.2

14656.6

12271.9

10033.6

8448.09

7145.83

5986.02

4608.04

4550.50

3741.17

3133.03

2402.32

1858.41

1449.75

1449.75

69056.5

62365.2

57222.9

49637.0

42781.9

36129.2

31401.1

24456.6

20886.0

18687.8

14983.4

12282.8

10579.8

8437.88

11650.6

16655.9

21937.5

21937.5

68289.5

68617.5

68644.2

61146.7

55769.1

49505.6

42266.7

35937.4

29993.5

24808.5

19951.2

16936.9

20580.1

64822.2

60816.2

54670.4

47786.3

42153.8

35770.2

29664.8

22856.0

19568.6

16723.4

19818.8

24887.7

29781.7

31086.2

69670.3

61529.0

55123.8

48520.1

42090.2
$\Delta T_{s}$

q"

8.11768

8.01715

7.84534

7.67612

7.02972

7.71448

7.81366

8.02298
36752.7

30254.2

25432.3

21051.2

17198.3

20304.9

25652.7

31149.1 
Table 14 Turbo-BIITM-LP electric resistance descending heating

$\begin{array}{cc}\Delta \mathrm{T}_{3} & q 1 \\ 4.05191 & 63468.2 \\ 3.70630 & 58285.0 \\ 3.35028 & 53145.1 \\ 2.99493 & 47096.5 \\ 2.55304 & 39593.6 \\ 2.39191 & 34524.8 \\ 2.11792 & 30946.8 \\ 2.10281 & 26674.3 \\ 2.10281 & 26674.3 \\ 4.39813 & 69911.5 \\ 4.68283 & 78248.2 \\ 4.66156 & 78295.6 \\ 3.93820 & 64680.3 \\ 3.56946 & 58648.7 \\ 3.28189 & 53218.4 \\ 3.25742 & 52775.1 \\ 2.89398 & 47244.3 \\ 2.73404 & 42476.8 \\ 2.50971 & 36238.1 \\ 3.43393 & 51932.0 \\ 4.08414 & 64280.8 \\ 4.61054 & 76968.6 \\ 4.28821 & 71554.3 \\ 3.85052 & 65038.6 \\ 3.46100 & 58691.0 \\ 3.15418 & 53055.9 \\ 2.84921 & 47706.4 \\ 2.69104 & 42804.8 \\ 2.38956 & 38640.4 \\ 2.23163 & 33633.2 \\ 2.02921 & 29481.2 \\ 1.88586 & 25579.9 \\ 1.65897 & 22122.5 \\ 1.48532 & 16260.4 \\ 1.28030 & 12138.8 \\ 1.16336 & 8553.83 \\ 0.980102 & 5840.80 \\ 0.766174 & 2404.99 \\ 4.19971 & 70619.0 \\ 4.47162 & 76466.2 \\ 3.80524 & 64835.3 \\ 3.48303 & 58600.0 \\ 3.23553 & 54031.3 \\ 3.02222 & 47965.3 \\ 2.69968 & 43146.0 \\ 2.42639 & 37386.9 \\ 2.18845 & 33082.4 \\ 1.99512 & 29352.3 \\ 1.80576 & 25057.7 \\ 1.66211 & 22093.6 \\ 1.57297 & 19572.9 \\ 1.49616 & 15653.0 \\ 1.35019 & 14034.8 \\ 1.25153 & 11827.6 \\ 1.17554 & 10180.1 \\ 1.09354 & 8737.31 \\ 1.91077 & 6912.69 \\ 0.862363110 & 5644.58 \\ & 4317.13\end{array}$


Table 15 Turbo-bll LP bubble activity summary

\begin{tabular}{|c|c|c|c|}
\hline $\begin{array}{c}q^{\prime \prime} \\
(\mathrm{kW} / \mathrm{m} 2)\end{array}$ & $\begin{array}{c}D_{b} \\
(m m)\end{array}$ & $\begin{array}{c}f_{b} \\
\text { (bub/s) }\end{array}$ & comments \\
\hline 1.2 & 2 & 50 & single, active site \\
\hline 9 & $0.6-0.8$ & $30-60$ & $\begin{array}{l}\text { entire channel simultaneously } \\
\text { active, channels spaced } 3 \mathrm{~mm} \text { apart } \\
\text { (no interaction) }\end{array}$ \\
\hline 12.8 & 0.9 & $30-135$ & $\begin{array}{c}\text { entire channel simultaneously } \\
\text { active, channels spaced } 1.4 \mathrm{~mm} \text { apart } \\
\text { and interacting }\end{array}$ \\
\hline 27 & $0.8-1.4$ & $15-200$ & $\begin{array}{l}\text { ten adjoining active channels then } \\
2-4 \text { inactive channels }\end{array}$ \\
\hline 36.5 & $0.8-1.6$ & $70-200$ & eight out of twelve channels active \\
\hline 77 & 0.6 & $\begin{array}{l}\text { nearly } \\
\text { continuously } \\
\text { active }\end{array}$ & $\begin{array}{l}\text { many adjoining channels } \\
\text { simultaneously active }\end{array}$ \\
\hline 160 & $0.7-2.3$ & $\begin{array}{l}\text { nearly } \\
\text { continuously } \\
\text { active }\end{array}$ & $\begin{array}{c}\text { nearly all channels producing } \\
\text { bubbles simultaneously and } \\
\text { cont inuously }\end{array}$ \\
\hline
\end{tabular}



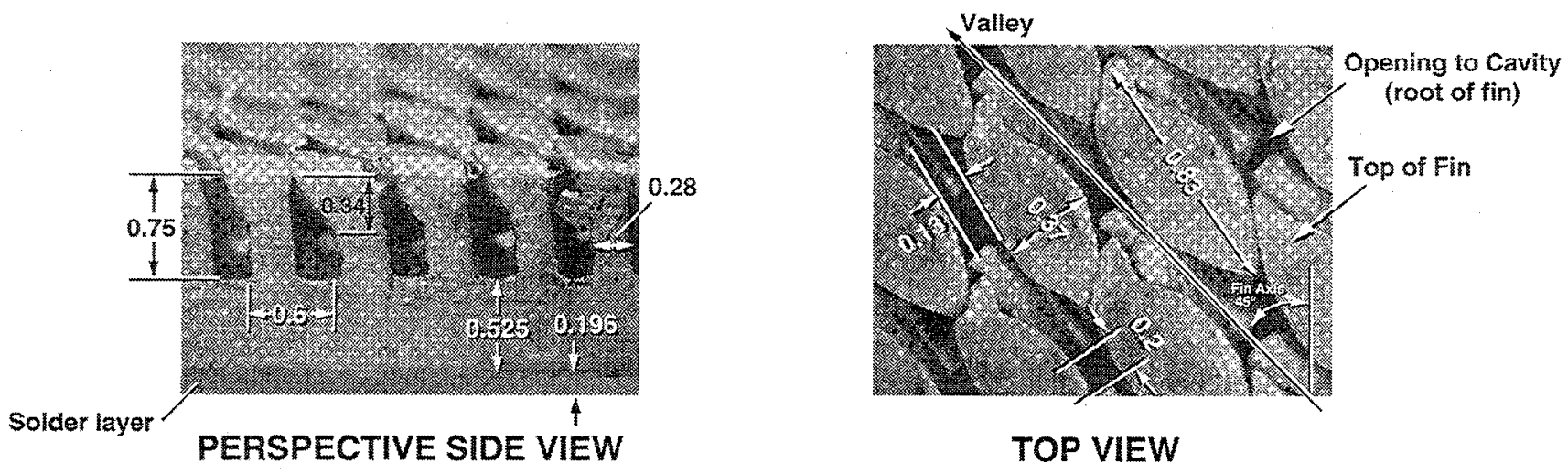

\section{TURBO-BII LP}

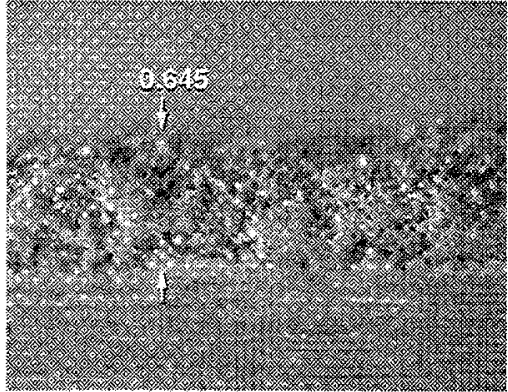

SIDE VIEW

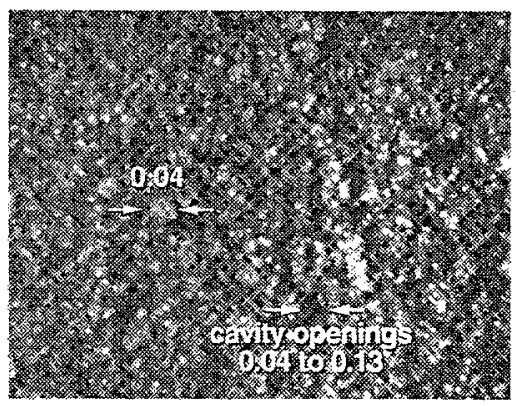

TOP VIEW

\section{HIGH-FLUX}

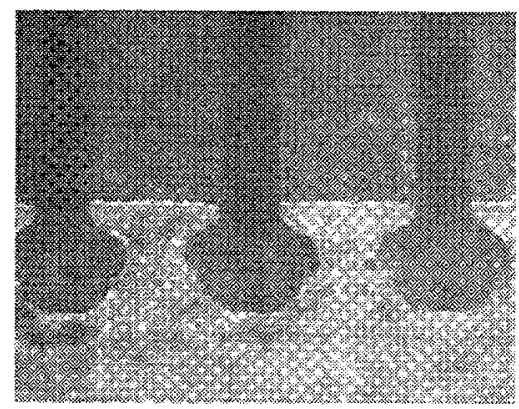

PERSPECTIVE SIDE VIEW

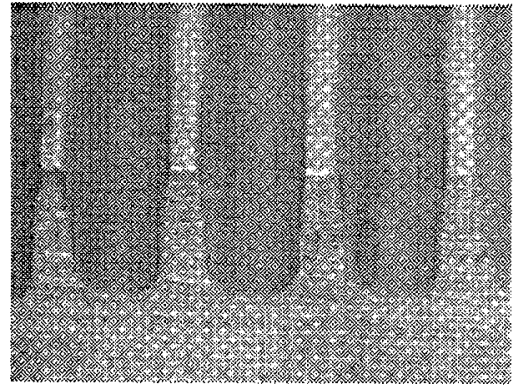

PERSPECTIVE SIDE VIEW

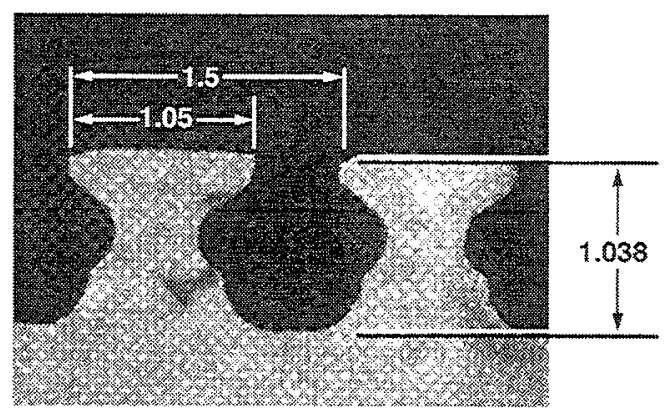

SIDE VIEW

\section{GEWA-T}

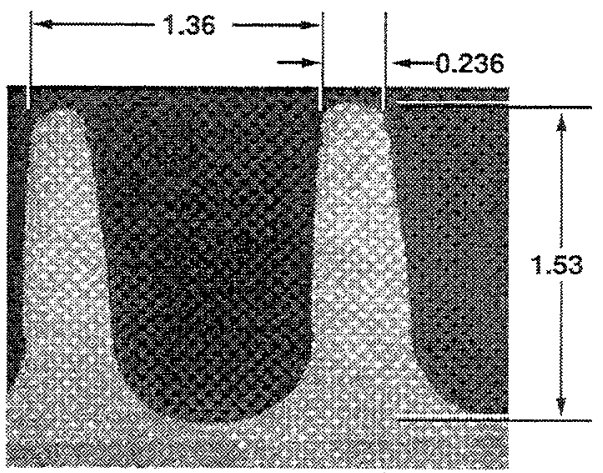

SIDE VIEW
Fig. 1 Enhanced surfaces of study

(all dimensions in mill imeters)
GEWA-K 


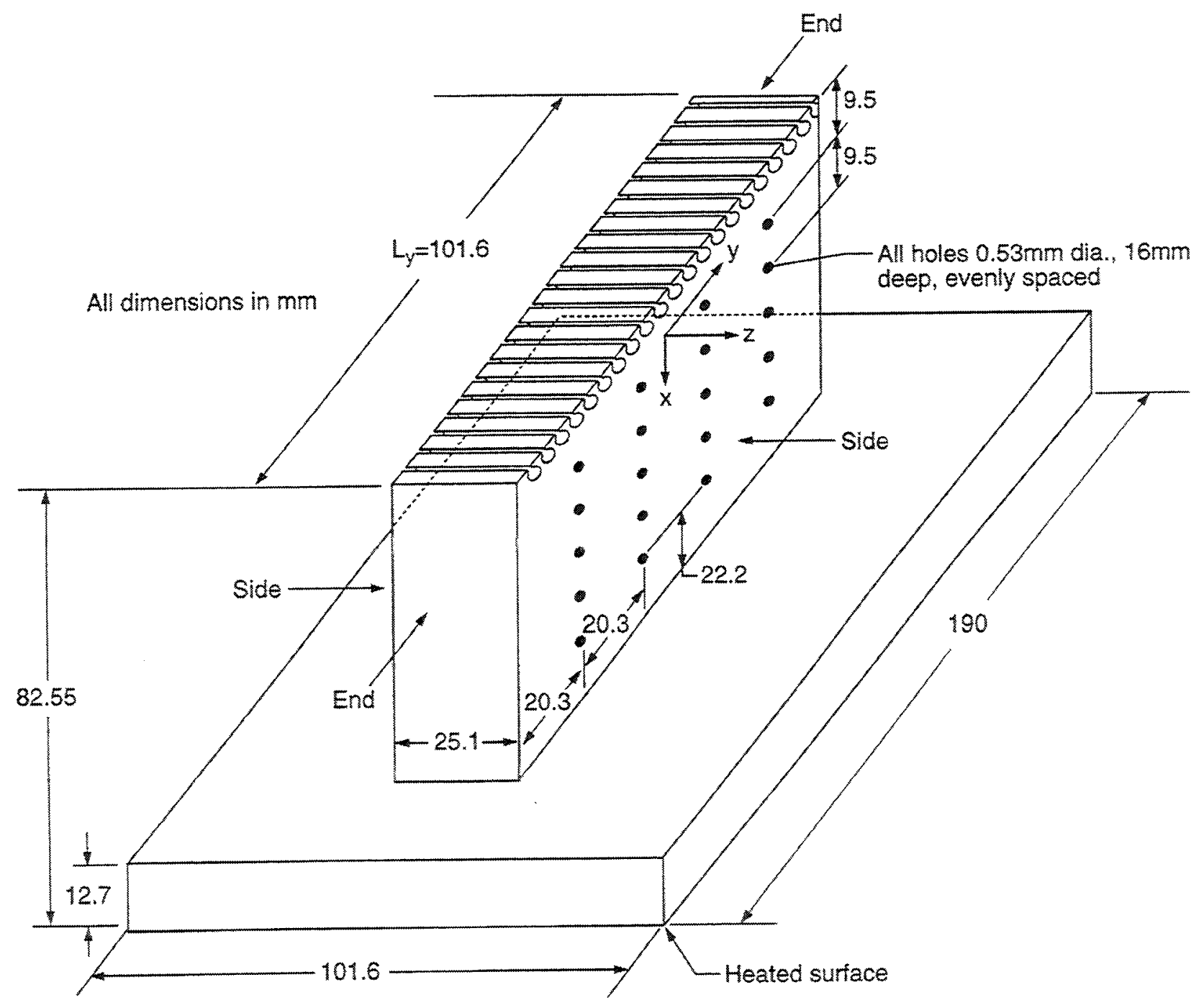

Fig. 2 GEWh-TM test plate and thermocouple coordinate system 


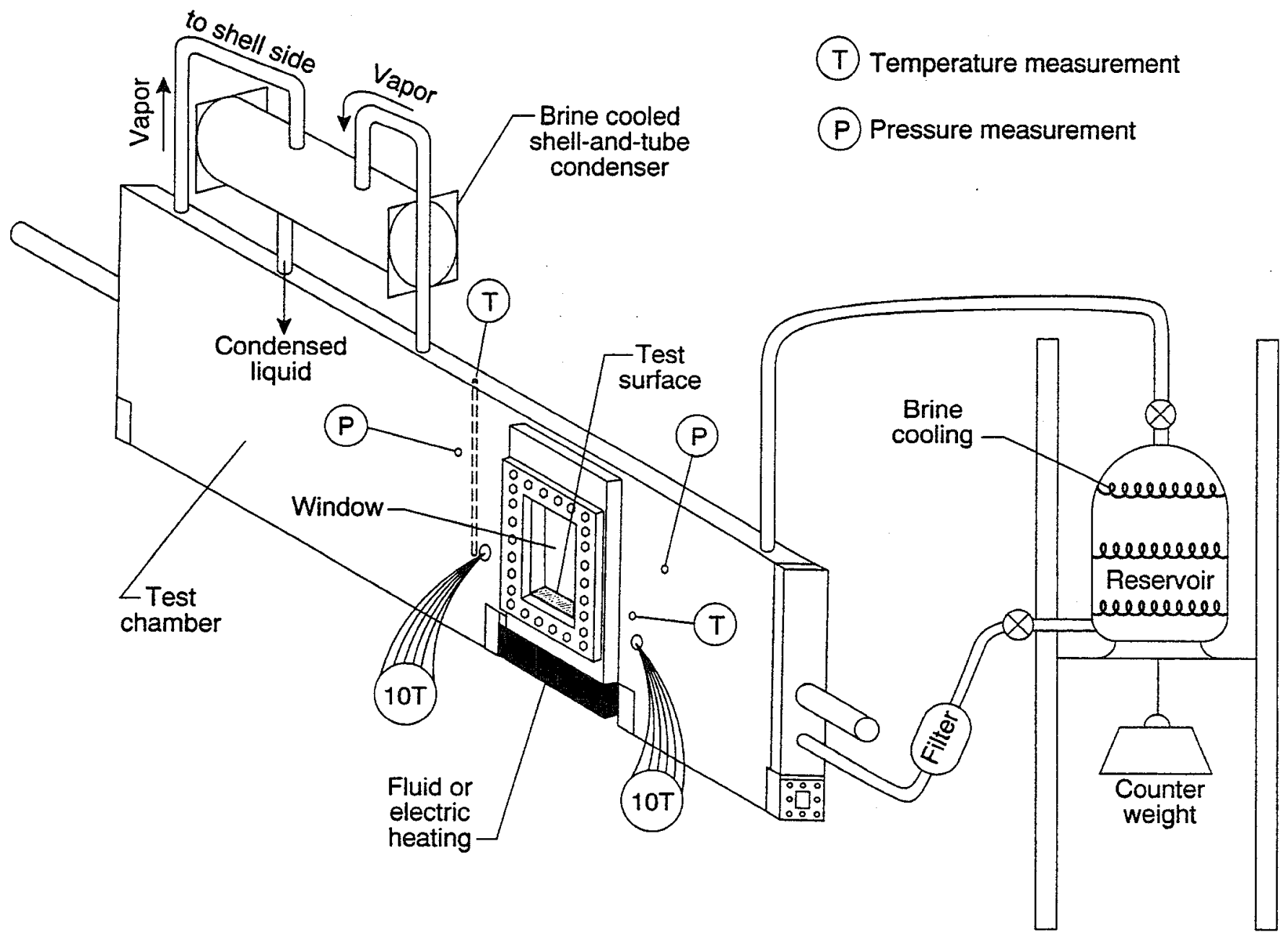

Fig. 3 Schematic of test rig 


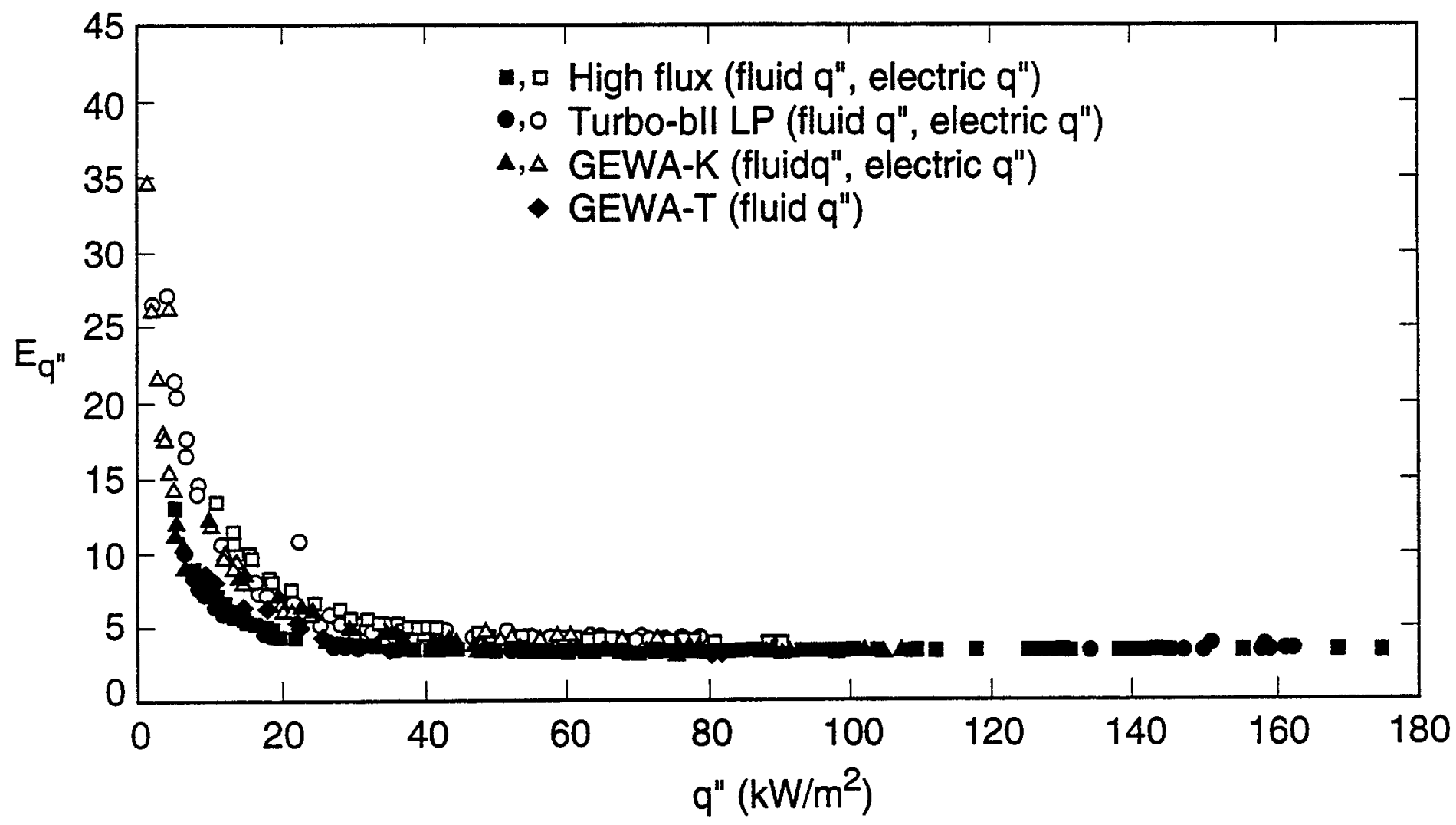

Fig. 4 Within-run heat flux measurement $u_{c}$ 


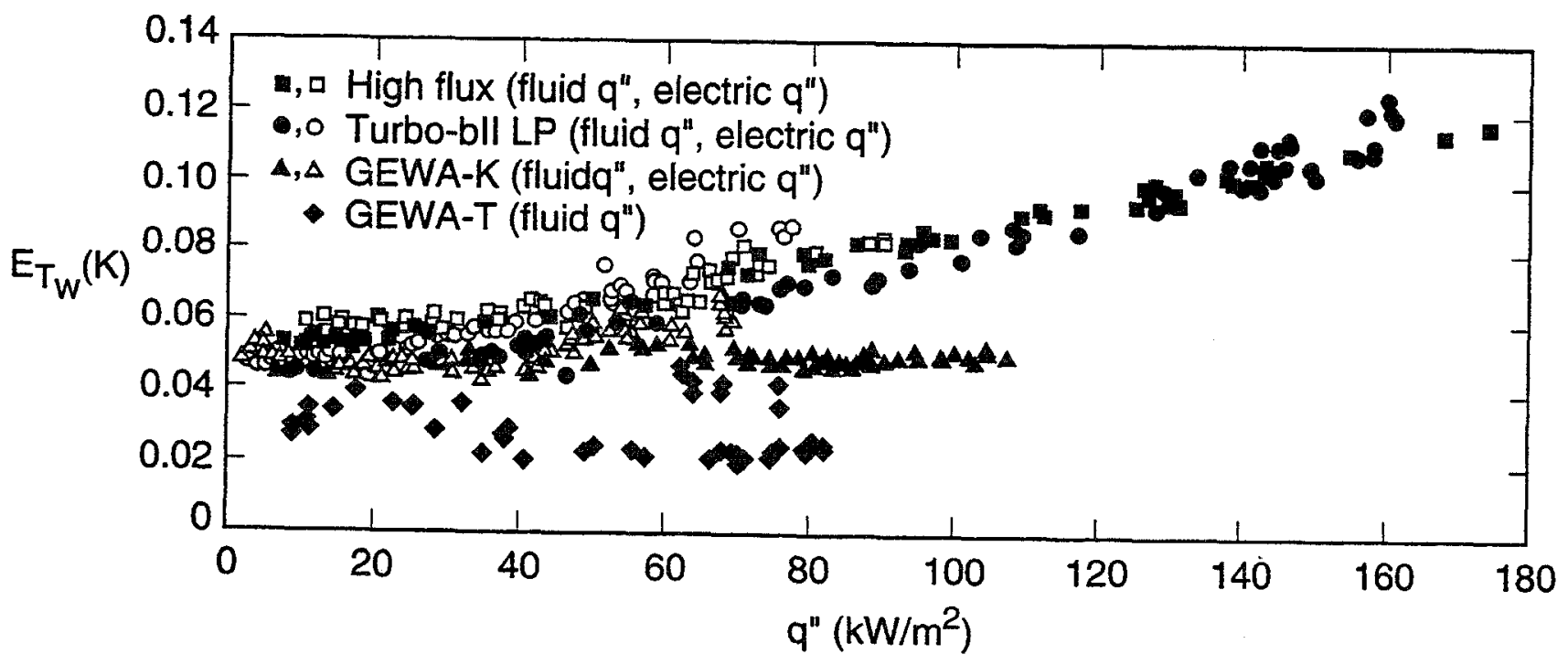

Fig. 5 Within-run wall temperature measurement $u_{c}$ 


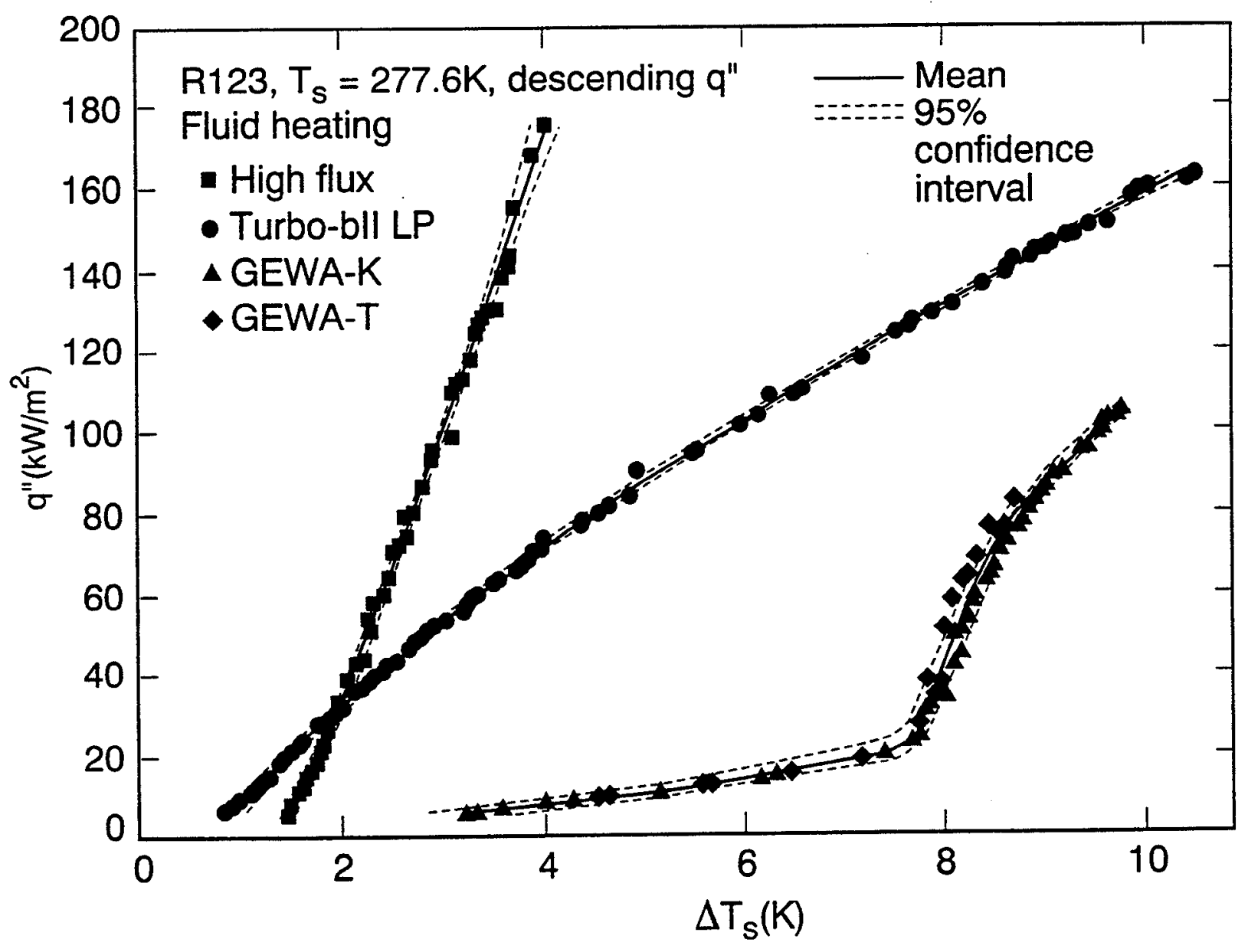

Fig. 6 Fluid heating descending q" pool boiling curves 


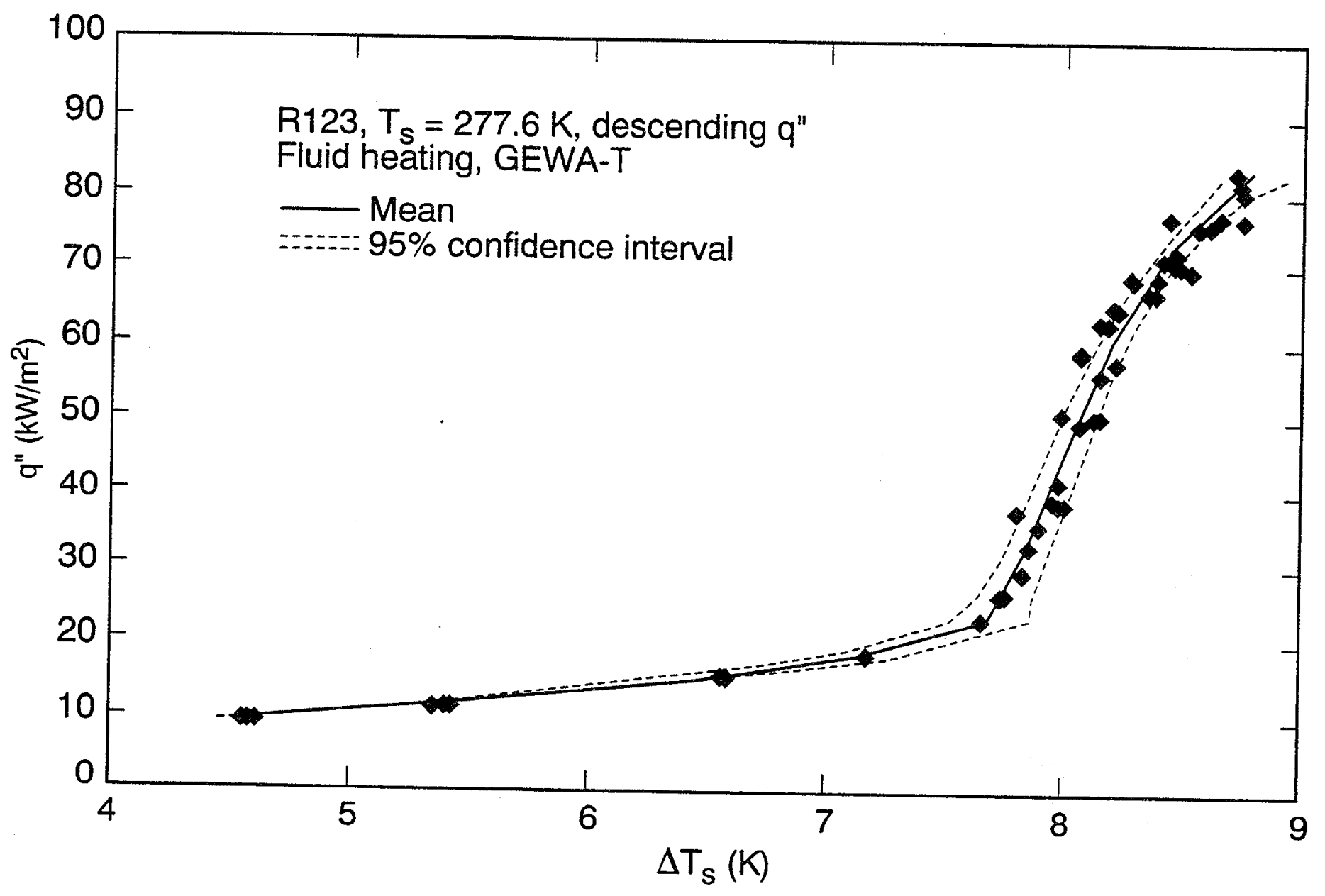

Fig. 7 GEWA-T TM pool boiling curve 


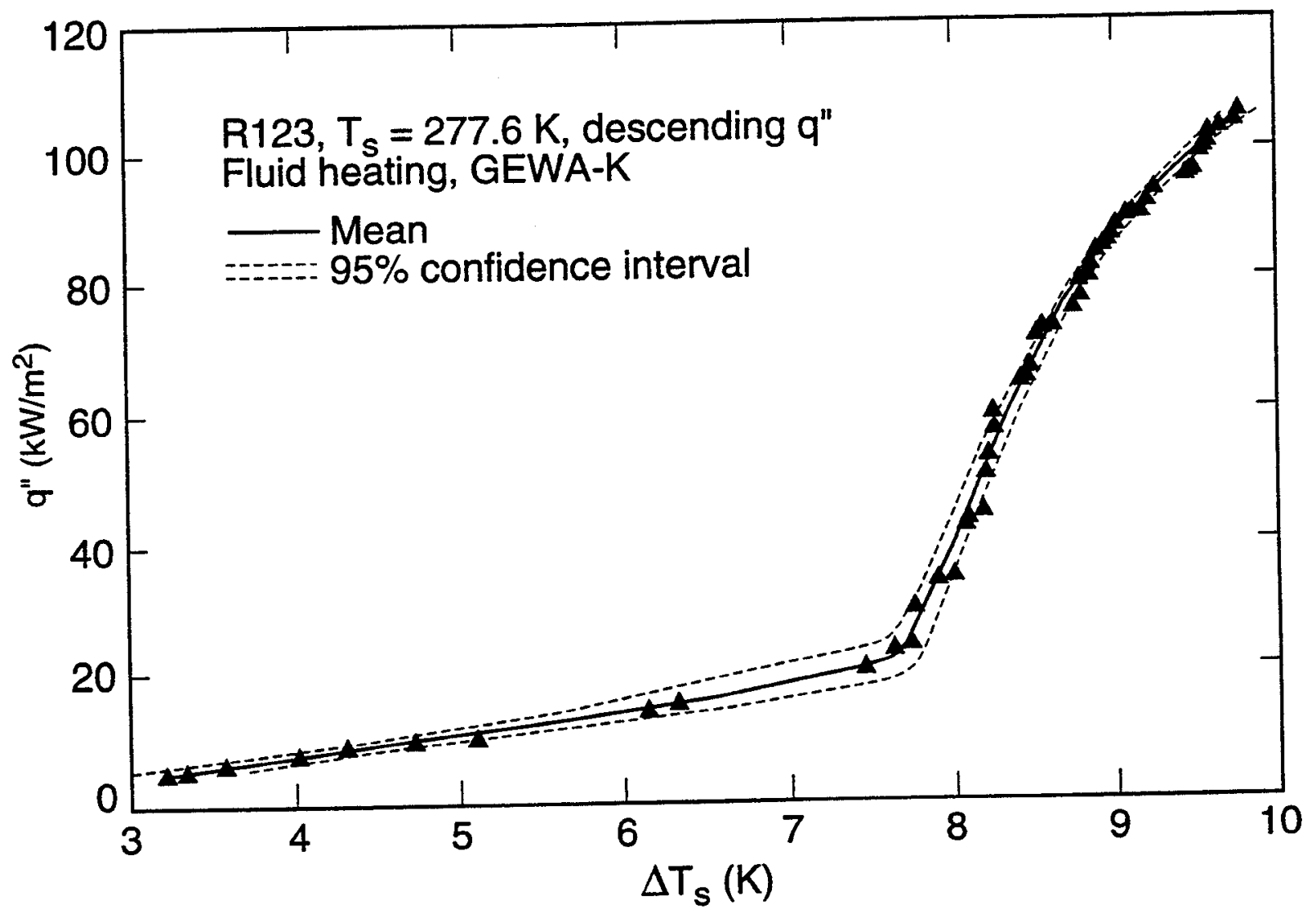

Fig. 8 GEWA-KTM pool boiling curve 


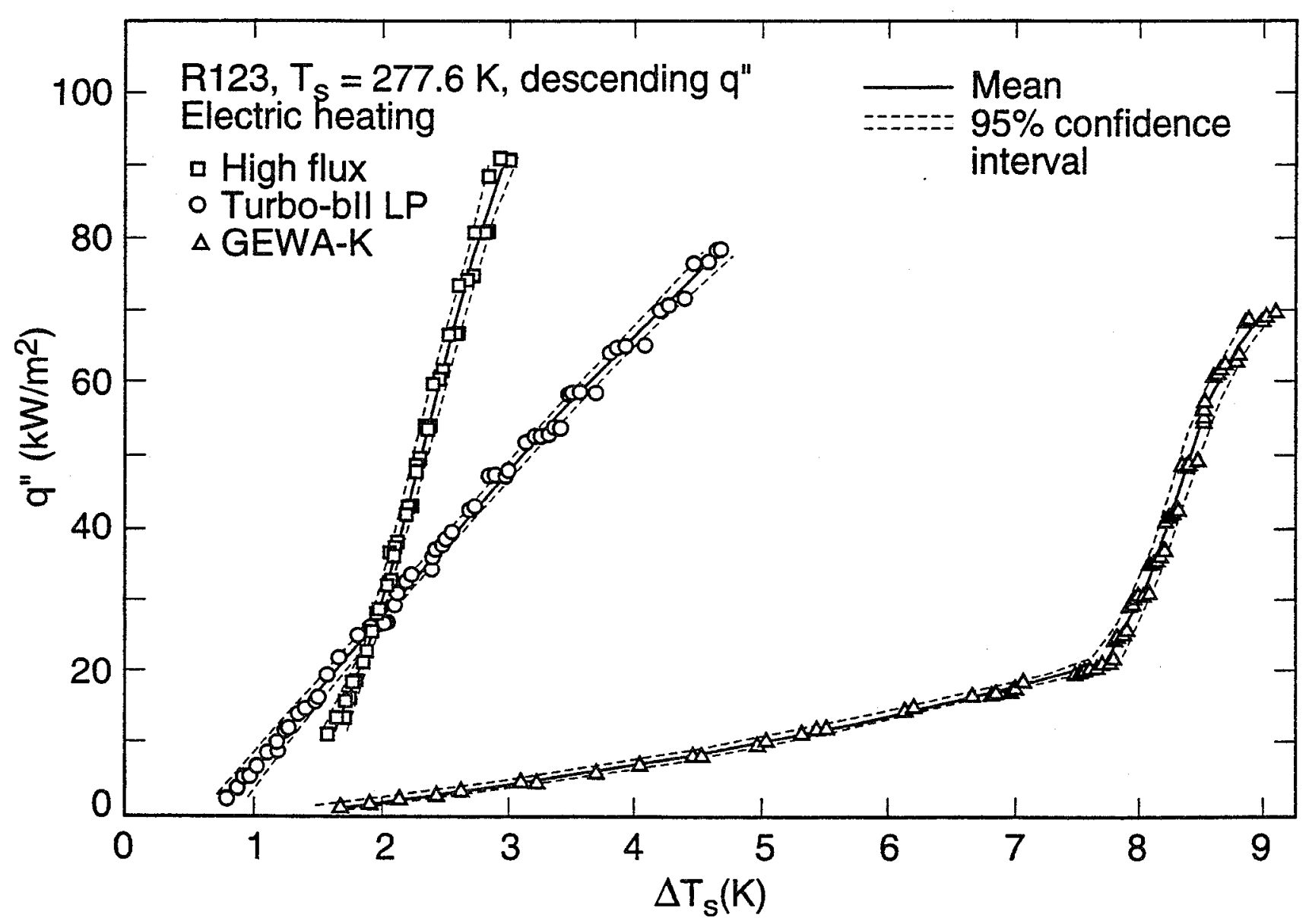

Fig. 9 Electric resistance heating descending $q^{n}$ pool boiling curves 


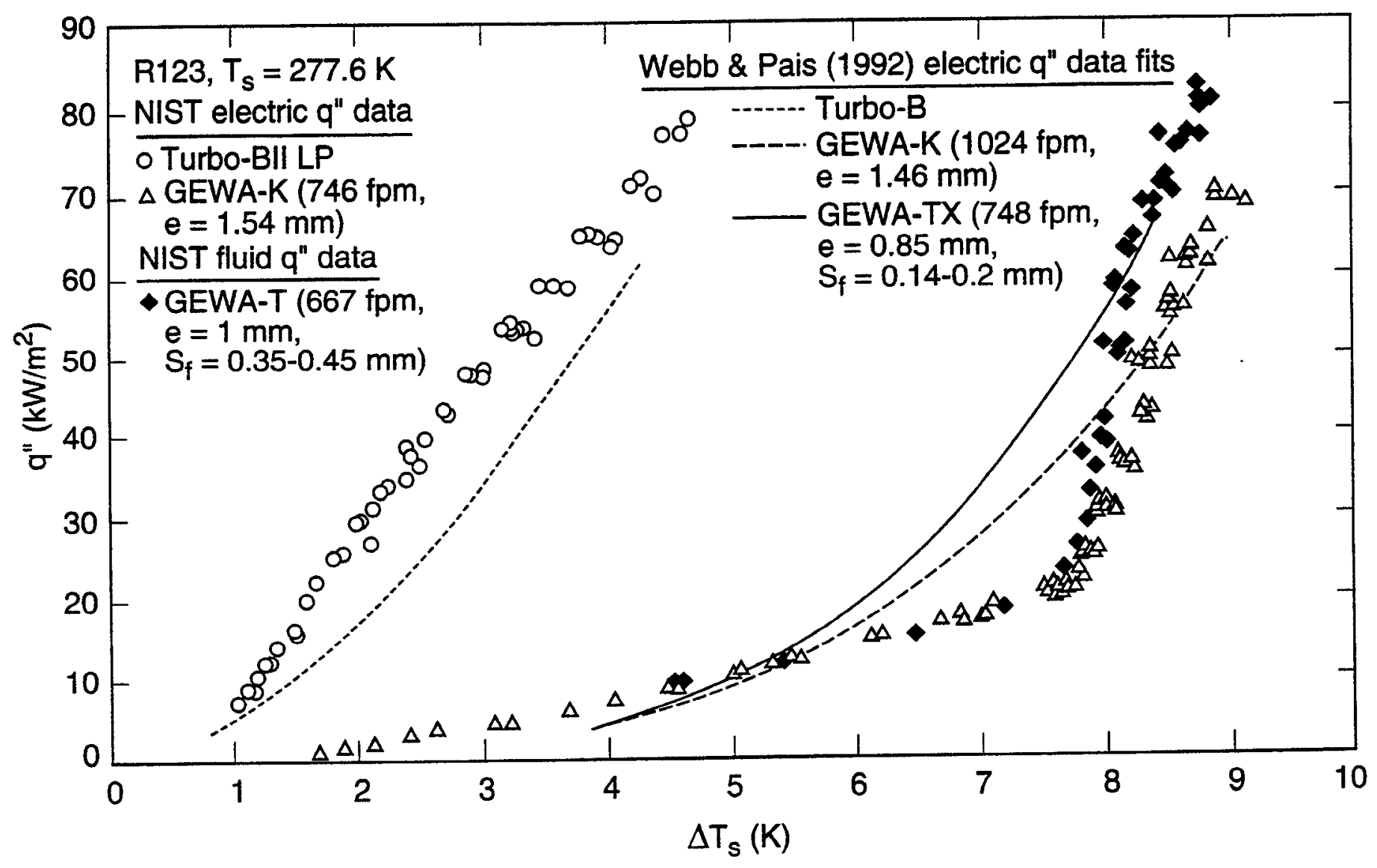

Fig. 10 Comparison of NIST data to Webb and Pais (1992) electric q" data fits 


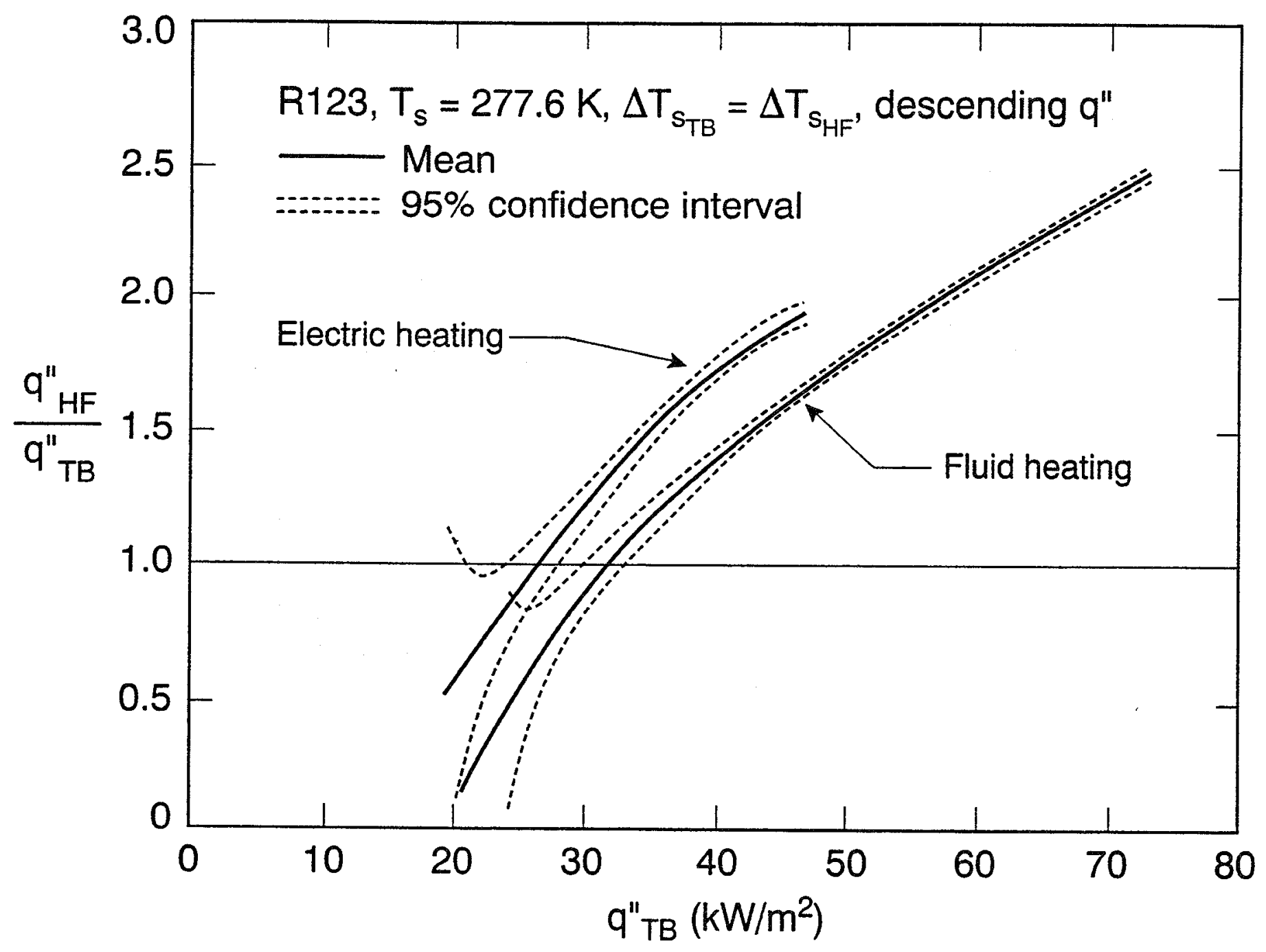

Fig. 11 Ratio of High-FluxTM to Turbo-BII TM-LP heat flux for electric and fluid heating 


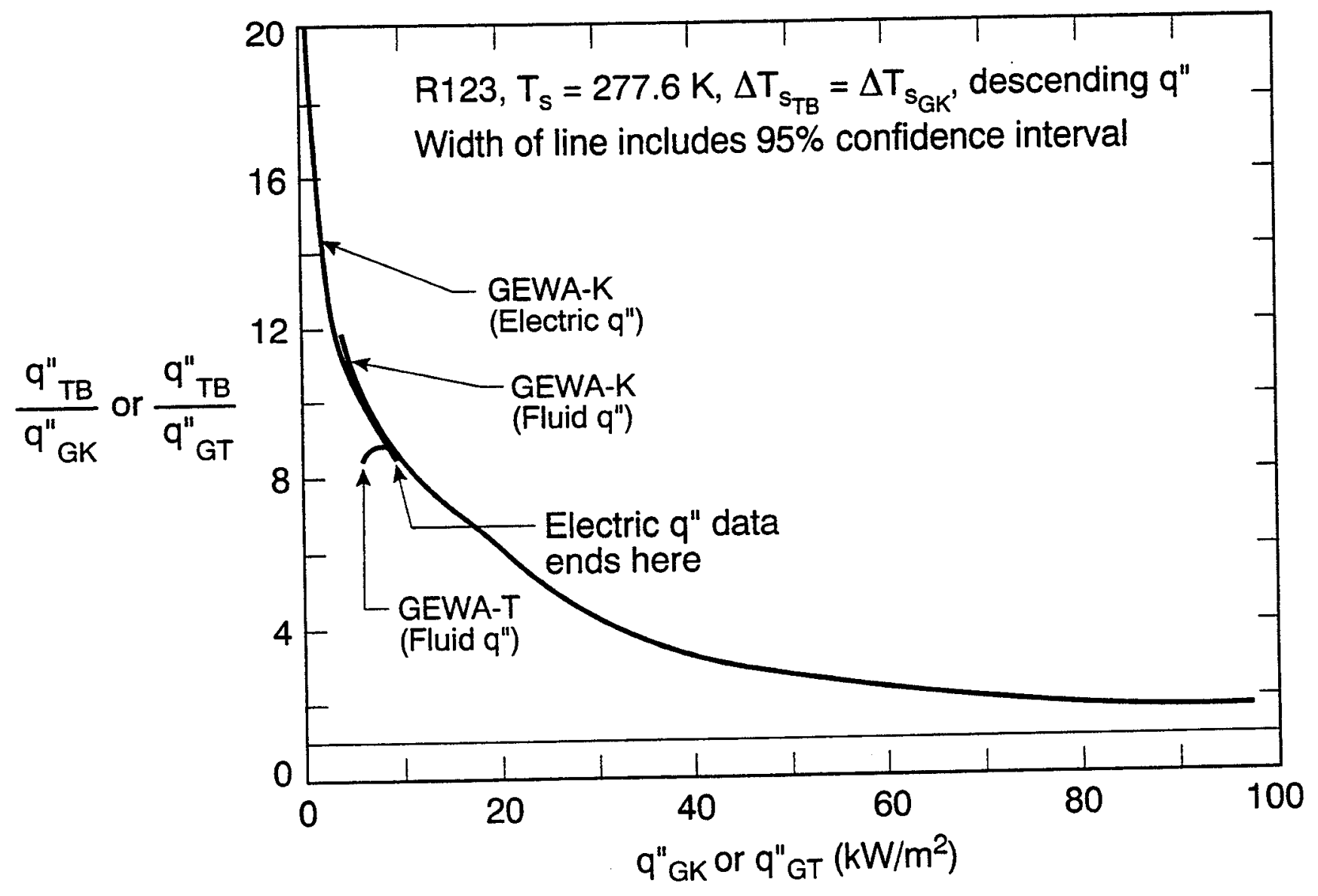

Fig. 12 Ratio of Turbo-BII TM-LP to GEWA-KTM and GEWA-T TM heat fluxes for electric and fluid heating 


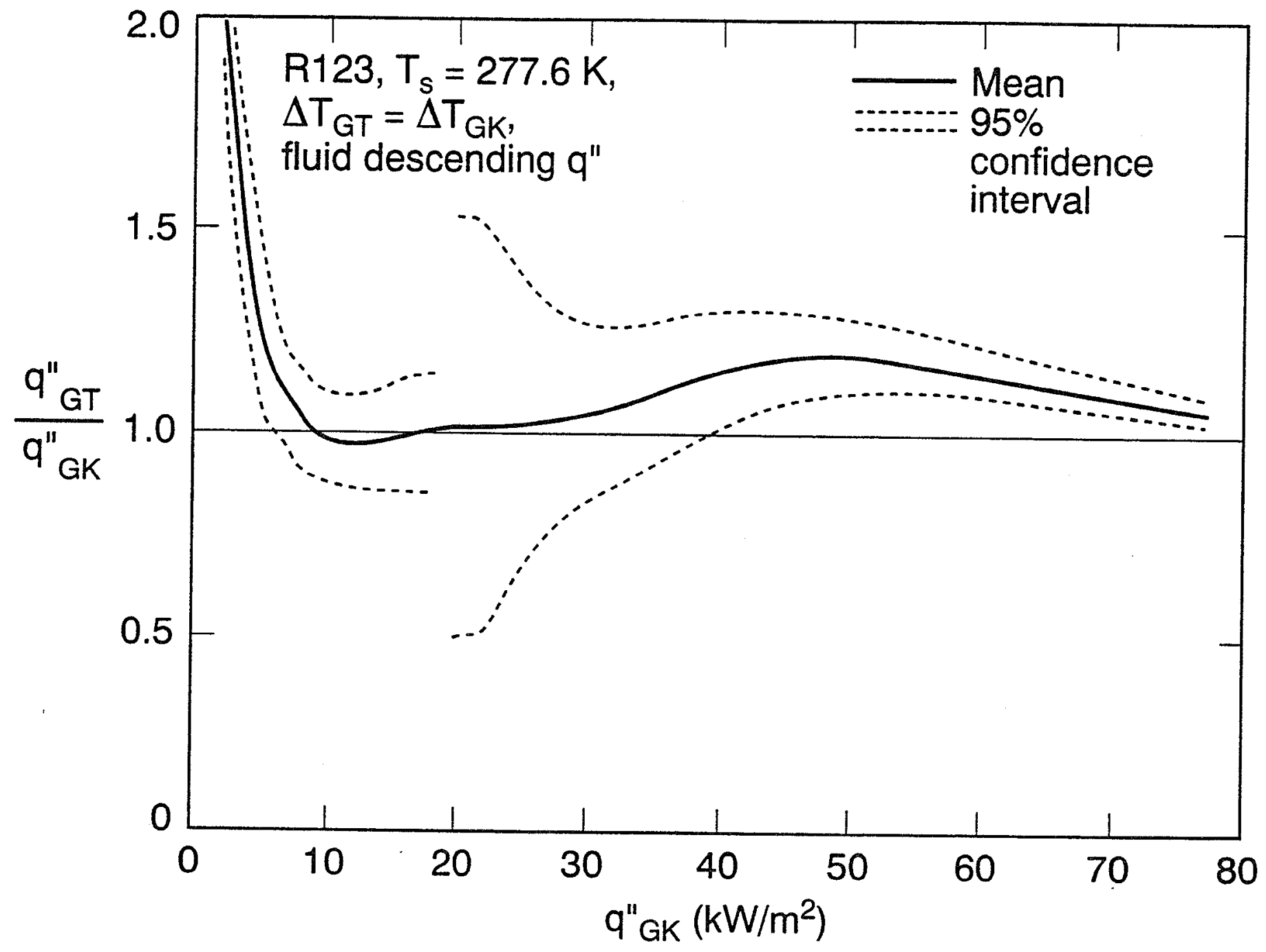

Fig. 13 Ratio of GEWA-TTM to GEWA-KTM heat flux for fluid heating 


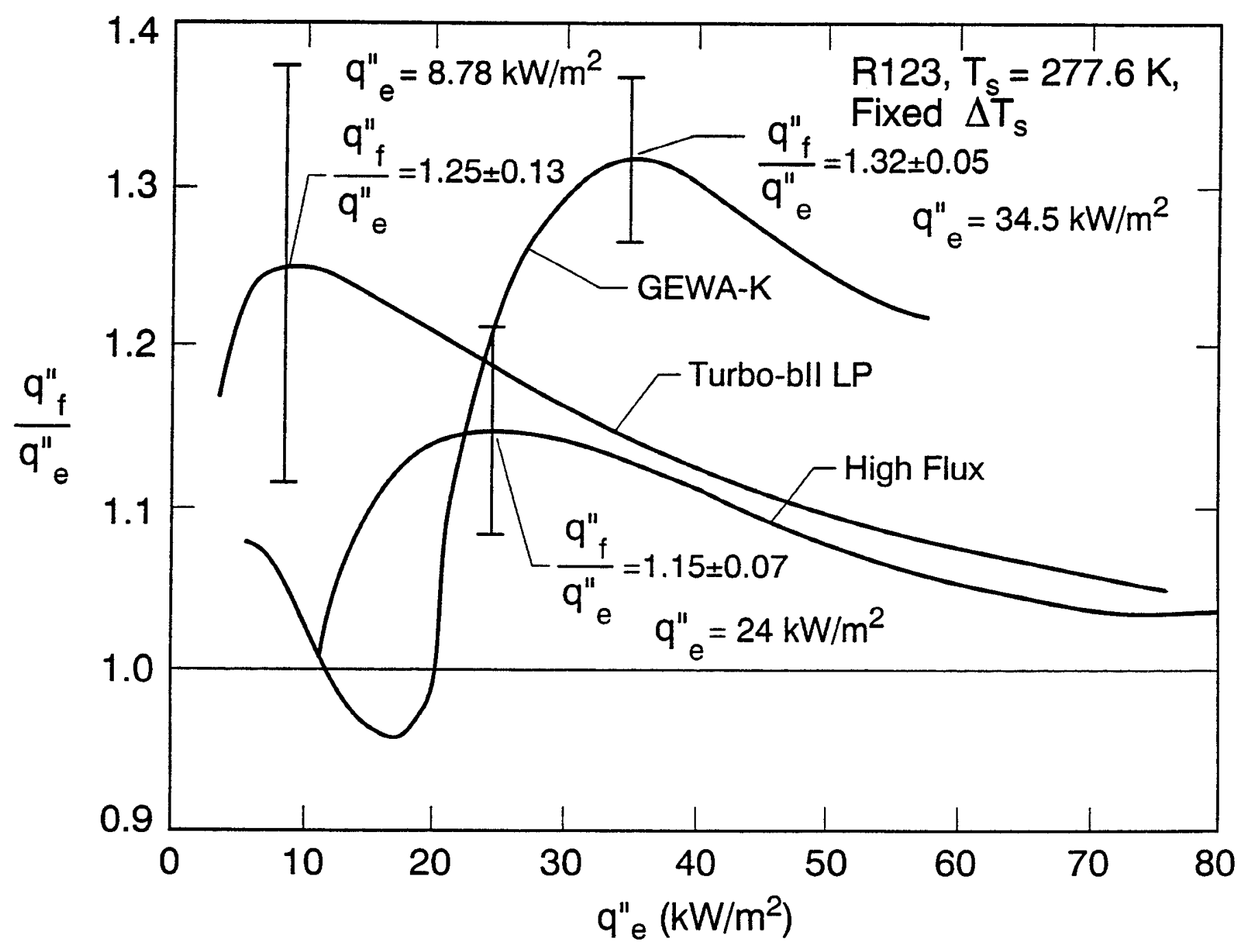

Fig. 14 Comparison of fluid to electric heating for the Turbo-BIITM-LP, High-FluxTM, and GEWA-KTM SUrfaces 


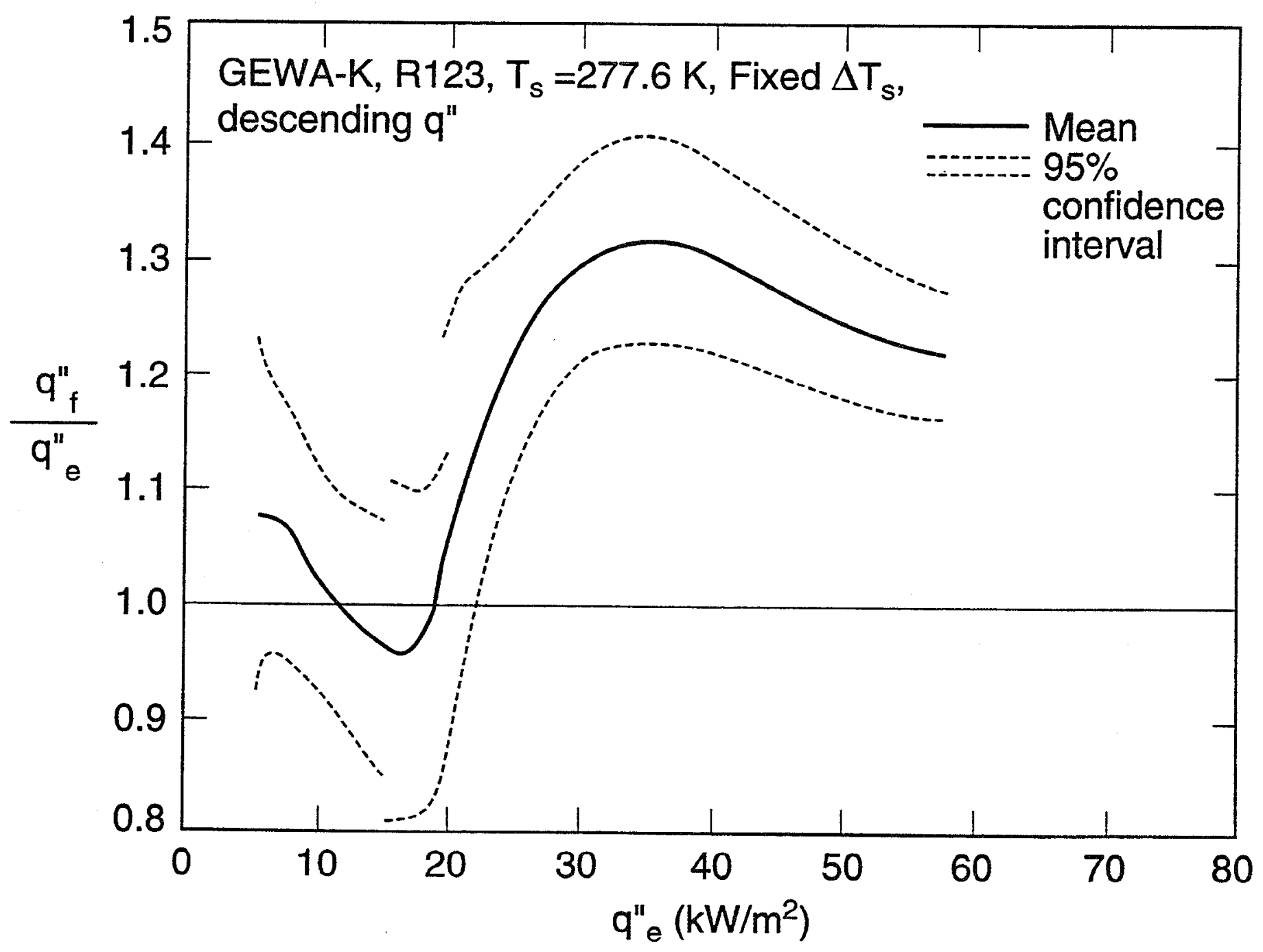

Fig. 15 Statistical verification of GEWA-KTM fluid and electric heating relationship 


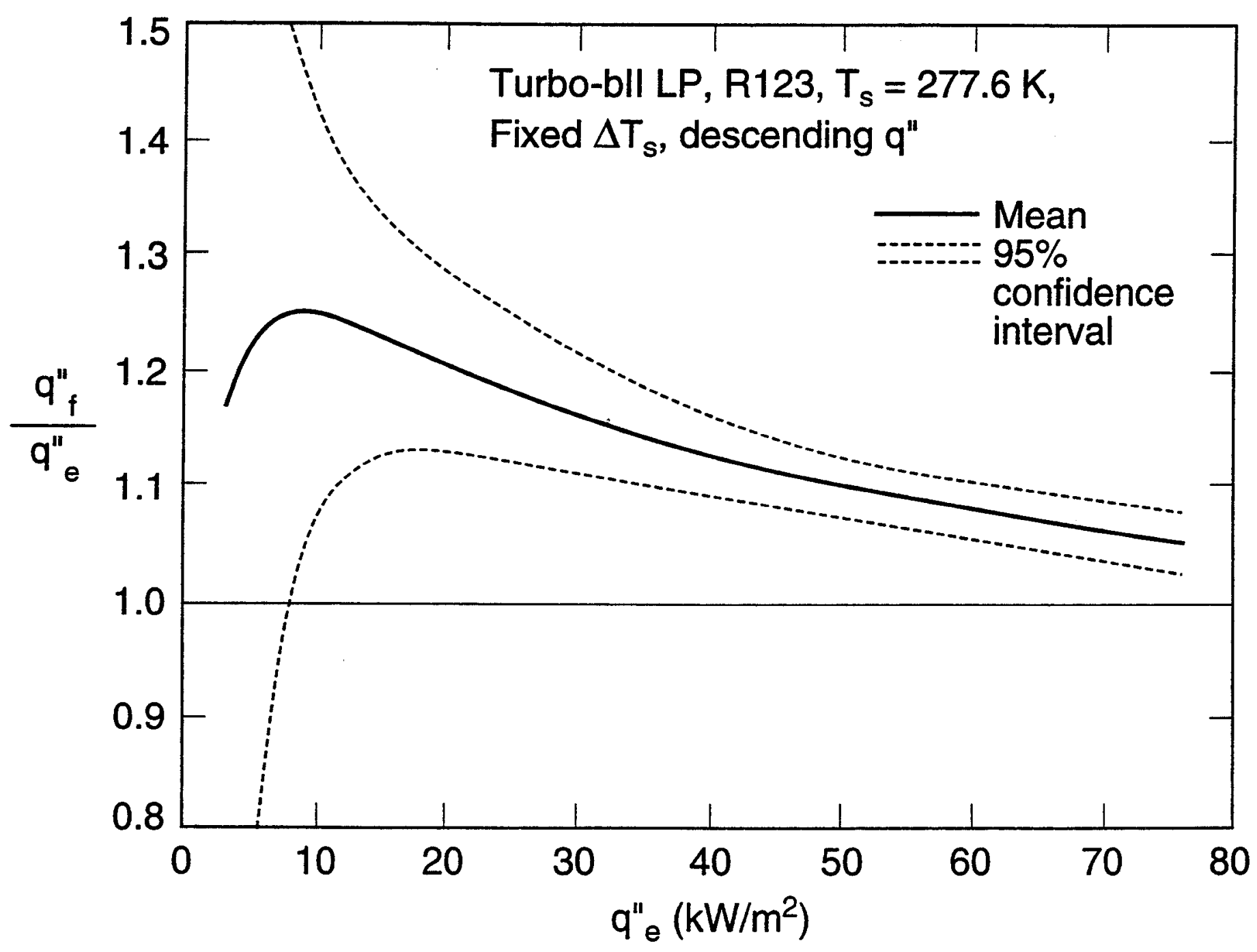

Fig. 16 statistical verification of Turbo-BII TM-LP fluid and electric heating relationship 


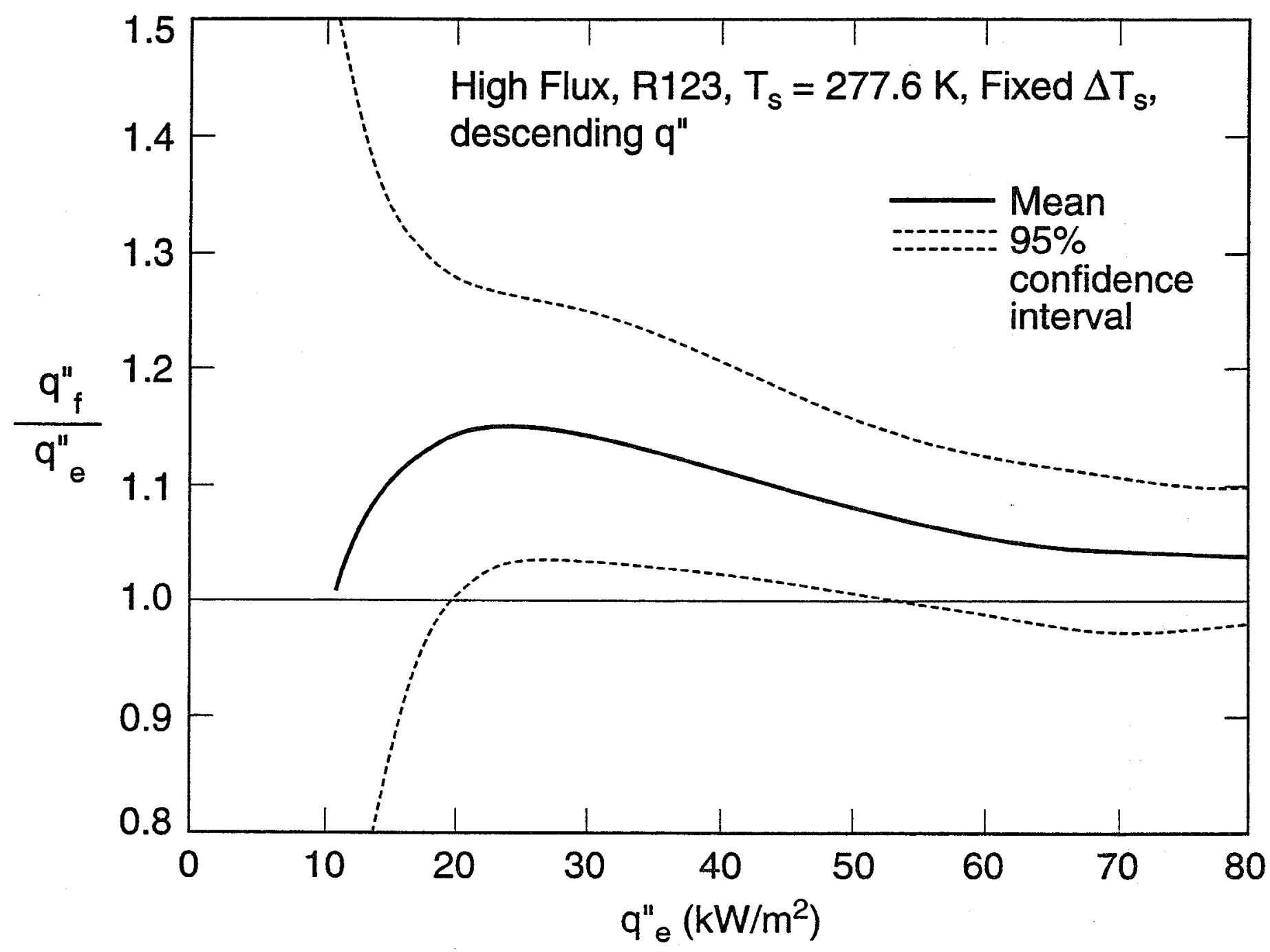

fig. 17 Statistical verification of High-FluxTM fluid and electric heating relationship 

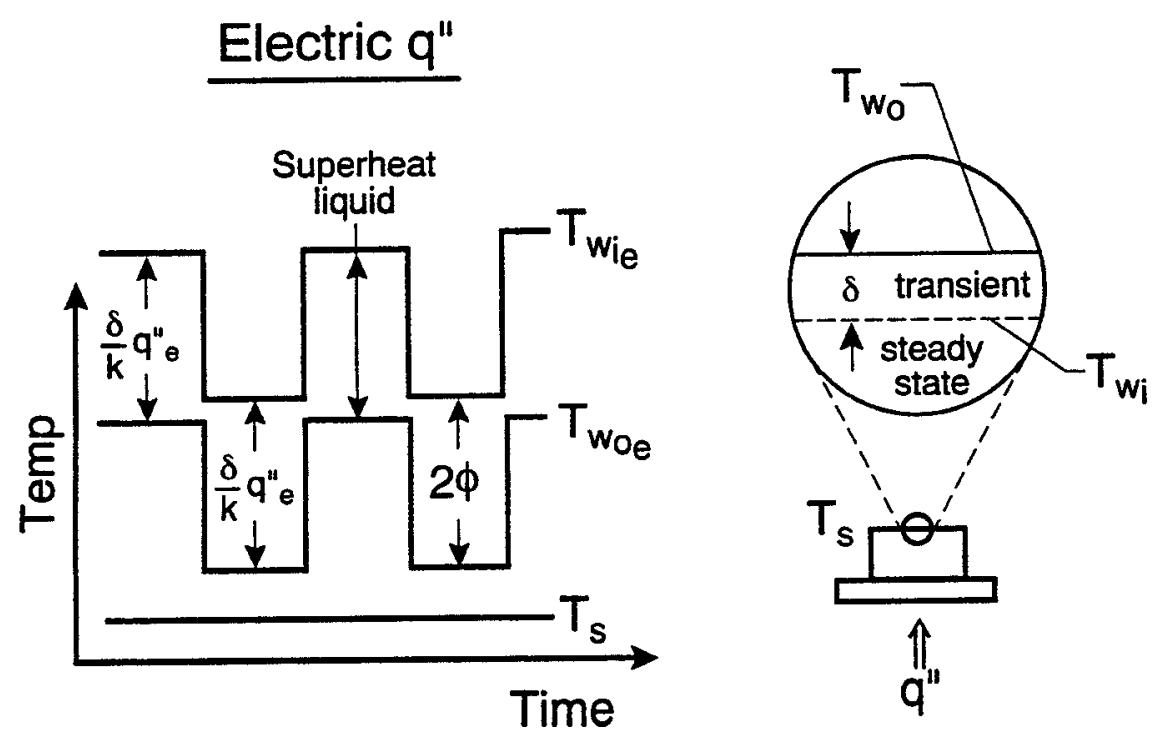

Fluid q"

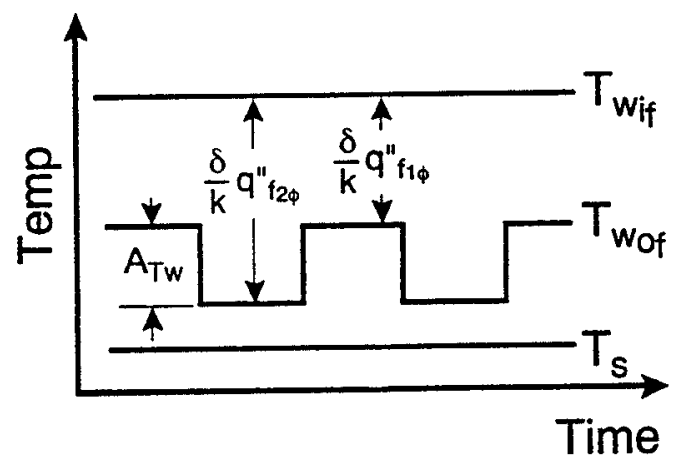

Fig. 18 Speculation on reason for difference between fluid and electric heating pool boiling curves 


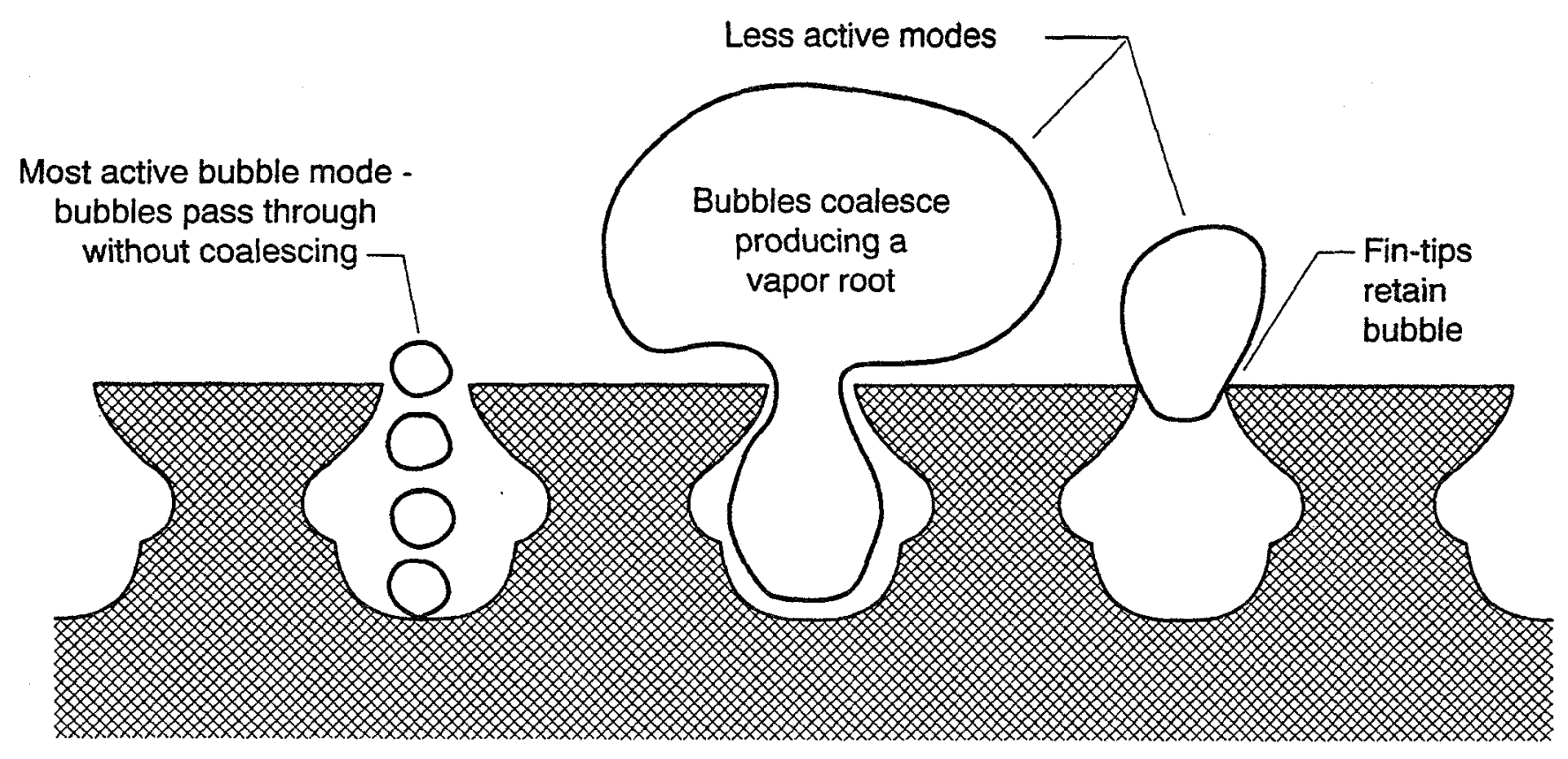

Three different modes of bubble evolution

Fig. 19 GEWA-TTM boiling modes for $\mathrm{R} 123$ at $\mathrm{q}^{11}=70 \mathrm{~kW} / \mathrm{m} 2$ 


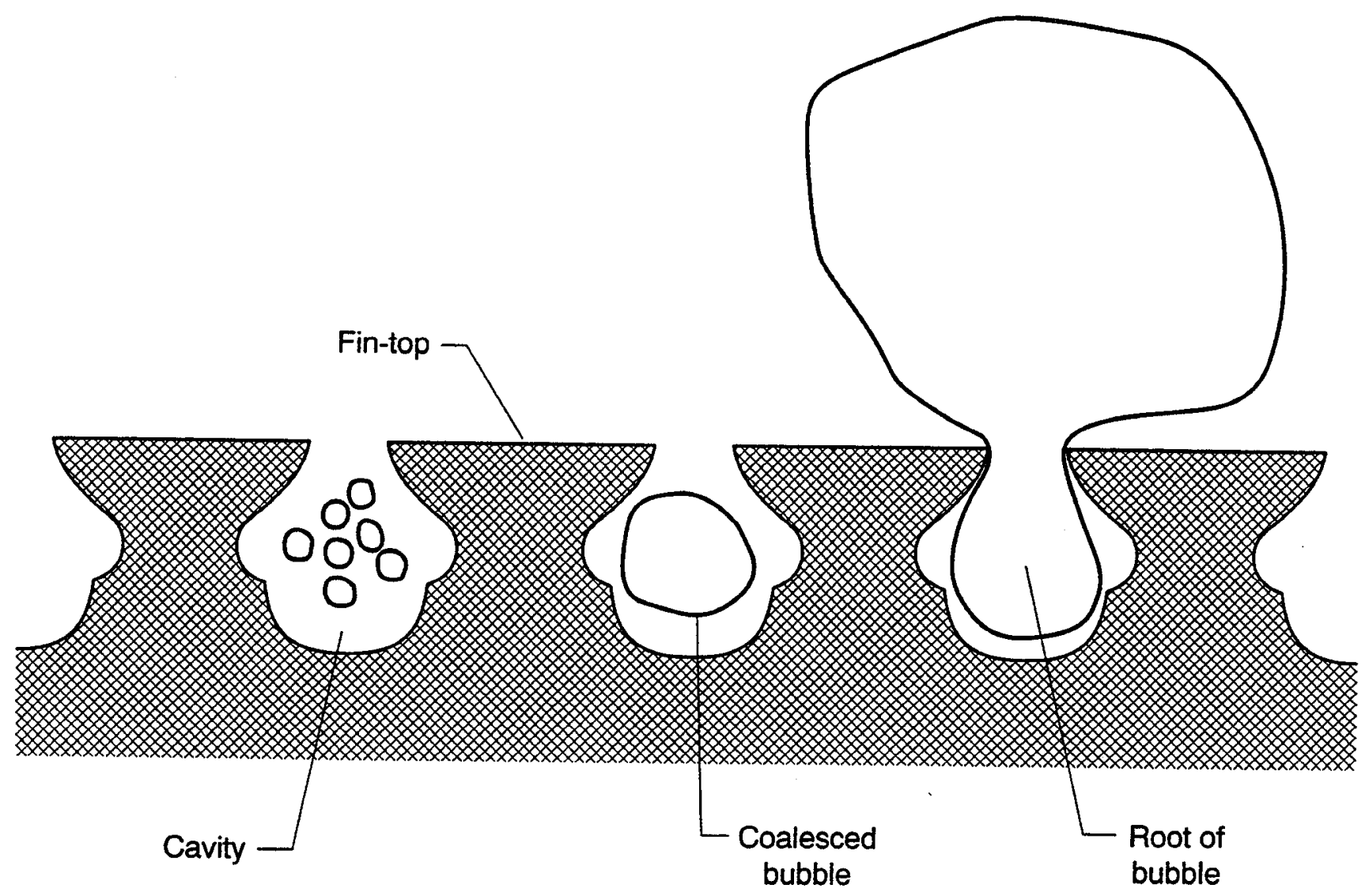

Sequence of events for large cavity bubble

Fig. 20 Mushroom bubble evolution in GEWA-TTM cavity for R123 


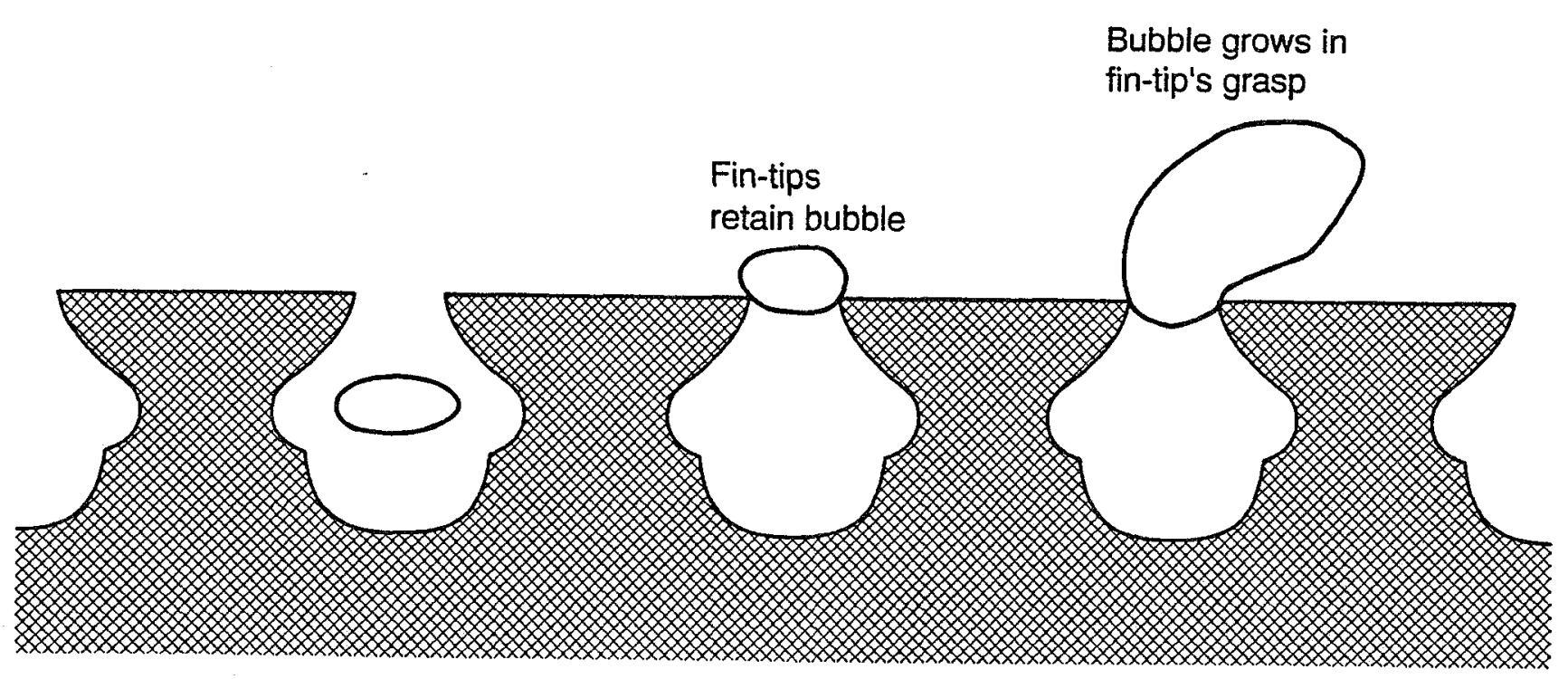

Sequence of events for intermediate size cavity bubble

Fig. 21 Intermediate size bubble evolution in GEWA-TTM cavity for R123 


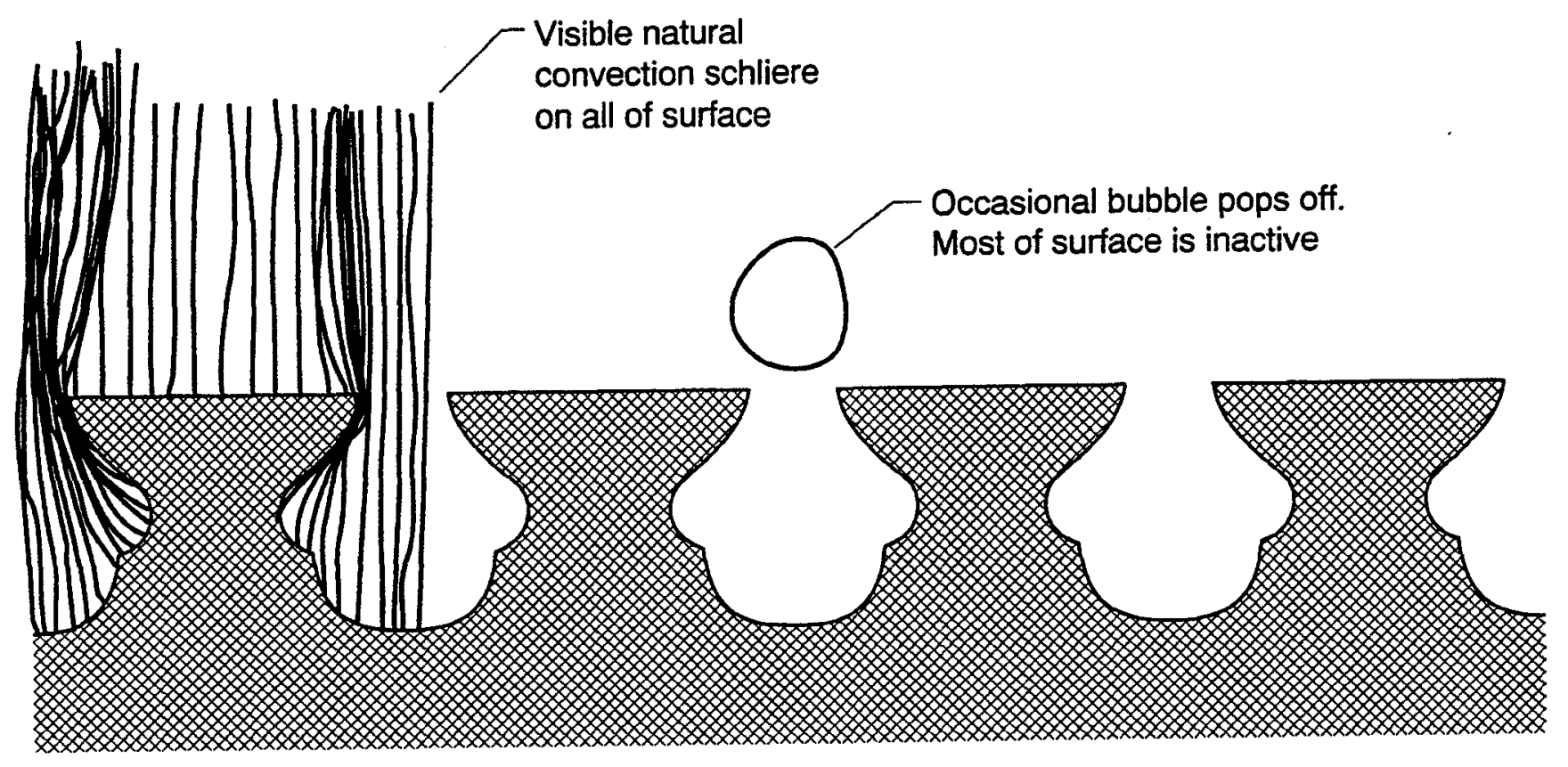

Fig. 22 Bubble activity for the GEWA-TTM surface with $R 123$ at $q^{\prime \prime}=30 \mathrm{~kW} / \mathrm{m}^{2}$ 


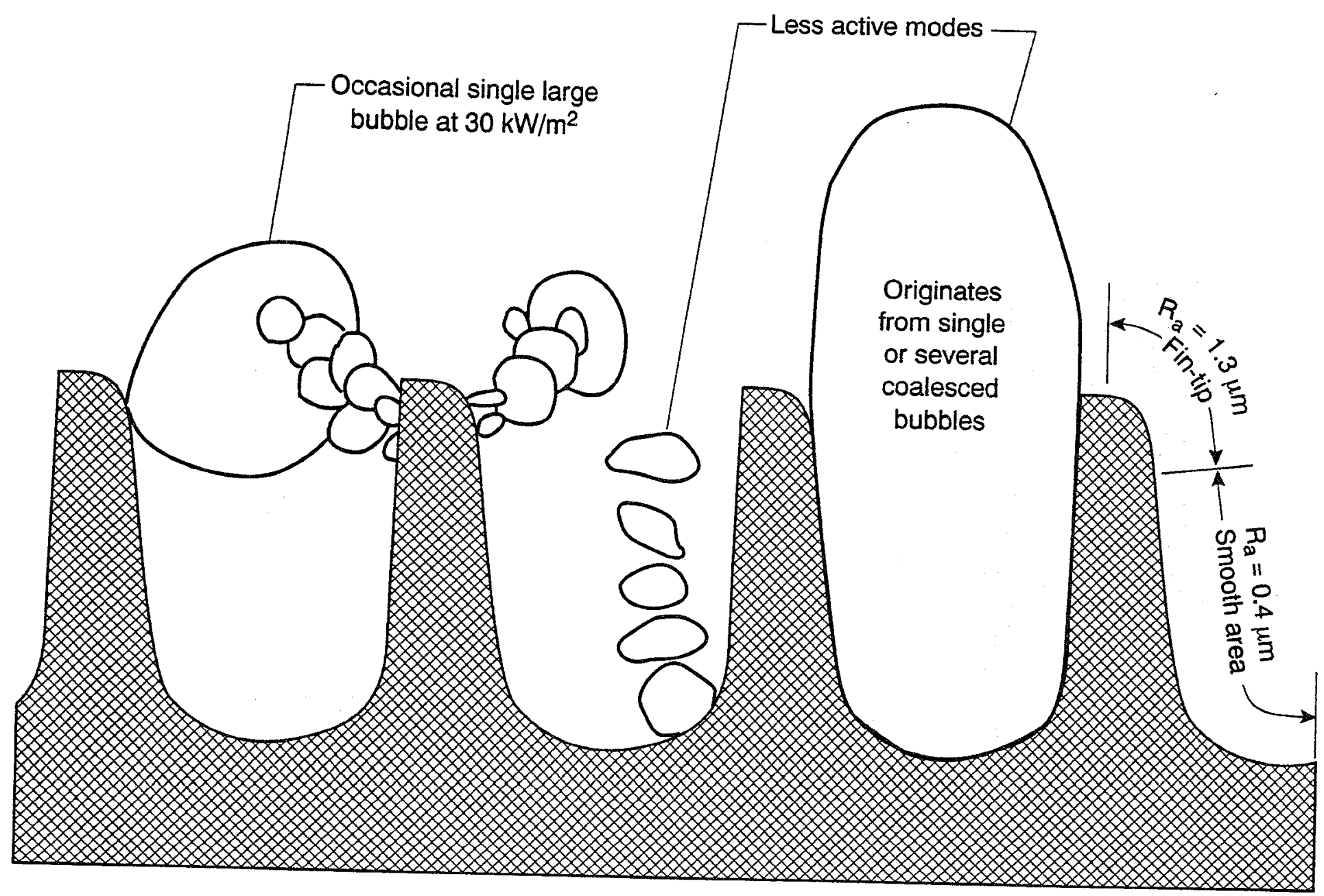

Four different modes of bubble evolution

Fig. 23 Four different boiling modes for the GEWA-KTM surface with R123 


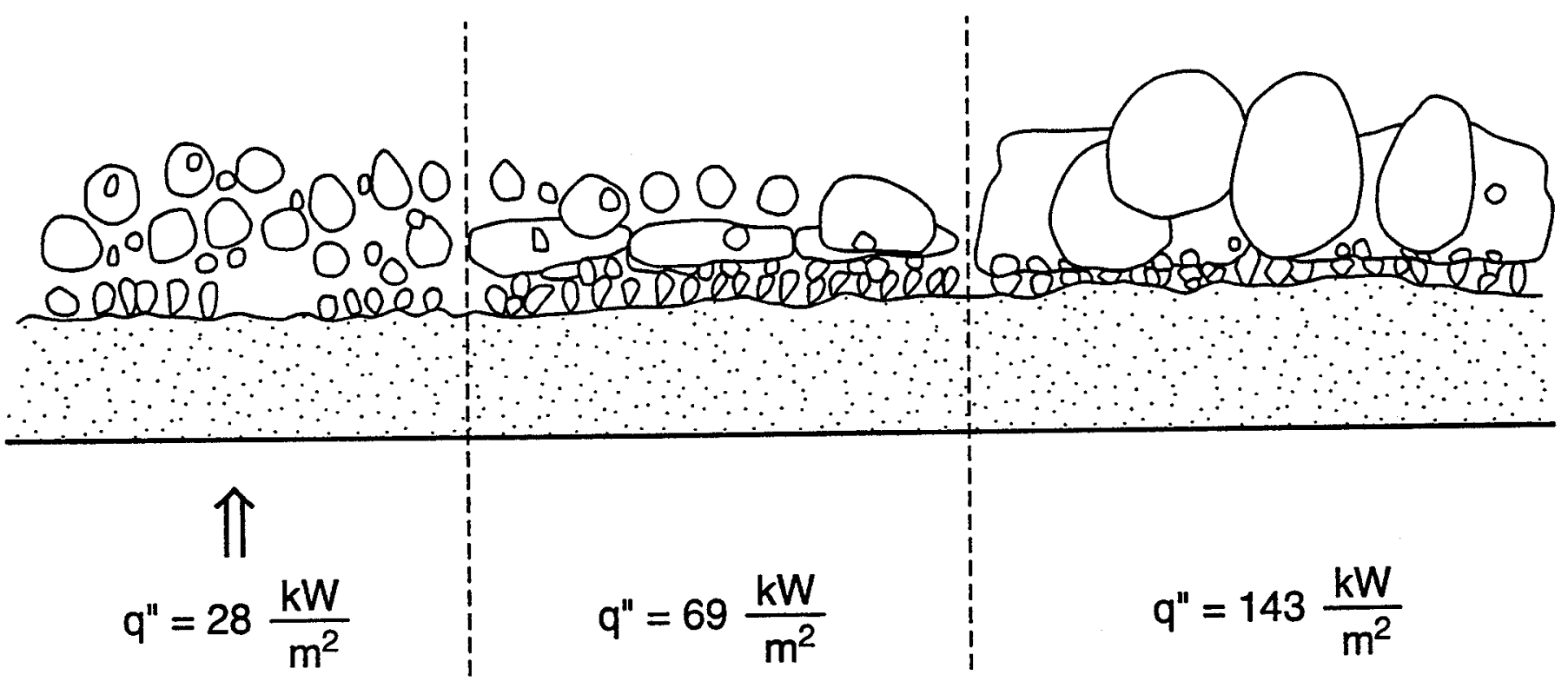

Fig. 24 Boiling activity for the High-FluxTM surface at 28,69 , and $143 \mathrm{~kW} / \mathrm{m}^{2}$ 


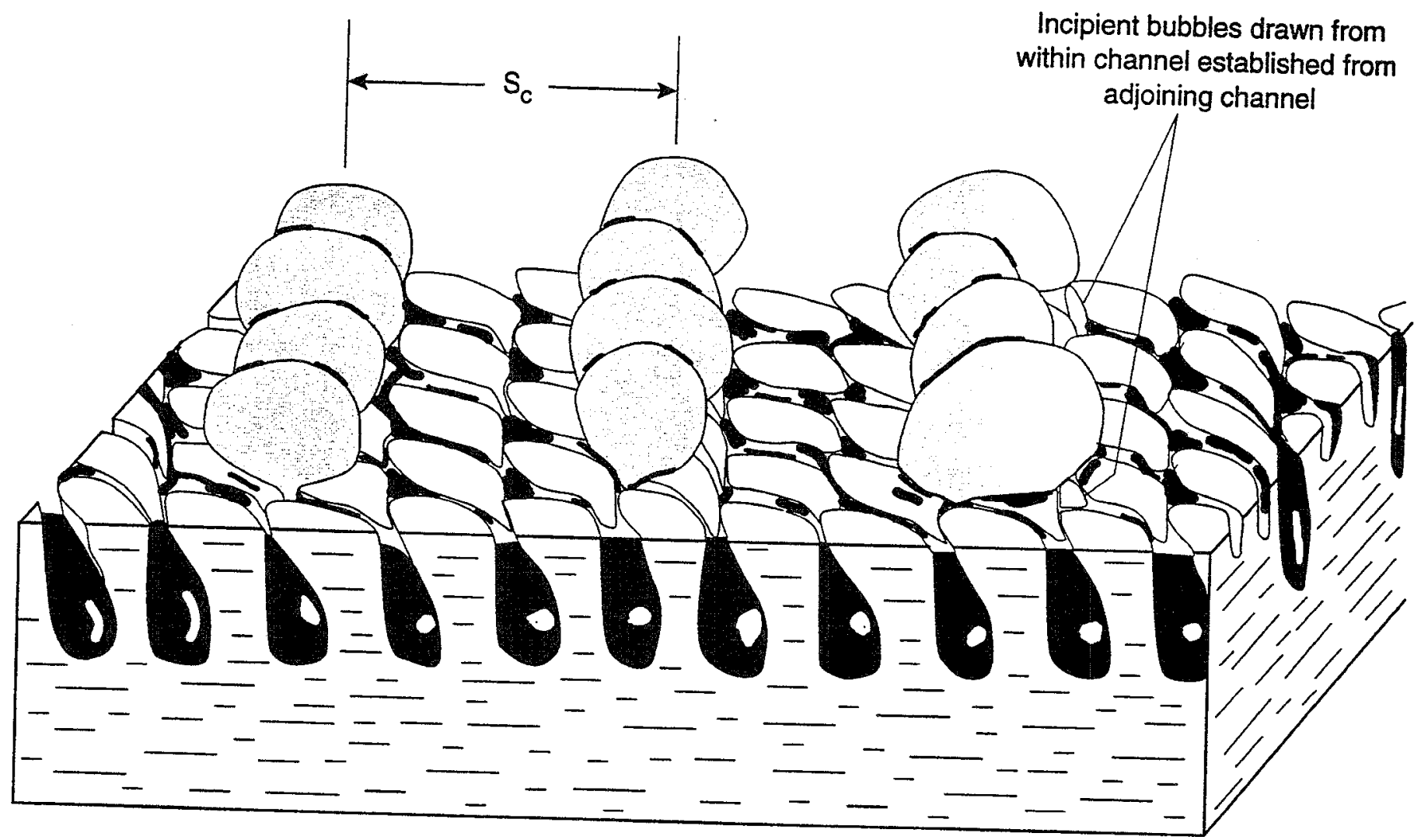

Fig. 25 R123 boiling activity on the Turbo-BIITM-LP surface 


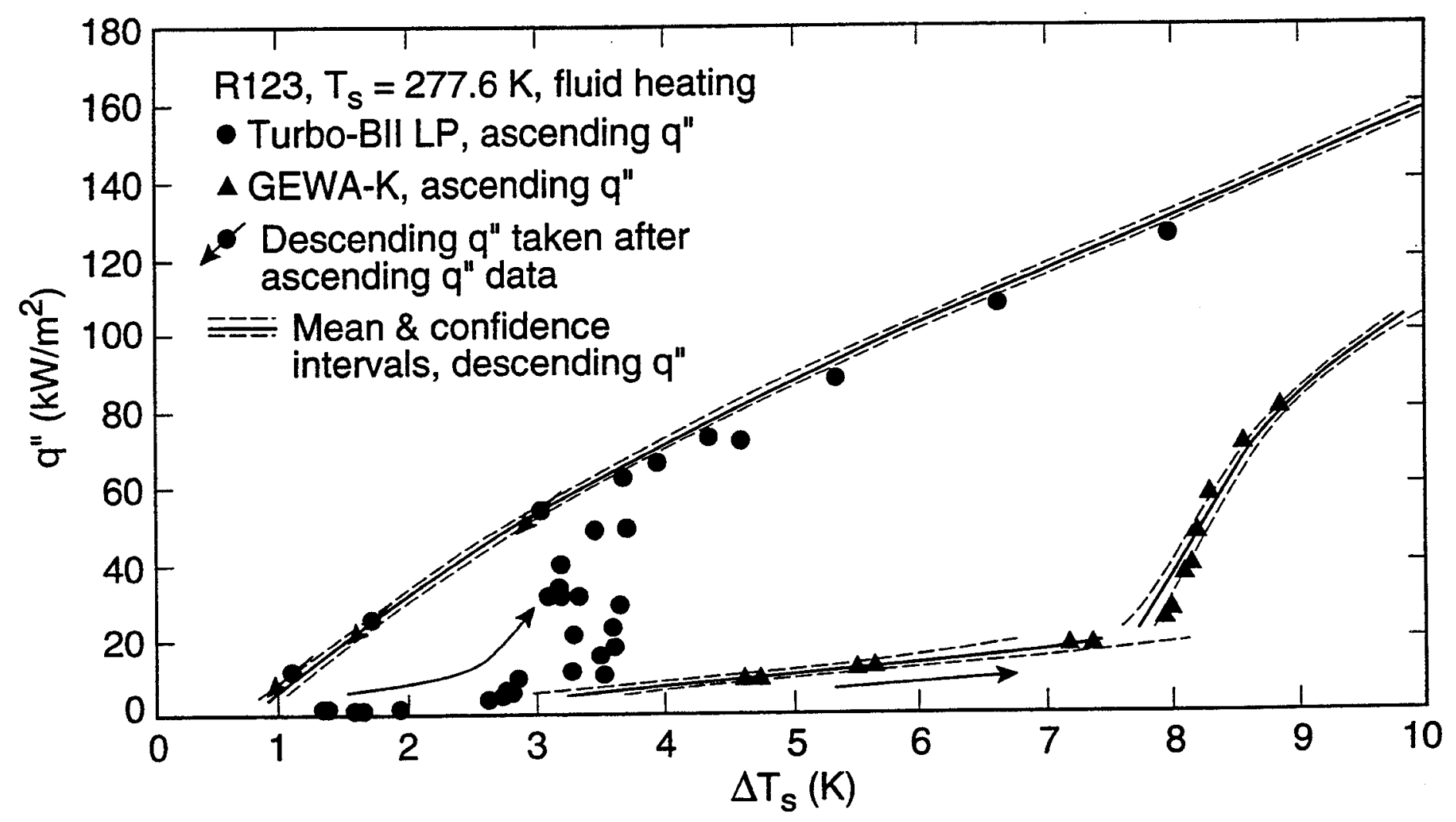

Fig. 26 Fluid heating ascending heat flux data for the Turbo-BII ${ }^{\mathrm{TM}}-\mathrm{LP}$, and GEWA-KTM surfaces 


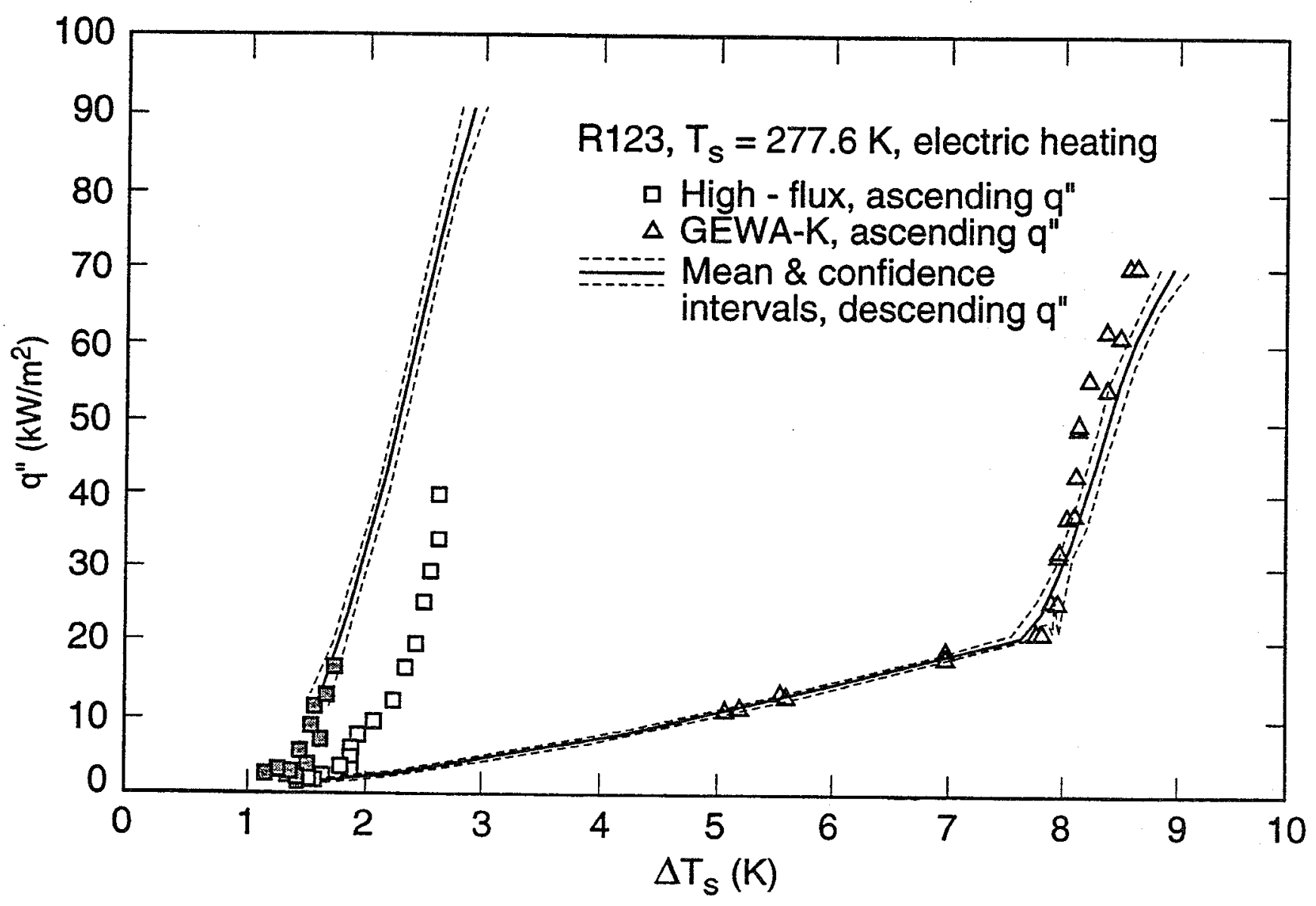

Fig. 27 Electric heating ascending heat flux data for the High-FluxTM, and GEWA-KTM surfaces 